\title{
Unemployment and employability : how firms can help
}

Citation for published version (APA):

Gerards, R. (2012). Unemployment and employability : how firms can help. [Doctoral Thesis, Maastricht University]. Universitaire Pers Maastricht. https://doi.org/10.26481/dis.20120510rg

Document status and date:

Published: 01/01/2012

DOI:

10.26481/dis.20120510rg

Document Version:

Publisher's PDF, also known as Version of record

\section{Please check the document version of this publication:}

- A submitted manuscript is the version of the article upon submission and before peer-review. There can be important differences between the submitted version and the official published version of record.

People interested in the research are advised to contact the author for the final version of the publication, or visit the DOI to the publisher's website.

- The final author version and the galley proof are versions of the publication after peer review.

- The final published version features the final layout of the paper including the volume, issue and page numbers.

Link to publication

\footnotetext{
General rights rights.

- You may freely distribute the URL identifying the publication in the public portal. please follow below link for the End User Agreement:

www.umlib.nl/taverne-license

Take down policy

If you believe that this document breaches copyright please contact us at:

repository@maastrichtuniversity.nl

providing details and we will investigate your claim.
}

Copyright and moral rights for the publications made accessible in the public portal are retained by the authors and/or other copyright owners and it is a condition of accessing publications that users recognise and abide by the legal requirements associated with these

- Users may download and print one copy of any publication from the public portal for the purpose of private study or research.

- You may not further distribute the material or use it for any profit-making activity or commercial gain

If the publication is distributed under the terms of Article $25 \mathrm{fa}$ of the Dutch Copyright Act, indicated by the "Taverne" license above, 


\section{Unemployment and employability: how firms can help}

Ruud Gerards 
This book was typeset by the author using LaTeX.

All rights reserved. No part of this publication may be reproduced, stored in a retrieval system, or transmitted, in any form, or by any means, electronic, mechanical, photocopying, recording or otherwise, without the prior permission in writing from the author.

Unemployment and employability: how firms can help

(c) Ruud Gerards, 2012

Cover design by Marco Jeurissen

Published by Universitaire Pers Maastricht

ISBN: 9789461591463

Printed in the Netherlands by Datawyse 


\title{
Unemployment and employability: how firms can help
}

\author{
Proefschrift \\ ter verkrijging van de graad van doctor \\ aan de Universiteit Maastricht, \\ op gezag van de Rector Magnificus, \\ Prof. mr. G.P.M.F. Mols, \\ volgens het besluit van het College van Decanen, \\ in het openbaar te verdedigen \\ op donderdag 10 mei 2012 om 14.00 uur
}

door

Ruud Gerards

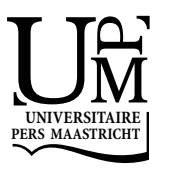




\section{Promotors:}

Prof. dr. Joan Muysken

Prof. dr. Andries de Grip

\section{Beoordelingscommissie:}

Prof. dr. Lex Borghans (voorzitter)

Prof. dr. Joop Hartog (Universiteit van Amsterdam)

Prof. dr. Hans Heijke

This research was partly funded by the Network Social Innovation (NSI), Maastricht, The Netherlands. 


\section{Acknowledgements}

This compact little book you hold in your hands may not look as if it takes a few years to complete, but looks can be deceiving. The actual writing of the book was the relatively easy part, although it was by no means easy in an absolute sense. All the stages that took place before any writing could be done could drive me to healthy episodes of madness from time to time. How I dealt with this madness is a matter I will discuss later. The most labor intensive part of the work has surely been the data collection. Although the fact that you hold the book in your hands means that everything worked out just fine, writing every chapter based on a different dataset is not something I would advise future PhD students. Unless they are very good at documenting every nitty gritty detail, which was surely not one of my strengths when I started the $\mathrm{PhD}$. I like to dive right in and start analyzing, as I am very output focussed. Although I have learned to go through the motions and spend a proper amount of time doing data reconnaissance, followed by a phase of data analysis, I enjoy the writing phase the most. As long as the data is still data, its potential output has yet to be revealed. The data reconnaissance presents a global picture of the treasures the data may hold and the data analysis phase attempts to uncover its most deeply hidden treasures. Still, the graphs and tables that are the usual output from the analysis phase, are not always comprehensible for laymen. All this comes to life for anyone outside academia when it is wrapped in proper words and sentences, giving it meaningful interpretation. Now that all chapters are written, bundled together and physically held together by a wonderful cover it is time to let this thesis out into the world.

To get this far would not have been possible without the continuing support of a large number of people. First, I would like to thank my supervisors Joan Muysken and Andries de Grip. When I started my PhD in 2007, 7 years had passed since I obtained my masters degree in economics. Although I had kept my economics knowledge up-todate in my years working as junior lecturer for the economics department of Maastricht 
University, my quantitative skills and knowledge had nearly evaporated. Still, Joan was supportive of the idea of me pursuing a $\mathrm{PhD}$ and came up with a construction that would enable this. Although I was not sure if doing a $\mathrm{PhD}$ was the right move for me, I am now happy I took the plunge and thank Tom van Veen for talking me into it. I remember vividly that we were on a train to Brussels and that he asked me what my plans for the future were. The teaching contract I had at the time would not provide a long term perspective and a PhD might be an option to enable a future career in academia. I don't remember the rest of the conversation exactly, but I do know that at the end of that day I decided to go for the PhD. In the second year of my PhD studies Andries joined and from then on I had two supervisors. Joan and Andries complemented each other perfectly and for me this had the great benefit that I could learn from two supervisors.

Next, I thank my dear friend and coauthor of one of the chapters, Riccardo Welters. We have spent countless evenings and nights in the Netherlands and Australia discussing all of life's joys and challenges. Usually this involved good Italian or Asian food and a fair amount of beer and/or wine. I have nothing but great memories from our evenings in pubs, our trip to the performance by DJ Tiesto in Belgium and the road trips and holidays we undertook together in Australia. Thanks for letting me stay at your place all those times in Australia. I have been lucky enough to visit Riccardo four times already in Australia and the next visit is bound to happen sooner than later. I truly miss our talks, beach walks and evenings at Juliette's and the Arrivederci. I want to especially thank Bill Mitchell of the Centre of Full Employment and Equity in Newcastle Australia and Natalie Stoeckl of James Cook University in Townsville Australia, for having me visit your inspiring institutes and for your great hospitality. Thanks to the many wonderful and hospitable people in your institutes for all the great times and inspiring discussions. Special thanks to James Juniper and Victor Quirk, I hope to meet you soon for a coffee at Swell's and a pizza at 'The Derc'. Special thanks also to my office mate at JCU, Wuying Zou. Thanks to all of you, Australia means something beautiful to me which is difficult to express in words but is felt all the better in my heart.

Next, I thank Manuel Muellers. We spent quite some time and energy on what was for both of us our first paper. However, our biggest shared interest is definitely everything related to Apple computers and products, which we could discuss at length. I also thank Maaike Witlox for being a dedicated and hard working research assistant, a clever and independent thesis student and a cheerful and warm person. It has been great working with you. Special thanks go to the members of the reading committee, Lex Borghans, Hans Heijke and Joop Hartog.

There have been many conference and seminar participants that have at some point contributed to this thesis; thanks to all of you. Thanks in particular to Kea Tijdens of the Amsterdam Institute for Advanced labour Studies (AIAS) for giving me the opportunity to present at two of your lunch seminars. Thanks to Trudie Schils for 
introducing me to Kea and for being a great colleague in general.

Several persons at Philips in Eindhoven have also been important to make this thesis possible. Without the trust that Yvonne van den Berg and Frank Visser put in our research proposals, there might not have been a thesis at all. Yvonne, thank you for our pleasant cooperation and for guiding me in the early stages of the research. Frank, thank you for four years of close cooperation. Our meetings and discussions have always been as enjoyable as they were insightful. Thanks for always having an eye for the academic perspective as well as the Philips perspective, I couldn't have wished for a better partner at Philips. Thanks also to Ton van der Bruggen, Bonnie Beerkens, Selma Oskam, Emilie Rozendaal, Petra van Mill-Smits, Ankie Swart, Frans van den Broek, Toon De Tollenaer, Riekie Hendriks and Jos Nelis, for your involvement and input at various stages. Thanks to Benny Leijdsman and Hans Dijkman for your continuous support for the research. Thanks also to the many people at reintegration firms and municipalities for their cooperation in interviews.

Now, how did I deal with the healthy episodes of madness that the $\mathrm{PhD}$ research could drive me to? There were a number of solutions. The quick fix was to go to the Preuverij for coffee or lunch (my second home, thanks also to the entertaining and friendly owners and staff Sjef, Freek, Danny, Giel and the others). This was frequently combined with a short or long walk around the park surrounding the faculty, taking stale bread from home to feed the ducks and birds. Throughout the years I have had many lunch and coffee partners which over time became good friends. Pomme Theunissen has been around for the longest time as colleague in teaching, but more importantly as lunch partner and friend. We fought (and lost) the same battle for university teaching careers and have both been secretary for the European Corner. Several years we taught together at the Faculty of Social Sciences which we always enjoyed most of all teaching due to the mature and worldly oriented students. Even though we both do not work at the university anymore, we still have our lunches in the Preuf from time to time.

Having been my officemate for four years, Raoul Haenbeukers has shared in many of the professional and personal ups and downs that are part of life. We mostly discussed these things (and politics) at the Preuf, as Raoul shares a taste for a relaxing lifestyle, involving real coffee, a proper out-of-office lunch and a late afternoon beer, or two... As a way to clear the mind and do some healthy exercise, we even play squash together. Pomme and Raoul know me pretty well by now and I am grateful to still have them as dear friends even though our careers have taken diverging paths. They were the logical choices for me to ask to become my paranymphs.

Another lunch and coffee partner, and good friend ever since we met in 1997 in the second year of our economics study, is Iwan Bos. Iwan who obtained his PhD in Amsterdam has been back in Maastricht for several years now and the day I heard that he would be returning was a very good day. This meant a good friend was 'coming 
home' and we could go to our favorite Preuf again, together, on a regular basis.

Someone who also frequently accompanied me for a Preuf visit or walk around the university surroundings is Geranda Notten. And this brings me to my main method of staying mentally and physically healthy: cycling. One day in 2004, I just decided to start cycling, I went into a shop, bought a bike pretty randomly (a grey Giant) and got hooked. After one year of cycling I decided to upgrade to a better bike and Geranda bought my Giant to start her cycling life. Since then, Geranda has been hooked on cycling as well and we have spent many hours cycling in the hills of Limburg and Belgium, the seaside hills of Saint-Tropez, the mountains in Les Vosges and the 'hors categorie' French Alps. Thanks Geranda, and also thanks to Ruud, Geranda's partner for all our great times together. By the way, have the Canadian's already sampled Ruud's world famous Peanut Sauce?

Through Geranda I got to know the fastest girl on a bicycle I know, who leaves many guys biting the dust: Britta Augsburg. I have great memories of all the cycling adventures we shared, from watching the Tour de France peloton come down the Col de la Croix de Fer into Allemont, to the many rides in Limburg and our own little quarter triathlon, to the thunderstorm we had to shelter from in the Les Vosges and to 'Look Mum No Hands', London. Simply unforgettable. Two more friends from university that found their way onto the bicycle are Melissa and Flo. Thanks for the lovely diners at your old place, cycling trips and jam sessions.

Apparently, the combination of cycling and doing a $\mathrm{PhD}$ is not a rare one in Maastricht and for anyone who reads this and is doing a PhD I can only advise to buy a roadrace bike and start cycling. You'll experience the mind-clearing effect cycling has and most likely will make some friends for life that can help you get through the $\mathrm{PhD}$ as well as up the mountain, when the going gets though.

Two sisters whom I consider dearest of friends have also been part of my life both at and outside the university, since the earliest days of my teaching and research career: Kirsten and Ingrid Rohde. Thanks for being there for me in good and bad times. Many more friends at the university have made my life here a wonderful time. From the really early days Michael Yang and his partner Audrey, Sabine Fuss, Hannah Kiiver, Martin Rehm, Bart Rienties, Jeroen van den Berg, Jan Piplack, Nils Holinski and Stefan Kuehn. In the more recent past Burak Can, Elena Cettolin, Antonio della Malva and Annemarie Nelen, and most recently Lenard Lieb, Andreea Bicu and Ehsan Vallizadeh. One of the things of working at the university is that it is a constant flow a people coming and going, you get attached really quickly but also let go in many cases. I will not attempt to mention everyone because with my bad memory, the risk of forgetting just one is too large. The coming and going and the occasional forgetting do not diminish in any way, the intensity of the short term friendships that happen. There are many more colleagues with whom I have shared funny, exciting, personal or great professional moments at places and events such as the university itself, Aachener 
Weihnachtsmarkten, BBQ's, lecturer days, in pubs and restaurants, on trains and interliners etc.. Thanks to all of you for making these years so great and memorable. It was like having a second go at student-life.

Next, I thank all the tenured colleagues in the economics departments. Over the years, I have worked together with many of you in teaching or we had casual chats about research, sports or other things. I have always felt truly at home with so many nice, warm and wise folks around. Special thanks to Aad van Mourik. If the department feels like home, then the office of Fleur Keune and Silvana de Sanctis is the kitchen where people like to linger around the diner table for hours to chat. This kitchen holds the ingredients for laughter, relaxation and relativizing. Apart from that very important social function, Fleur and Silvana are always ready to help when you need to get paperwork or other chores done. Apart from these 'kitchen chefs' we also have a navigator on board our vessel. Sylvia Beenen knows all the routes and shortcuts through the vast world a university can be. Without Sylvia navigating, plenty of my efforts to efficiently organize my teaching, buy bicycles with the bicycle scheme, make the most of my budgets etc. etc. would have ended going in circles. Thank you Fleur, Silvana and Sylvia for making life so much easier and contributing greatly to the warm atmosphere. I also thank Joyce Gruijthuijsen for always swiftly handling payments from my Liber account.

I want to thank my longtime friends Koen, Ivo, Marco, Maaike, Maurice, Hans, Sjoerd, Ronald, Constance, Klaas and their partners for their lasting friendship in my life outside the university. I can write books about the adventures we shared together and the things that bind us, but I better not bother the reader with that. A special thanks goes to Anne who has always given me confidence and good advice. I thank Patricia for coloring my life and supporting me in the finishing stage of the thesis process. Eternal gratitude goes to my family; my grandmother Oma, my brother Frank and his partner Silvia and my parents Nob and Anja. Your unconditional support and pride in whatever I undertake and wherever I undertake it means the world to me. Mom and dad, thank you for the wonderful genetic mix you have given me and for raising me into who I am. The achievement of this $\mathrm{PhD}$ is as much your success, as it is mine. 



\section{Contents}

Acknowledgements $\quad$ v

Contents $\quad x i$

List of Tables $\quad$ Xv

$\begin{array}{ll}\text { List of Figures } & \text { xvii }\end{array}$

1 Introduction $\quad \mathbf{1}$

1.1 Aim of the thesis . . . . . . . . . . . . . . . . 1

1.2 Economic developments and the labor market 1980-2010 . . . . . . . 3

1.2.1 The early 1980s: The inheritance of the oil crises and the Wassenaar Agreement . . . . . . . . . . . . . . 3

1.2.2 The late 1980s and 1990s: Globalization, Skills Biased Technological and Organizational Change and Crowding Out . . . . . . 3

1.2.3 The new millennium: continued importance of skills upgrading on all levels ..................... . . . . 7

1.3 Developments within Philips . . . . . . . . . . . . . . 8

1.3.1 The Wassenaar Agreement and the Philips Employment Scheme 8

1.3.2 Increased skills demands and the Vocational Qualification Program 9

1.3.3 The educational expansion, SBTC, SBOC and the E-miles employability vouchers . . . . . . . . . . . . . . . 9

1.4 Discussion and implications . . . . . . . . . . . . . . . . . . 10

1.4.1 Firms and unions taking responsibility for job growth . . . . . . 10

1.4.2 Aggregate potential of the WGP if implemented by the 700 largest Dutch firms . . . . . . . . . . . . . . . 11 
1.4.3 Brief summary and generalizability of our main findings . . . . . 12

1.4.4 Final words: Why is full employment nowadays an unorthodox idea? . . . . . . . . . . . . . . . . . . 13

2 From Dutch Disease to Dutch Miracle: why some institutional $\begin{array}{ll}\text { reforms work and others do not } & 17\end{array}$

2.1 Introduction . . . . . . . . . . . . . . . . . . . 17

2.2 Data on institutional reforms f . . . . . . . . . . . . . . . . . 19

2.2.1 Content analysis . . . . . . . . . . . . . . . . . . . 19

2.3 The incidence of reforms in the Netherlands . . . . . . . . . . . . . 22

2.4 Econometric evidence . . . . . . . . . . . . . . . . . . . . . . . . . 28

2.5 Conclusions . . . . . . . . . . . . . . . . . . . . . . . . 34

Appendix I: Overview of our sources . . . . . . . . . . . . . . . 35

Appendix II: The ranking scheme table . . . . . . . . . . . . . . . . . 36

Appendix III: Our dependent variables and the business cycle . . . . . . . . 37

Appendix IV: Our reform dummies over time . . . . . . . . . . . . . . . . . 40

Appendix V: Reforms database . . . . . . . . . . . . . . . . . . . . 41

3 Active Labor Market Policy by a Profit Maximizing Firm 57

3.1 Introduction . . . . . . . . . . . . . . . . . . 57

3.2 A private initiative: The Philips Employment Scheme (WGP) . . . . . 58

3.2 .1 Selection . . . . . . . . . . . . . . . . . 60

3.2.2 Treatment and outflow counseling . . . . . . . . . . . 63

3.3 The gross effect of the WGP . . . . . . . . . . . . . . . . . . . . . . 64

3.3.1 Who get a job after the WGP? . . . . . . . . . . . 64

3.3 .2 A closer look at the inflow of the WGP . . . . . . . . . . 66

3.4 Performance of the WGP . . . . . . . . . . . . . . . . . . . . . . . 69

3.5 What are the benefits to the firm? . . . . . . . . . . . . . . 72

3.6 Concluding remarks . . . . . . . . . . . . . . . . . . . . . . . . . . . . . 74

Appendix I: Data on individuals in the WGP . . . . . . . . . . . . . . 75

4 The effects of firm sponsored general training on low skilled workers $\mathbf{7 9}$

4.1 Introduction . . . . . . . . . . . . . . . . . . 79

4.2 Literature . . . . . . . . . . . . . . . . . . . . . 80

4.2.1 Training, wages, job performance and employability . . . . . . 80

4.2.2 General vs. specific training and the focus on low skilled workers 81

4.3 The Vocational Qualification Program . . . . . . . . . . . . . 82

4.4 Data . . . . . . . . . . . . . . . . . . . . . . . . 84

4.4.1 Descriptives . . . . . . . . . . . . . . . 85

4.4 Dependent variables . . . . . . . . . . . . . . . . . 86

4.5 Analysis methods . . . . . . . . . . . . . . . . . . . . . . . . . 88

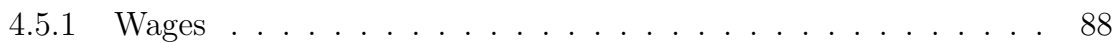


4.5.2 Job-level and internal promotions . . . . . . . . . . . . . . . . . 89

4.5.3 Performance ratings . . . . . . . . . . . . . . . 9 90

4.5.4 Involuntary separations: i.e. fired . . . . . . . . . . . . . 90

4.6 Results . . . . . . . . . . . . . . . . . . . . . . . . . . . . 90

4.6.1 The effect of training completion on wages and wage development 90

4.6.2 Internal mobility: The effect of training completion on job-level 93

4.6.3 The effect of training completion on performance ratings . . . . 94

4.6.4 The relation between training and external mobility . . . . . . . 96

4.7 Conclusions . . . . . . . . . . . . . . . . . . . . . 97

Appendix I: First stage estimation results . . . . . . . . . . . . . . . . . . . 99

Appendix II: Philips wage structure . . . . . . . . . . . . . . . . . . . . . 102

5 Training vouchers and employability awareness 103

5.1 Introduction . . . . . . . . . . . . . . . . . . . . . . . 103

5.2 Literature . . . . . . . . . . . . . . . . . . . . . 105

5.2.1 Voucher schemes . . . . . . . . . . . . . . . 105

5.2.2 Personality traits and training participation . . . . . . . . 106

5.2.3 Personal characteristics and training participation . . . . . . . 108

5.2 .4 Schematic overview . . . . . . . . . . . . . . . . 109

5.3 Data . . . . . . . . . . . . . . . . . . . . . 109

5.3 .1 Descriptives . . . . . . . . . . . . . . . . . 110

5.3 .2 Dependent variables . . . . . . . . . . . . . . . . . . 113

5.3 .3 Independent variables . . . . . . . . . . . . . . . 115

5.4 Results . . . . . . . . . . . . . . . . . . . . . . 116

5.4.1 Which workers use their voucher? . . . . . . . . . . 116

5.4.2 Does voucher use increase employability awareness? . . . . . . . 119

5.5 Discussion and conclusions . . . . . . . . . . . . . . . . . . . . . . 124

Appendix I: Survey questions . . . . . . . . . . . . . . . . . 126

$\begin{array}{lr}\text { Bibliography } & 127\end{array}$

$\begin{array}{ll}\text { Nederlandse samenvatting (Summary in Dutch) } & 137\end{array}$

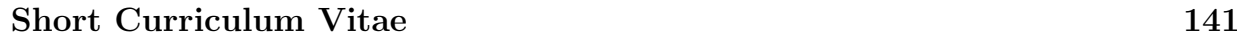





\section{LIST OF TABLES}

1.1 Aggregate private sector potential of the WGP based on 2010 data . . 12

2.1 Three levels of content analysis . . . . . . . . . . . . . . . 20

2.2 Potentially relevant reforms, to test in section $2.4 \ldots \ldots$. . . . . . . . 21

2.3 Reform areas and reform relevance. . . . . . . . . . . . . . . . . 24

2.4 Reform types and reform relevance. . . . . . . . . . . . . . . 26

2.5 Reform relevance ratios by area and type. . . . . . . . . . . . . . 27

2.6 The relation between institutional reforms and unemployment - 1980 to

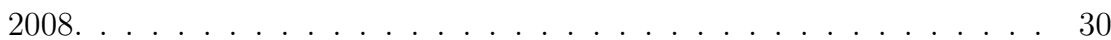

2.7 The relation between institutional reforms and UB claimants - 1980 to

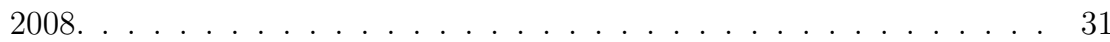

2.8 The relation between institutional reforms and sickness benefit claimants - 1980 to 2008.

2.9 The relation between institutional reforms and disability benefit claimants

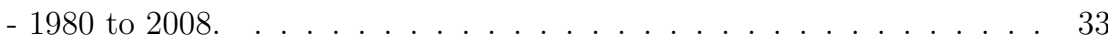

2.10 Reforms database . . . . . . . . . . . . . . . . . . . . . . . . . . . . . . . . .

3.1 Summary of annual data . . . . . . . . . . . . . . . . . 60

3.2 Employability of WGP inflow: a sample of August 2002 - April 2003 . . 62

3.3 Explaining participants' job finding chances . . . . . . . . . . . . . 65

3.4 Effect of labor market conditions on participants quality, 1987-2006 . . 67

3.5 Effect of business cycle and inflow characteristics on time spent in WGP, $1987-2006 \ldots \ldots \ldots \ldots$. . . . . . . . . . . . . . . . . . . .

3.6 Descriptive statistics of matching variables (mean values) . . . . . . . . 70

3.7 Measuring WGP treatment effect using nearest neighbor matching technique ........................... 71 
3.8 Who stay with Philips?, $1999-2007 \ldots \ldots$. . . . . . . . . . . 73

3.9 Reasons important to run the WGP . . . . . . . . . . . . . . . . . 74

3.10 Summary of main variables '8900 dataset'. . . . . . . . . . . . . . . . . 75

3.11 Prior education level of WGP participants. . . . . . . . . . . . . . 76

3.12 Summary of main variables 'Questionnaire dataset'. . . . . . . . . . . . 76

4.1 Descriptive statistics of sample . . . . . . . . . . . . . . . . . 85

4.2 Training status of sample . . . . . . . . . . . . . . . . . 86

4.3 External mobility: Training status and separation reason. . . . . . . . . 88

4.4 The effect of training completion on wages . . . . . . . . . . . . . . . . 91

4.5 The effect of training completion on job-level . . . . . . . . . . . . . . . 93

4.6 The effect of training completion on promotions . . . . . . . . . . . . . 94

4.7 The effect of training completion on performance ratings. . . . . . . . . 95

4.8 Training completion and involuntary separations 2002-2011. . . . . . . 97

4.9 First stage estimation results of IV regressions on wages . . . . . . . . 99

4.10 First stage estimation results of IV regressions on Function-level, Jobpromotion and Performance rating . . . . . . . . . . . . 100

4.11 First stage estimation results of IV regression on 'Fired dummy' . . . . 101

5.1 Voucher training courses . . . . . . . . . . . . . . . . . . 111

5.2 Descriptive statistics of the sample . . . . . . . . . . . . . . . . . 114

5.3 Voucher redemption . . . . . . . . . . . . . . . . . . . . . 117

5.4 Participation in non-voucher training . . . . . . . . . . . . . . . . 118

5.5 Ordered logit estimates of voucher use and the change $\left(t_{2}-t_{1}\right)$ in employability awareness and willingness to train . . . . . . . . . . . 121

5.6 Treatment effects model of voucher use and the change $\left(t_{2}-t_{1}\right)$ in employability awareness and willingness to train . . . . . . . . . 123

5.7 Survey questions corresponding with variables* . . . . . . . . . . 126 


\section{LIST OF FIGURES}

1.1 Unemployment by education 1981-2010, the Netherlands . . . . . . . . 1

1.2 Number of vacancies and unemployed 1980-2009 . . . . . . . . . . . . . . . . 4

1.3 The Dutch Labor force by education 1981-2010 . . . . . . . . . . . . . 6

1.4 Unemployment in the Netherlands 1945-2010 . . . . . . . . . . . . . . . 14

2.1 Social security benefit recipients . . . . . . . . . . . . . . . . 18

2.2 Number of reforms by relevance, years and government . . . . . . . . . 22

2.3 Unemployment in the Netherlands . . . . . . . . . . . . . . . . . . . 37

2.4 The sickness rate and the business cycle . . . . . . . . . . . . . . . . 38

2.5 The disability rate and the business cycle . . . . . . . . . . . . . . 38

3.1 WGP inflow . . . . . . . . . . . . . . . . . . 60

3.2 Education level of WGP inflow compared to total population of unemployed . . . . . . . . . . . . . . . . . 6 61

3.3 Unemployment duration of WGP inflow compared to total population of unemployed . . . . . . . . . . . . . . . . 62

3.4 Aggregate job success of WGP . . . . . . . . . . . . . . . . . . 64

4.1 Unemployment rate for workers without and with start-qualification. . 83

4.2 Wage growth profile of successfully trained vs untrained worker . . . . 92

4.3 Wages according to job-level (x-axis) and step within job-level. . . . . . 102

5.1 Structure of the empirical analysis and hypotheses. . . . . . . . . . . . 109

5.2 Which voucher training did you take? . . . . . . . . . . . . . . 111

5.3 Voucher use by age (Panel A) and tenure (Panel B) . . . . . . . . . . 112 



\section{Introduction}

\subsection{Aim of the thesis}

In the wake of the two world wide oil crises of the 1970s many OECD countries, including The Netherlands, witnessed a tremendous increase in unemployment levels. Figure 1.1 shows that unemployment in The Netherlands increased sharply until 1983 across all levels of education, although the burden was highest for the low-skilled. It was not until the late 1990s that unemployment decreased to a considerably lower level.

Figure 1.1: Unemployment by education 1981-2010, the Netherlands

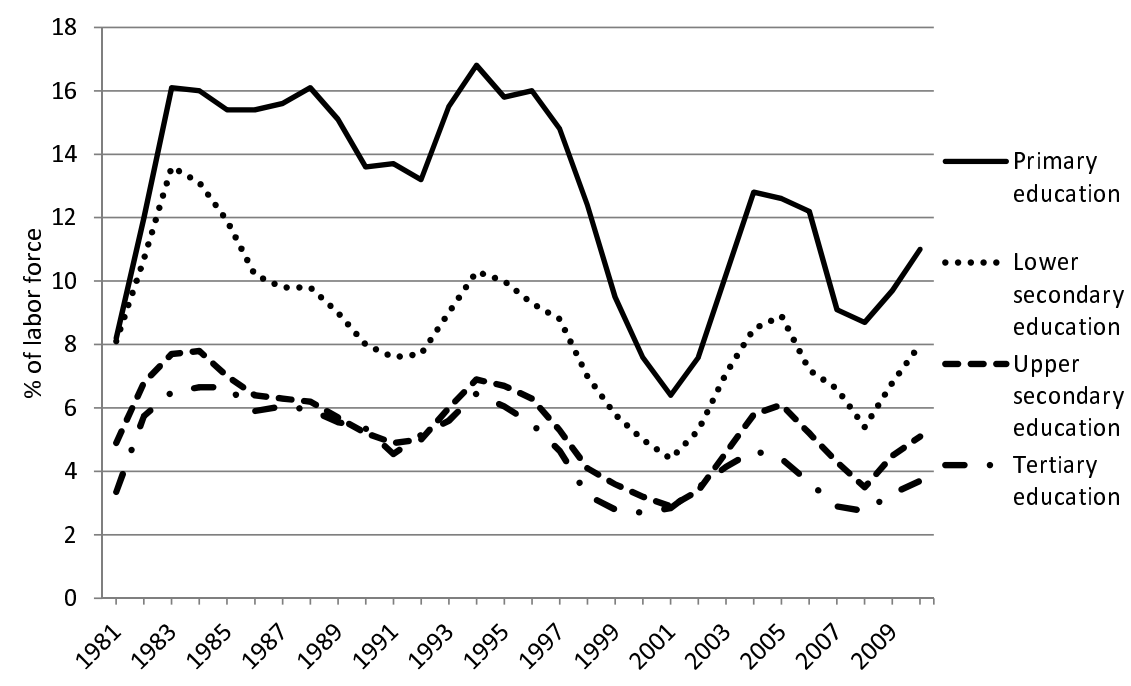

Source: Statistics Netherlands Labor Force Survey (EBB)

Prolonged unemployment is harmful for both individual workers as well as society. There are many costs associated with it that range from output loss to the economy 
to psychological harm to the individual (see Sen (1997) for an elaboration). In The Netherlands, workers are insured against the financial costs of unemployment via the welfare state since 1949. However, the welfare state is generally not equipped to mitigate the non-financial (social and psychological) costs of unemployment that weigh heavily on the unemployed individual. This suggests that preventing unemployment is preferred to curing it. Moreover, through a process that has become known as 'managed liberalization' (Van der Veen and Trommel, 1999) the government has increasingly privatized and decentralized responsibilities and has started to rely more and more on the market system for the financing and administration of social insurance. This process has changed the nature of the traditional welfare state towards the 'enabling state', which is coined by Gilbert and refers to the enabling role of the state "...to provide social protection through public support for private responsibility." (Gilbert, 2005, p. 6). In this move towards the enabling state, the role of the government has changed from being a provider to being a facilitator. According to Van der Veen (2009) this does not mean that public responsibility is eroding but merely that it has been 'recalibrated' from financing to regulating. Whether one agrees with Gilbert and sees this as a "silent surrender of public responsibility" (Gilbert, 2002) or whether one agrees with Van der Veen in concluding that it is not a retrenchment of the welfare state, the reforms (and to this Van der Veen concedes) have led to increased private responsibility for welfare arrangements.

The changing responsibilities of the government and the private sector and the consequences this has for the implementation of labor market policy are two themes that run throughout this thesis. Our first objective is to analyze the major labor market reforms that have been undertaken by the government since the 1980s and assess which types of reforms have been most successful in reducing unemployment. We do this in Chapter 2 where we distinguish five types of reforms. Level reforms change real money levels of income from benefits. Responsibility reforms refer to reforms that shift responsibilities from the government to the private sector or change responsibilities between employers and employees. Access reforms change the specific groups of people which are eligible for a certain benefit scheme. Duration reforms change the length of benefit entitlement, whereas stimuli reforms refer to reforms that provide financial or other incentives to employers and/or employees to seek out, create or accept work.

Given the changing responsibilities between the government and the private sector, our second and main objective is to answer the question how firm based initiatives can play a role in reducing and preventing unemployment and what lessons might be learned from this for the design and implementation of future labor market policies. To answer this question, we study three firm based unemployment and employability initiatives in Chapters 3 through 5, which are all initiated by Philips Electronics Netherlands. These initiatives are the Philips Employment Scheme (WGP), the Vocational Qualification Program (VQP) and the E-miles program. All four chapters 
(2-5) are self-contained and can be placed on a timeline of economic developments.

In this introduction chapter we first elaborate on these economic developments. We distinguish three phases: the early 1980s, the late 1980s and 1990s and the new millennium. Next, we elaborate on our findings with regard to the three firm based initiatives, respectively, and explain how each of them aligns with one of the three phases. Finally, we discuss the implications of this thesis.

\subsection{Economic developments and the labor market 1980-2010}

\subsubsection{The early 1980s: The inheritance of the oil crises and the Wassenaar Agreement}

In the 1980s, the decade that inherited massive unemployment of the two oil crises (see also Figure 1.1 above), the primary concern was to curb the costs of the welfare state and to reduce unemployment. To accomplish this the newly elected government set in motion two decades of intensive reforms which are analyzed in Chapter 2. The first reforms were initiated by the 1982 Wassenaar Agreement in which unions and employer organizations agreed to lower working hours (from 40 to 38 hours per week) in exchange for wage moderation. As a result of the Wassenaar Agreement the profitability of the private sector increased (Visser, 1998).

The focus on job creation in the Wassenaar Agreement was to a large extent a curative measure against unemployment which matched the spirit of the early 1980s. Figure 1.2 shows that the number of vacancies did not nearly grow fast enough to bring down unemployment in the first half of the 1980s. It merely slowed down the rapid growth of unemployment.

In the mid and late 1980s, most government reforms focused on trying to curb the costs of the welfare state and bringing the number of claimants down. Replacement rates were lowered, not only with regard to unemployment but also with regard to sickness and disability benefits. Furthermore, in 1987 all unemployment benefit laws were completely overhauled (in the so called: 'Stelselherziening sociale zekerheid') although several studies we refer to in Chapter 2 revealed that it did not yield the envisioned results. As Figure 1.2 shows, unemployment decreased only modestly and rose to a new peak in the early 1990s. It was not before 1995 that unemployment started to decrease.

\subsubsection{The late 1980s and 1990s: Globalization, Skills Biased Technological and Organizational Change and Crowding Out}

In retrospect, we know that it was not merely the aftermath of the two oil crises that affected the labor market. Throughout the 1980s and 1990s, developments such as globalization, skills biased technological and organizational change (SBTC and SBOC) and the crowding out of low skilled workers have complicated policies to reduce 
Figure 1.2: Number of vacancies and unemployed 1980-2009

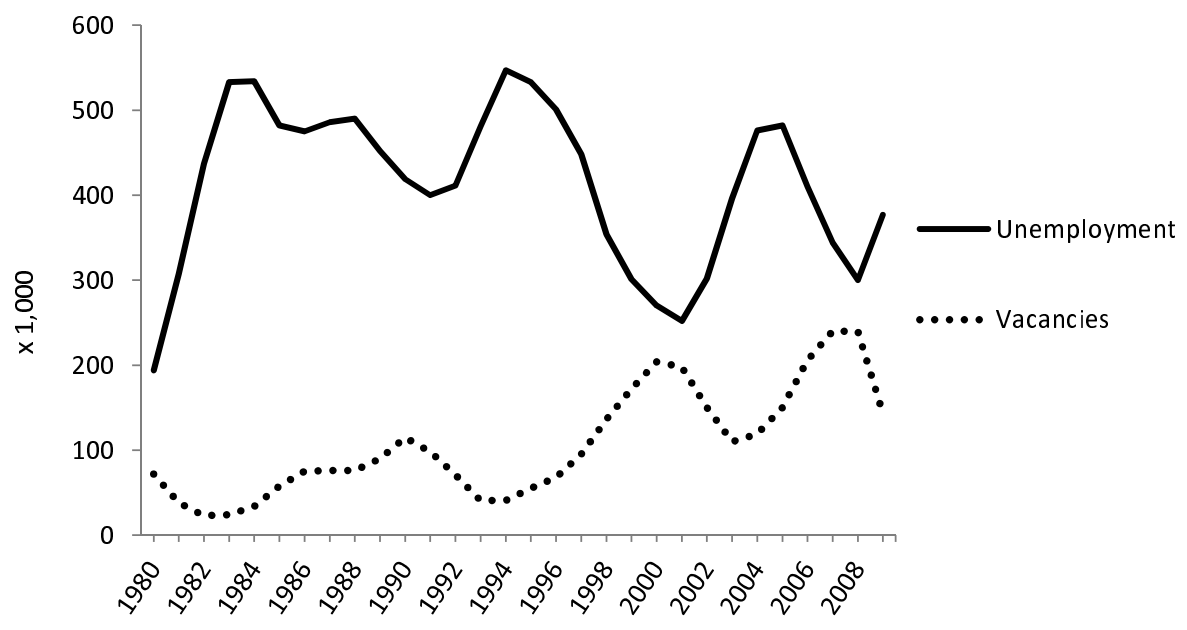

Source: Macroeconomic Outlook 2011, Netherlands Bureau for Economic Policy Analysis (CPB)

unemployment. Strauss-Kahn (2003) finds that in many countries globalization and SBTC led to diverging developments for low skilled and high skilled workers. Low skilled workers suffered absolute or relative wage decreases and higher unemployment levels than high skilled workers. According to Berman, Bound and Machin (1998, p. 1245) "Demand for less-skilled workers plummeted in developed countries in the 1980s". As Figure 1.1 shows, unemployment in The Netherlands in the 1980s and 1990s was particularly high for low educated workers and the gap between low and high educated workers has started to widen in the late 1980s and 1990s.

Globalization is particularly reflected in outsourcing of low skilled work. Outsourcing means that for production processes that can be broken down into many intermediate products, the relatively low skilled activities can be relocated to low wage countries (Feenstra and Hanson, 1996). This leads to a diverging demand for low skilled and high skilled workers because the further processing of these intermediate inputs into final products relies relatively more on high(er) skilled labor. Therefore, the relative demand for high skilled labor increases (Feenstra and Hanson, 1996). In their study on 14 countries (including The Netherlands), Hummels, Ishii and Yi (2001) show that the share of outsourcing in these countries' exports of final goods increased by 30\% from 1970 to 1990. Similarly, Falk and Wolfmayr (2008) find for several countries including the Netherlands, that in the period 1995 to 2000, growth in imported materials is larger than growth in output, meaning that imports are becoming increasingly important in the production process. In an earlier study they show that imported materials from low wage countries have a negative impact on total employment in the importing country, especially in low skill intensity industries (Falk and Wolfmayr, 2005). More recent literature shows a somewhat less grim picture. 
Munch (2010) finds for Denmark between 1990 and 2003 that outsourcing leads to short-run adjustment costs especially for low skilled workers. The costs are mainly expressed as an increased unemployment risk and lower re-employment earnings. However, Munch notes that the size of the effects is modest and that the flexibility of the labor market determines how large these costs will be. Bachmann and Braun (2011) find for Germany between 1991 and 2000 that outsourcing increases the risk of leaving the labor market especially for medium skilled and older workers.

Autor, Levy and Murnane (2003) analyze the underlying mechanism of Skills biased technological change (SBTC) by looking at the effects of advances in computer technology. They find that computer technology substitutes labor in tasks that rely on cognitive or physical routines (often low skilled) and that computer technology complements labor in non-routine cognitive tasks (usually high skilled). This leads to an increasing demand for skilled labor compared to unskilled labor and increased relative wages for skilled labor (Autor et al., 2003). Furthermore, Berman et al. (1998) find that nonproduction workers have been substituted for production workers in 10 leading OECD countries including the US, UK and Germany. This happens consistently within the same industries across countries, by which they argue that SBTC is pervasive throughout the developed world.

Similar to how the introduction of new technologies leads to a skills bias in labor demand, the introduction of new ways of organizing work also tends to shift labor demand to favor high skilled workers (Caroli and Van Reenen (2001) and Bauer and Bender (2004)). This is known as Skills Biased Organizational Change (SBOC). Examples of organizational changes include amongst others just-in-time production scheduling, work teams and multi-tasking (Piva, Santarelli and Vivarelli (2005), who also present an overview and discussion of the literature on skills biased organizational change.). Using data on 400 Italian manufacturing firms, Piva et al. (2005) are able to jointly estimate SBTC and SBOC and find that SBOC is important in explaining changes to the workforce composition especially on the shopfloor-production level. Combined with SBTC the impact is stronger suggesting that SBTC and SBOC complement each other. Piva et al. argue that these organizational changes increase the need for improved general skills among all skill levels to ensure that all workers are equipped to easily adapt to organizational and technical changes.

The final phenomenon we briefly discuss here is 'crowding out'. In the context of the labor market this refers to the process that higher educated workers occupy jobs that demand a lower skill level than they possess, displacing the low skilled worker who used to occupy this job (Borghans and De Grip, 2000). Figure 1.3 shows the composition of the Dutch labor force by educational attainment. The labor force increasingly consists of workers with upper secondary or tertiary education and the workers with tertiary education show the steepest volume growth. Gesthuizen and Wolbers (2010) argue that this educational expansion outpaces the growth in high skilled jobs, forcing high skilled workers to accept a job on a lower level. The workers they displace on this lower 
Figure 1.3: The Dutch Labor force by education 1981-2010

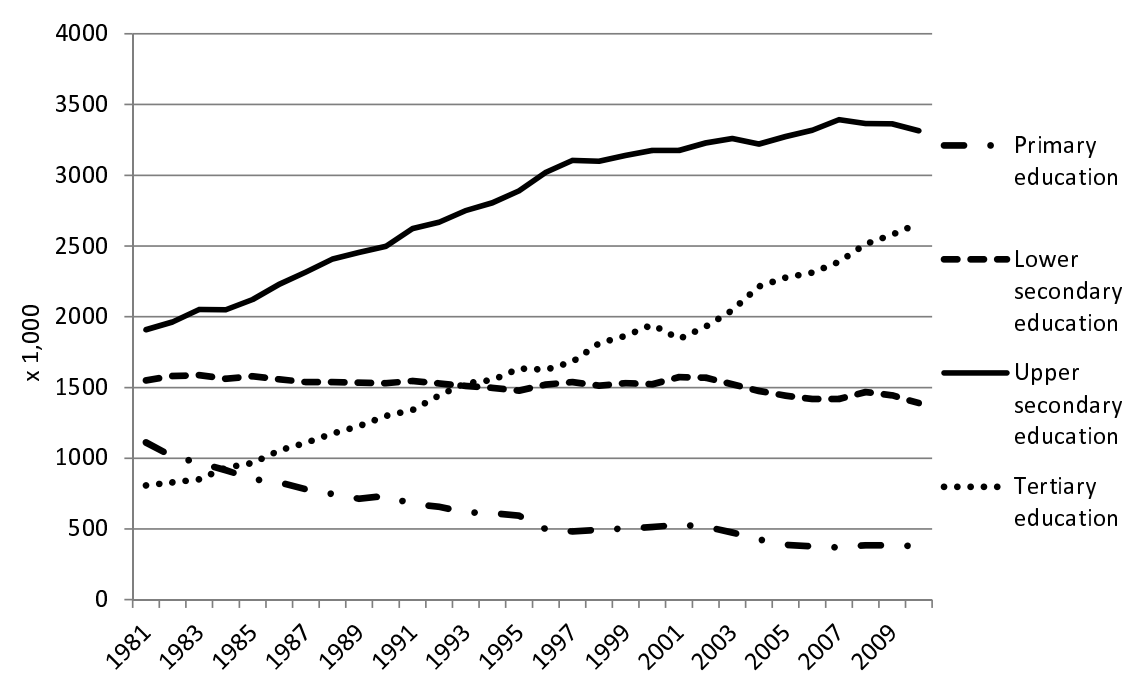

Source: Statistics Netherlands

job level then accept a job on an even lower level. This process of bumping down in the end becomes most problematic for workers at the lowest level. Gesthuizen and Wolbers (2010) show that crowding out has contributed to the worsening of the labor market position of low educated male workers in The Netherlands between 1980 and 2004. Crowding out reduces the opportunities for low educated workers to enter or re-enter the labor market. Borghans and De Grip (2000) explain that this phenomenon can be interpreted from two perspectives. Crowding out can be interpreted as a signal of excess supply of high skilled workers. In that case, there is overeducation and as a result the skills of the higher educated are underutilized. However, crowding out can also be interpreted from an upgrading perspective, when jobs today require more skills than in the past (Borghans and De Grip, 2000).

While globalization, SBTC and SBOC, and crowding out contributed to the widening unemployment gap between low skilled and high skilled workers in the 1980s and 1990s, the government was still struggling to get unemployment under control. However, whereas in the 1980s reforms that cut replacement rates or changed benefit eligibility were popular, the 1990s became the era of Active Labor Market Policies (ALMP), changes in employment protection legislation (EPL) and decentralization and privatization of social insurance. The so called 'Melkert jobs' of the mid 1990s which provided subsidized jobs for the long term unemployed have been among the few relatively (but not indisputably) successful ALMP policies. However, these activation and participation measures, although sometimes successful in employing the long term unemployed, are culprits for the increasing risk of in-work poverty among low skilled workers in the 1990s (Snel, De Boom and Engbersen, 2008). Yet another sign of 
diverging developments between skill levels.

Overall, most authors discussed above find significant negative effects of outsourcing, SBTC and SBOC on (low skilled) employment in developed OECD countries throughout the 1980s and 1990s, which is compatible with the skills upgrading perspective of crowding out. Combined with the complication of increasing risks of in-work poverty among low skilled workers, this paints a gloomy picture for low skilled workers. Not surprisingly, most authors advocate policies towards the upgrading of the skills of low skilled workers.

\subsubsection{The new millennium: continued importance of skills upgrading on all levels}

As Figure 1.2 shows, around the year 2000 unemployment was finally down to the lowest level in over twenty years. The amount of vacancies was approaching the number of unemployed, signalling a tight labor market. However, this situation did not last for long as unemployment started to rise again. The trends in globalization, SBTC, SBOC and crowding out did not stop at the turn of the millennium, they still prevail today. Figure 1.3 shows that the educational expansion is ongoing and in recent years the growth in upper secondary education is leveling off whilst growth in tertiary education seems to be higher than ever. The question whether this has led to more crowding out is not something we analyze in detail in this thesis, but the evidence presented by Gesthuizen and Wolbers (2010) shows that until at least 2004 this has been the case. This is likely to continue unless SBTC leads the growth in the relative demand for high skilled workers to overtake the growth in relative supply of high skilled workers (as predicted to occur between 2000 and 2020 by Jacobs (2004)). However, whether it is due to crowding out or SBTC, in both cases the low skilled workers get the short end of the stick. Figure 1.1 shows that with the renewed rise of unemployment from 2001 onwards, which coincides with the accelerated growth in tertiary education (Figure 1.3), the unemployment gap between low and high skilled workers immediately grew larger again. Moreover, Groot and De Groot (2011) find that wage inequality between on the one hand low skilled workers and on the other hand medium and high skilled workers has increased between 2000 and 2008 .

The government's response to the renewed increase in unemployment consisted of cuts in benefit duration, more stringent eligibility criteria and a further decentralization and privatization of reintegration services. Unemployment declined across the board until the subprime mortgage crisis hit and unemployment again started to increase, again rising faster for low skilled workers.

Unemployment rates over the past 30 years have been at least twice as high for the lowest skilled workers than for the highest skilled workers. Combined with the findings on in-work poverty, wage inequality and the ongoing educational expansion, it is clear that the low skilled have ended up in the worst position, fighting to hold on to the bottom sport of the labor market ladder and competing for their job with 
higher educated workers, migrant workers as well as low skilled workers in low wage countries.

\subsection{Developments within Philips}

\subsubsection{The Wassenaar Agreement and the Philips Employment Scheme}

In the early 1980s, at the time of the Wassenaar agreement, Philips Electronics Netherlands was one of the Dutch largest employers. Whereas the unions and employer organizations agreed in the Wassenaar Agreement to reduce working hours, Philips preferred a different approach to combat unemployment. Being such an important employer, Philips was able to negotiate with the unions to implement a different approach. As particularly youth unemployment was very high at that time, Philips created the 'Youth Work Plan' (JWP) which offered unemployed youngsters one year of work and training with Philips. With the JWP commencing in 1983, Philips committed itself to pro-actively contribute to the fight against unemployment, a role that before that time was not performed by the private sector. The JWP ran successfully for a number of years after which the target population was expanded in 1986 to include other groups of unemployed. The main criterium became that a participant should have a large distance to the labor market (eg. the long term unemployed or the unemployed among ethnic minorities). The name of the program was changed into Philips Employment Scheme (WGP) but the basic setup remained largely unchanged and still entailed one year of full-time employment and training at Philips. To avoid confusion with the commonly used abbreviation PES for Public Employment Services, we will abbreviate Philips Employment Scheme to 'WGP' in this thesis (based on 'Werkgelegenheidsplan', the Dutch name of the program).

In Chapter 3 we analyze the performance of the WGP. Our analysis reveals that the WGP has an average treatment effect of 18 percent, which means that the average program participant has a 18 percentage point higher probability to find a job than an unemployed person who did not participate in the program, but with otherwise similar characteristics. The impact of the WGP is much larger than the impact of participating in a public reintegration program. Furthermore, the WGP has a number of benefits for Philips. It serves for example as an additional recruitment channel, as Philips offers suitable WGP participants the possibility to continue into regular employment within the company. The WGP continues to be in operation today and is approaching its 30st anniversary in 2013. The longevity of the program is one of the features which contrasts sharply with that of public labor market instruments, which tend to last no longer than a political business cycle as is shown in Chapter 2. 


\subsubsection{Increased skills demands and the Vocational Qualification Program}

The increased skills demands that resulted from the economic developments in the 1980s and 1990s were also felt within Philips. In 2000, after having had 17 years of experience with the WGP and seeing participants flourish as a result of the renewed work experience and training, Philips wanted to apply the lessons learned from the WGP to benefit their regularly employed low skilled workers. Building on the experience from the WGP, Philips designed the Vocational Qualification Program (VQP) which started in 2002. Its goal was to train all low skilled but experienced workers within Philips Netherlands to meet the increased skills demands of Philips as well as the external labor market. The VQP was aimed at all low skilled employees (without any vocational qualification) within Philips Netherlands. Many of these workers had more than a decade of experience but they lacked a formal qualification or had a qualification which was too low to be recognized considering the increased skills demands. Ultimately, all low skilled workers within the firm should obtain a vocational qualification. The VQP has been running between 2002 and 2011. We analyze the VQP in Chapter 4.

Our analysis of the VQP shows that workers who complete the VQP training -which means that they obtain a vocational qualification- enjoy an average wage increase of 4.3 percent compared to those who did not participate in the training. We also find that the wage effect of training diminishes over time, canceling out after 7 years. In addition we find two effects that signal an improved employability as a result of the training. Firstly, workers who completed the training have a higher chance to be internally promoted than those who do not participate in the training and secondly, completing the training leads to a lower chance of getting fired. These effects show that the VQP can be regarded as a preventive measure against low skilled unemployment. As such the VQP helps to address the problem of diverging opportunities between low and high skilled workers.

\subsubsection{The educational expansion, SBTC, SBOC and the E-miles employ- ability vouchers}

The continued educational expansion discussed in Section 1.2.2 has led to an increasing risk of crowding out across all skills levels. Even for medium or high skilled workers, staying idle with respect to human capital development may harm one's employability as the risk to be bumped down has increased with the rapid expansion of workers with tertiary education. Moreover, SBTC and SBOC spur the need to invest in human capital development to prevent skills obsolescence (De Grip, 2006). To make workers across all levels of education aware of the importance of continuous personal development, Philips started the E-miles voucher scheme in 2009. Under the E-miles ((E)-mployability miles) scheme, all Philips employees received a voucher worth 1,000 E-miles, that workers could redeem for training that increases workers' insights in their 
own employability and further career opportunities.

In Chapter 5, we analyze the E-miles voucher scheme and find that workers who use their voucher and thus participate in employability training, show a significant improvement of their employability awareness compared to workers who do not spend their voucher and hence do not take employability training. Workers who use their voucher also show an increased willingness to invest in future training compared to those who do not spend their voucher. Increasing workers' employability awareness and willingness to train can be considered as an early intervention to help safeguard the workers' future employment.

\subsection{Discussion and implications}

In this thesis we analyze the labor market reforms in The Netherlands from 1982 till 2005 and three Philips based employment and employability initiatives: the Philips Employment Scheme, the Vocational Qualification Program and E-miles.

\subsubsection{Firms and unions taking responsibility for job growth}

In Chapter 2, we find that more than two decades of reforms have (1) changed the nature of labor market policies from passive to active policies, and (2) shifted responsibilities with regard to social insurance from the public to the private sector. Notwithstanding a torrent of reforms, it took more than 15 years after the Wassenaar Agreement for unemployment to be reduced to a relatively low level again, while in the same period inequality in wages and employment opportunities between low and high skilled workers increased and a new phenomenon of in-work poverty emerged. This hints at an apparently small influence the government can exert over the level of unemployment, at least when they solely rely on orthodox policy options (in a moment we will come back to heterodox policy options). Indeed, Zagha and Nankani (2005) derive from several studies, that the quality of institutions matters more for economic growth than specific policy instruments. This aligns with the main conclusions of a detailed discourse of Dutch industrial relations by Visser (1998), who finds that corporatism in the Netherlands, embodied in for example the Wassenaar Agreement, has been instrumental in the achievement of the employment growth of the 1990s. Visser (1998) stresses the importance of unions and employers acting in unison to achieve the wage moderation and reductions in working hours that were the main drivers of the economic recovery that materialized from the mid 1990s. In the same period the government flourished in piecemeal initiatives, trying countless active labor market policies which were often short lived and of limited success. As Chapter 2 shows, it does not help that we find government interventions and reforms to be highly related to the political business cycle.

Contrary to the volatile nature of government policy, we find the Philips Youth Work Plan (JWP) and its successor the Philips Employment Scheme (WGP) which 
have created additional jobs for the unemployed. Starting in 1983 with the JWP, Philips had the first private sector program that created additional jobs for the unemployed workers. It was not until 1987 that the government itself for the first time created additional jobs for unemployed workers through the so called 'Tijdelijke Voorziening Gemeentelijke Werkgelegenheidsinitiatieven voor Jongeren' (TV-GWJ), targeting only on young unemployed. However, one year earlier, in 1986, Philips had already opened up the JWP and evolved it into the WGP, creating additional jobs for unemployed workers with a variety of disadvantaged backgrounds. The first public sector attempt to create additional jobs for a wider range of unemployed was the 1989 'Experiment Additionele Arbeid' (Experiment Additional Labor). In the following years a variety of (subsidized) job creation schemes had been introduced, none of which went into history as indisputably successful and none of which lasted long. Conversely, the WGP is still in operation today.

\subsubsection{Aggregate potential of the WGP if implemented by the 700 largest Dutch firms}

As we show in Chapter 3, running a program like the WGP has certain benefits to the firm as well. Philips on average hires $15 \%$ of the WGP participants into regular employment within the company, saving on recruitment costs. Furthermore, WGP participants sometimes temporarily replace a regular employee at times when the latter is being trained, thus dampening productivity losses. This also implies that the work experience the WGP participant gets is as close to a regular job as can be, which is one of the success factors of the WGP. Finally, the WGP is seen as a contribution to corporate social responsibility of the firm and may help improve firm-union relations. There is no reason to think these benefits would not apply similarly to other companies running a similar program.

To give an impression of the potential role firms could play in reducing structural unemployment, Table 1.1 provides a rough calculation based on the number of large firms in the Netherlands and the current stock of long term unemployed.

In 2010 there were 290 firms in The Netherlands that were larger than 2,000 employees and 410 firms that had between 1,000 and 2,000 employees. Together they employ a minimum of 990,000 persons in the Netherlands. Note that this is a conservative estimate as we took the lower bound for our calculation. For example, Philips already employs 15,000 people. If all these firms would run a program such as the WGP and would all aim to create a yearly inflow of long term unemployed of $1 \%$ of their total employment (as has always been the Philips WGP target which has been attained on average), these firms could annually offer at least 9,900 long term unemployed an opportunity to reintegrate. If we define long term unemployed as those who have been receiving either unemployment benefits (WW) or welfare benefits (WWB) for more than 12 months, the 9,900 additional jobs these 700 firms could create annually equals $3 \%$ of the current stock of 330,060 long term unemployed. If 
Table 1.1: Aggregate private sector potential of the WGP based on 2010 data

Number of firms with 1,000-2,000 employees

-Total employment at least

Number of firms with 2,000+ employees

-Total employment at least

Total employment at the $1,000+$ firms

Number of long term unemployed $12+$ months in WW (UB)

$12+$ months in WWB (welfare)

Total number of long term unemployed

Target job creation percentage

Job creation potential of these 700 firms

\begin{tabular}{|c|c|c|}
\hline $410 \times 1,000=$ & $\begin{array}{r}410 \\
410,000\end{array}$ & $\begin{array}{l}\text { firms } \\
\text { persons }\end{array}$ \\
\hline $290 \times 2,000=$ & $\begin{array}{r}290 \\
580,000\end{array}$ & $\begin{array}{l}\text { firms } \\
\text { persons }\end{array}$ \\
\hline \multirow{4}{*}{$\begin{array}{r}76,050 \\
254,010\end{array}$} & 990,000 & persons (at least) \\
\hline & & \\
\hline & 330,060 & persons \\
\hline & $1 \%$ & $\begin{array}{l}\text { of total } \\
\text { employment } \\
\text { within firms }\end{array}$ \\
\hline $1 \%$ of $990,000=$ & 9,900 & $\begin{array}{l}\text { reintegration } \\
\text { jobs per year }\end{array}$ \\
\hline
\end{tabular}

Thus the 700 largest firms could, ceteris paribus, help reintegrate at least $3 \%$ of the current stock of structurally unemployed, per year.

Source: Own calculations on data from Statistics Netherlands

we include firms that employ between 500 and 1,000 workers in this calculation (there are 805 of these) and use the lower bound of 500 workers we find that the $500+$ size firms can, ceteris paribus, create additional jobs for $4.2 \%$ of the current stock of structurally unemployed yearly. In 5 years the $500+$ size firms could, ceteris paribus, create additional jobs for about $20 \%$ of the current stock of structurally unemployed.

\subsubsection{Brief summary and generalizability of our main findings}

Overall, we find that the three Philips based initiatives WGP, VQP and E-miles succeed in their respective goals of reintegrating the unemployed into the labor market, increasing the employability of low skilled employees and increasing the "employability awareness' of employees. Meanwhile, these initiatives entail benefits for Philips as well. For instance, the WGP serves as additional recruitment channel and the workers that complete the VQP on average earn more, make more promotions and get fired less often than their not trained low skilled colleagues. In other words, the trained worker has a higher added value for Philips.

All three initiatives are suitable for implementation by other firms. Only an employment scheme set up in a similar vein as the WGP, probably requires a somewhat larger firm to properly function due to the intensive supervision and involvement it requires of human resources staff members. Nevertheless, the example set by 
Philips with the WGP has recently been picked up by a number of other firms who started similar employment schemes. These include the 'Step2Work' program of NUON (a large utility company with approx. 5,800 employees); 'NS Werktoer' of the Nederlandse Spoorwegen (Dutch railways with approx. 11,000 employees); and the 'NXP werkgelegenheidsplan' of semiconductor producer NXP (approx. 4,800 employees). Although the numbers of participants in these other employment programs are still relatively small, the mere existence of these programs and their resemblance to the WGP lends external validity to the results we find in Chapter 3 of this thesis.

In 2002 the EU adopted the Lisbon Strategy, which aimed at making Europe the most advanced knowledge based economy by 2010. Since then, the training of low skilled employees has been stimulated intensively by the European Social Fund (ESF). Many firms, both small and large, have made use of partial funding by the ESF to provide training to their low skilled workers. If this would not benefit these firms, they would not engage in training their low skilled workers. Therefore, we expect that the results in Chapter 4 of this thesis regarding the VQP will hold similarly for other firms of any size, that provide a vocational training program for their low skilled workers.

Finally, a recent report by De Grip, van Breugel and Dohmen (2011) (which discusses amongst others the E-miles voucher system) shows that voucher systems to promote personal development and lifelong learning exist in several firms and organizations of similar size as Philips. Therefore the results we find for the E-miles voucher system can be expected to hold for other firms as well.

The Philips WGP, VQP and E-miles show that firms can contribute to reducing unemployment and increasing the employability of (low skilled) workers while also benefitting themselves. This is especially important to observe in times when the government feels the need to rigourously cut social spending and privatize responsibilities for social insurance. In a sense, the government is leaving a gap which firm based initiatives such as those analyzed in this thesis help to fill.

These initiatives are to be praised as they contribute to the amelioration of unemployment in the broadest sense. As such they benefit society at large and deserve to be copied by other firms. Especially in the case of the WGP, this has a clear and significant aggregate potential to reduce long term unemployment. We hope the stable and long lasting success of the WGP provides inspiration for other firms, social partners and the government so that they may act to develop its full aggregate potential.

\subsubsection{Final words: Why is full employment nowadays an unorthodox idea?}

We could have stopped at the last paragraph, but we promised to get back to two earlier points in this introduction. We now present our opinion on the differing academic views of Gilbert and Van der Veen as mentioned in Section 1.1 and come back to our note on orthodox and heterodox policy options (Section 1.4.1).

In our opinion, the often heralded 'Dutch Miracle' of the late 1990s economic 
growth and unemployment decline should be seen in a broader perspective. Even though this decline in unemployment is a good thing, there are many details that are not captured by the aggregate unemployment figure. First, it is an established fact that the vast majority of newly created jobs in the 1990s were part-time jobs (Visser (1998)), possibly representing significant underemployment. Second, the wage moderation that was the main driver of this unemployment decline, is a contested instrument. Visser (1998) draws attention to an argument of the Deutsches Institut für Wissenschaftsforschung (DIW, 1997) that wage moderation and workingtime reduction are not wealth promoting but distributive policies that may lead to impoverishment, and connects this to the relative decline of Dutch GNP per capita between 1982 and 1996 compared to other EU countries. We would like to further connect this to the increasing inequality of employment opportunities and earnings between low and high skilled workers and the rise of in-work poverty in the same period, as discussed in Section 1.2.3. Finally, the relatively successful unemployment performance of the late 1990s is a lot less successful when we compare it to the level of unemployment in the 1960s instead of the early 1980s (See Figure 1.4).

Figure 1.4: Unemployment in the Netherlands 1945-2010

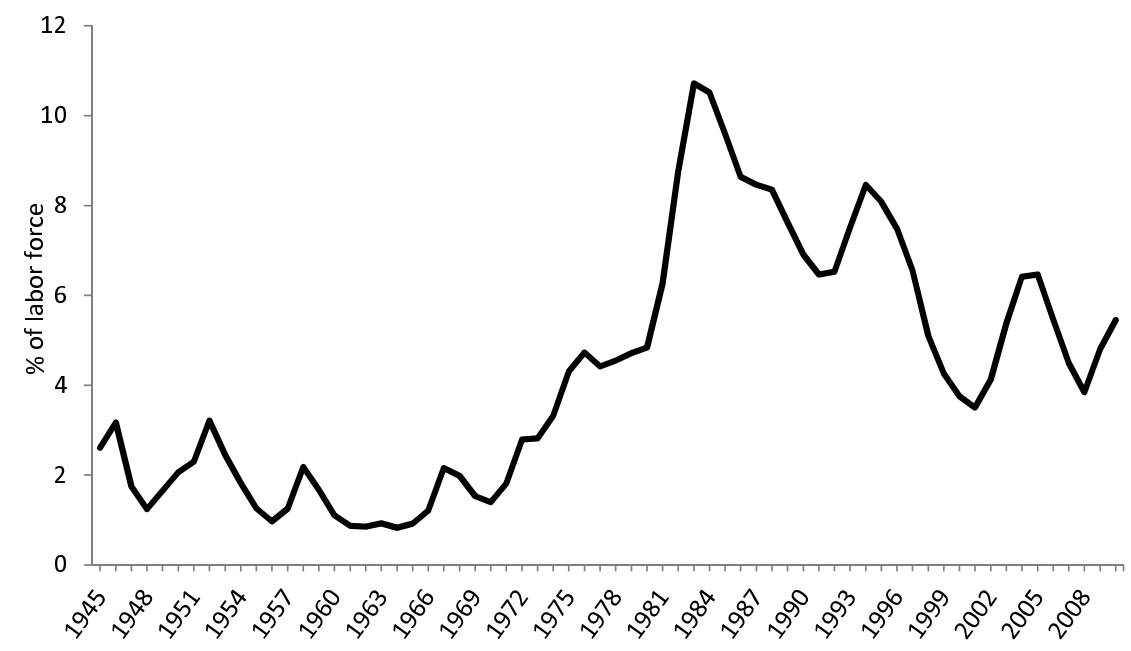

Source: Statistics Netherlands

This illustrates that we should put the 'Dutch Miracle' into perspective. Although since 1983 the Dutch constitution (Chapter 1, Article 19.1) contains the fundamental social right that 'it shall be the concern of the authorities to promote the provision of sufficient employment', Figure 1.4 shows that the government, despite the cooperative attitude of unions and firms, has not been able to provide a stable and successful employment promoting policy, let alone full-employment. In our opinion the limited government involvement in actual job creation and the fact that the Philips 
JWP/WGP preceded the government's first attempt for job creation by four years, is exemplary of Gilbert's notion of the 'enabling state' and the silent surrender of public responsibility. If a firm based initiative like the Philips WGP can successfully provide a job-based path back into regular employment for almost 30 years now, why can the government, with vastly more resources available, not do the same and on such a scale as to achieve full employment? This is in a sense a rhetorical question, as the development by which many governments have abandoned the pursuit of full employment have been described in detail by for example Mitchell and Muysken (2010). Nevertheless, the findings of this thesis warrant continued attention to this question. Besides giving a detailed discourse of the observed abandonment of full employment as a policy objective, Mitchell and Muysken $(2008,2010)$ argue that the introduction of employment guarantees should be a central plank in modern macroeconomic policy. Detailed explanations of how such a Job Guarantee (JG) is designed and embedded in the macroeconomy are presented as well and form convincing and compelling study material. What the results of this thesis add to the JG proposal and what may help convince those that inaccurately think a JG may involve 'too much state', is that firms have a large potential to be part of the solution, as the example of the WGP shows.

Hopefully this thesis inspires economists, social partners and the government to put full employment back on the agenda and consider the development of a JG program with involvement of firms and unions and therewith finally honoring the fundamental right of sufficient employment and responsibility as stated in the Dutch constitution. Hardly any country in the world might provide a more suitable birth ground for the return to full employment than the corporatist Netherlands. 



\section{From Dutch Disease to Dutch Miracle: why some institutional reforms work and others do not}

\section{$2.1 \quad$ Introduction $^{1}$}

In 1977 The Economist supplied the Netherlands with the (in this case notorious) honor of having an economic phenomenon named after the country: The Dutch Disease. $^{2}$ A massive growth of the social security system occurred throughout the 1970s period of Dutch Disease, as is evident in Figure 2.1 from a huge surge in benefit recipients between 1969 and the early eighties. ${ }^{3}$ To counter this development the Dutch government embarked on a reform path that would give the Netherlands a frontrunner position within the European Union with regard to the intensity and outreach of institutional reforms. It would also repair the honor of the Netherlands with regard to the country-name based economic phenomena: With the Dutch Miracle and the Dutch 'Poldermodel' the score was more than settled. ${ }^{4}$

Nickell and Van Ours (2000: 173) acknowledge the Dutch Miracle and conclude that the Netherlands have seen a 'major decline in equilibrium unemployment and nonemployment [sickness and disability] rates since the early 1980s.' Using institutional data from amongst others Nickell and Layard (1999), Scarpetta (1996) and Elmeskov et al. (1998), they point to a positive relation between institutional reforms and a

\footnotetext{
${ }^{1}$ This chapter is joint work with Manuel Müllers

${ }^{2}$ The Dutch Disease refers to the phenomenon of declining manufacturing industry caused by appreciation of the exchange rate when natural resources are found.

${ }^{3}$ Population growth was not markedly large in this period so the surge in benefit recipients is not mitigated by population growth.

${ }^{4}$ The Dutch Miracle refers to the period of high economic growth and low unemployment in the second half of the 1990s. The Poldermodel refers to consensus based policy making by government, unions and employers. An important outcome of the Poldermodel was wage moderation, which was a main driving force behind the Dutch Miracle. See Muysken (2003)
} 
Figure 2.1: Social security benefit recipients

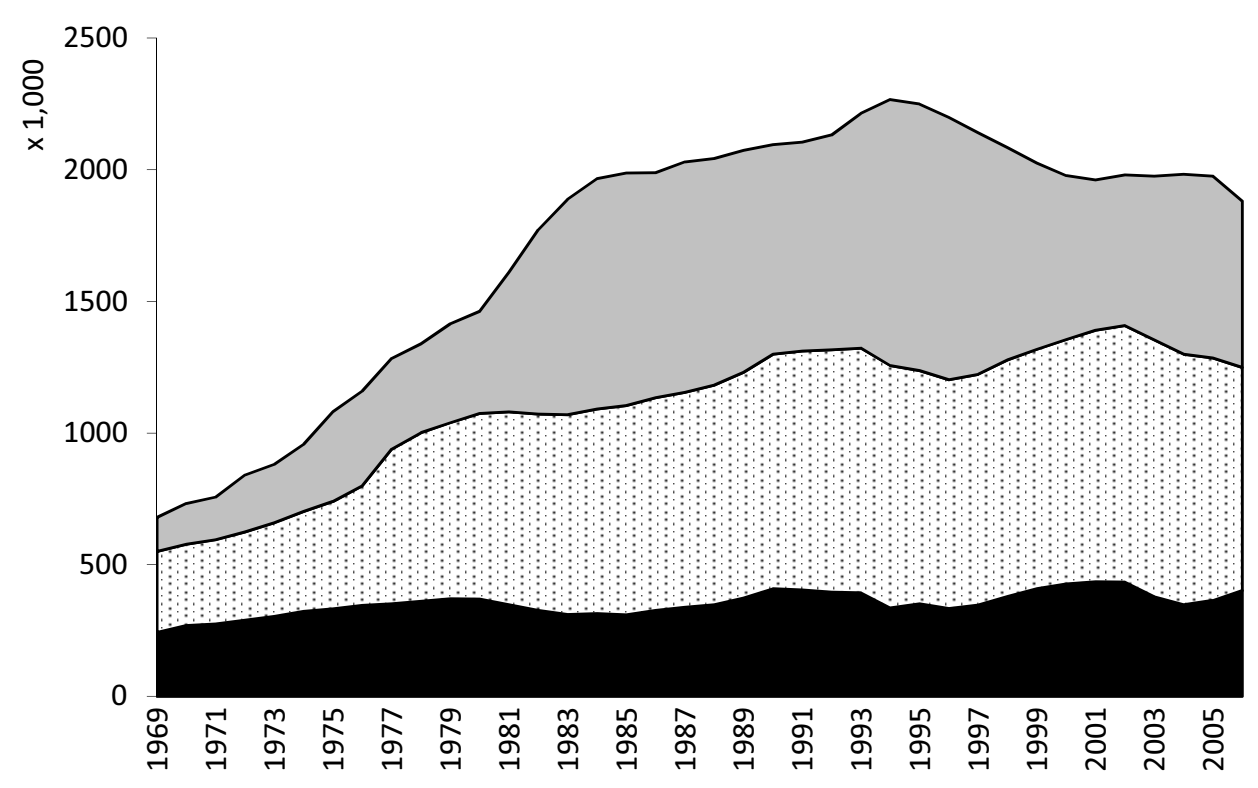

- Sickness 口Disability 口Unemployment or Social Assistance

Based on CPB data from Macro-economic Outlook 2011

lowered equilibrium unemployment rate. These institutional data are based on a relatively limited data source, originally dating back to the OECD Jobs Study of 1994. The data have been widely used, re-used and modified but only allow for very general conclusions about the effectiveness of institutional reforms - see Baker et al (2004), Baccaro and Rei (2005), Bassanini and Duval (2006) and Furceri and Mourougane (2009).

In this chapter we take a deeper look at the Dutch institutional reform history and use a different approach to analyze the effectiveness of the institutional reform efforts undertaken by the Dutch government. ${ }^{5}$ We aim to identify which reforms and types of reforms are (most) relevant, how the effectiveness of reforms is related to the business cycle and how the incidence of reforms is related to the political business cycle.

Given the aim of most reforms, an effective reform is defined as a reform that leads to a significant reduction of the number of benefit claimants at which the reform is targeted. Therefore we will conduct a statistical evaluation of the reforms' abilities to reduce the number of claimants. For this evaluation we need data. We start in section 2.2 explaining how we constructed our data. In section 2.3 we discuss the incidence of reforms. We look at the policy areas they target and their relation with the political

\footnotetext{
${ }^{5}$ For a brief description of the Dutch social security system before the start of the reforms see Bovenberg (2000).
} 
business cycle. We also present a typology of reforms. In section 2.4 we test which reforms actually are effective and how their effectiveness is related to the business cycle. Section 2.5 concludes.

\subsection{Data on institutional reforms}

Our first concern was to find data on the reforms themselves. The literature on Dutch labor market reforms usually distinguishes between sickness (ZW), disability (WAO) and unemployment (WW) reforms - see Koning and van Vuuren (2007) and Stegeman (2005). These are mostly reforms that directly aim at reducing the amount of sickness, disability or unemployment benefit claimants. In addition to that, the international literature differentiates also between active labor market policies (ALMP) and employment protection legislation (EPL) - e.g. (Nickell et al., 2005). These last two reform areas are often used to classify the more broadly targeted reforms that try to activate persons to participate in the labor market or that try to optimize the functioning of the labor market. To get a comprehensive picture of the Dutch reform history we thus distinguish sickness, disability, unemployment, ALMP and EPL as the five main reform areas and study the literature to catalogue all past reforms. We elaborate this process below.

\subsubsection{Content analysis}

The available literature discusses a vast amount of reforms over a relatively short time-period, which means that there is more information than statistical methods can handle properly. To determine what variables we should include in our further analyses we must exclude those reforms that were probably irrelevant and only focus on the relatively important reforms. In order to reduce the density of the reform data we apply Content Analysis, see Neuendorf (2002), Krippendorf (2003) and George (2008). The content analysis we apply is built on three hierarchical levels of information ranging from the most exhaustive source on reforms to the most specialized sources which often only discuss a single reform. Since the types of sources we used all suffer from some inertia when it comes to being up to speed on the latest reforms, we only look at reforms that were implemented prior to 2005 and hence display a mature coverage by our sources. Based on the information we find on the reforms in these three levels of analysis, we construct a ranking of reforms to determine which reforms are possibly relevant and which are not. The underlying assumption here is that the more often a reform shows up in our analysis, the more relevant it is. We elaborate this process below. Table 2.1 presents an overview of the three levels of analysis. ${ }^{6}{ }_{7}$

\footnotetext{
${ }^{6}$ For an extensive overview of our level one and two sources see Appendix I.

${ }^{7}$ Note also that we excluded newspaper articles, TV media/news content or other forms of discussions on labor market reforms. These sources suffer from availability issues and can not assumed to be as reliable as the databases we are working with.
} 
Table 2.1: Three levels of content analysis

\begin{tabular}{c|l|c|c}
\hline \hline Level & \multicolumn{1}{|c|}{ Source(s) } & Document type & \multicolumn{1}{c}{ Function } \\
\hline \hline 1 & $\begin{array}{c}\text { Kroniek van de } \\
\text { sociale verzekeringen }\end{array}$ & $\begin{array}{c}\text { Exhaustive administrative } \\
\text { document }\end{array}$ & Our reference point \\
\hline 2 & $\begin{array}{l}\text { - Brandt et al } \\
\text { - FRDB } \\
- \text { Labref } \\
- \text { OECD }\end{array}$ & Comprehensive reform overviews & $\begin{array}{l}\text { The bulk of our } \\
\text { analysis }\end{array}$ \\
\hline
\end{tabular}

The first level content analysis is based on the 'Kroniek van de sociale verzekeringen' (from here on referred to as 'Kroniek'), published by the Dutch institute for employee insurance ('Uitvoeringsinstituut Werknemersverzekeringen' - UWV). The UWV is the administrative body that is responsible for the social security payments. ${ }^{8}$ One part of their annually published Kroniek is a historical overview of the reforms in all policy areas in question: 'Elk hoofdstuk opent met een historisch overzicht van de betreffende wetgeving, gegroepeerd naar enkele thema's.' (Kroniek 2008, p.5). We therefore assume that the Kroniek is the most fundamental source of information concerning Dutch social security reforms, and thus serves as our reference point.

The second level of our analysis revolves around a number of sources that claim they comprehensively reflect the Dutch social security reform history in the time frame they are covering. We collected all labor market reform information available in Brandt et al (2005), the Social Reforms database of the Fondazione Rodolfo DeBenedetti (FRDB), the LABREF database of the European Commission EC (EC), and the OECD economic surveys of the Netherlands (OECD, 2000). This was necessary because although all of these databases are supposed to include all important reforms, there are huge discrepancies between them. These second level sources constitute the bulk of our content analysis. Reforms that were mentioned in the 'Kroniek', but not in at least one our second level sources are assumed to be irrelevant. Therefore these reforms are excluded from our sample and play no further role in later econometric analysis and do not end up in our ranked list of reforms. Reforms that we do encounter in our second level sources mark the start of our ranking exercise and are treated as follows. If a reform is not mentioned in Brandt et al (2005), FRDB, or LABREF

\footnotetext{
${ }^{8}$ In 2009 the UWV was merged with the Dutch Public Employment Services.
} 
in the relevant time frame, we reduce its ranking score by 1 for each database it is not mentioned in. If the reform is defined as 'Structural reform' in FRDB, or if it is mentioned in OECD economic surveys, we augment its score by 1 each time. ${ }^{9}$

The third level of content analysis involves a literature review to find evidence regarding the relevance of institutional reforms. For example, when a certain reform is topic of discussion in an academic paper we augment its score by 1 . With regard to a limited number of reforms, we find that an academic paper not only discusses the reform, but also convincingly shows evidence that the particular reform has been effective (or ineffective). In these cases, we augment or reduce the score of the reform with a maximum of 2 points. ${ }^{10}$

Although the final list contains reforms with scores ranging from -5 to +4 , we only need to distinguish possibly relevant reforms from the irrelevant ones. All reforms that rank higher than 0 are considered to be relevant, while the reforms that rank 0 or lower are assumed to be irrelevant. ${ }^{11}$ The relevant reforms are presented in Table 2.2. ${ }^{12}$ In Section 2.4 we test if these reforms were significantly able to reduce the number of benefit claimants in respectively unemployment, sickness and disability benefit schemes.

Table 2.2: Potentially relevant reforms, to test in section 2.4

\begin{tabular}{|c|c|c|}
\hline Unemployment & Sickness & Disability \\
\hline $\begin{array}{l}\text { Exemption } 57+\text { and Wassenaar } \\
1987 \text { structural reform } \\
\text { PES reform } \\
\text { nABW } \\
\text { Flexwet } \\
\text { Replacement rate reduction } \\
\text { Reduction of benefit duration }\end{array}$ & $\begin{array}{l}\text { TZ/Arbo } \\
\text { WULBZ } \\
\text { Replacement rate reduction } \\
\text { Poortwachter (WVP) } \\
\text { Extension sickness payments WVLZ }\end{array}$ & $\begin{array}{l}\text { TBA/TAV } \\
\text { AMBER } \\
1998 \text { package } \\
\text { Poortwachter } \\
2004 \text { package }\end{array}$ \\
\hline
\end{tabular}

\footnotetext{
${ }^{9} \mathrm{We}$ are aware that these reform databases treat different time frames. The FRDB database covers 1987 - 2005, Brandt et al. cover 1994 - 2004, and LABREF covers 2000 - 2006. Thus, for 1980 - 1986, we could only rely on the OECD economic surveys and on our literature review. In Appendix II we show the ranking scheme and how we dealt with these discrepancies in time periods covered.

${ }^{10}$ With regard to the 1995 Amber reform and the 2004 reduction in UB duration, we found the outcome of the ranking procedure counterintuitive. The low score was caused by the Amber reform not being mentioned in both Brandt et al and FRDB and the 2004 reduction in UB duration not in the LABREF. In these two cases we corrected these odd findings by augmenting the score with 1 point. This shows in Appendix II and V under the heading of 'theoretical consideration'.

${ }^{11}$ Due to the different time periods covered by the different databases, as mentioned in footnote 9 , the assignment of reforms to either 'relevant' or 'irrelevant' was done around the ranking score ' 1 ' for reforms before 1987 .

${ }^{12}$ Short descriptions of these reforms can be found in Appendix V.
} 


\subsection{The incidence of reforms in the Netherlands}

As described in the previous section we have constructed a reform database and developed a ranking scheme that enables us to distinguish between important reforms and irrelevant reforms. A first visualization of our reform database is shown in Figure 2.2 , which depicts the number of reforms ${ }^{13}$ over time as well as over government, distinguishing also between important reforms and the total number of reforms (thus including irrelevant reforms).

An interesting observation is that there are four main waves of reforms; 1986/1987, 1995/1996, 1998/1999 and 2004. ${ }^{14}$ One sees from Figure 2.2 that these waves occur each time just after the installment of a new government. The concentration of reforms is significantly lower towards the end of a political business cycle, which usually lasts four years. The often unpopular nature of social security reforms, which is reasonably expected to be an influence on chances for re-election, is very likely to be a factor in this timing pattern. Another factor likely to be of influence here is the time needed to see if a certain wave of reforms actually produces the desired results. Especially after 1986/1987 (in which a structural reform was implemented) we see a fairly long 'waiting period' of relatively moderate reform activity. From a point of policy implementation this makes sense, since implementing reform upon reform might result in uncontrolled accumulation of effects, possibly leading to unwanted side effects.

Figure 2.2: Number of reforms by relevance, years and government

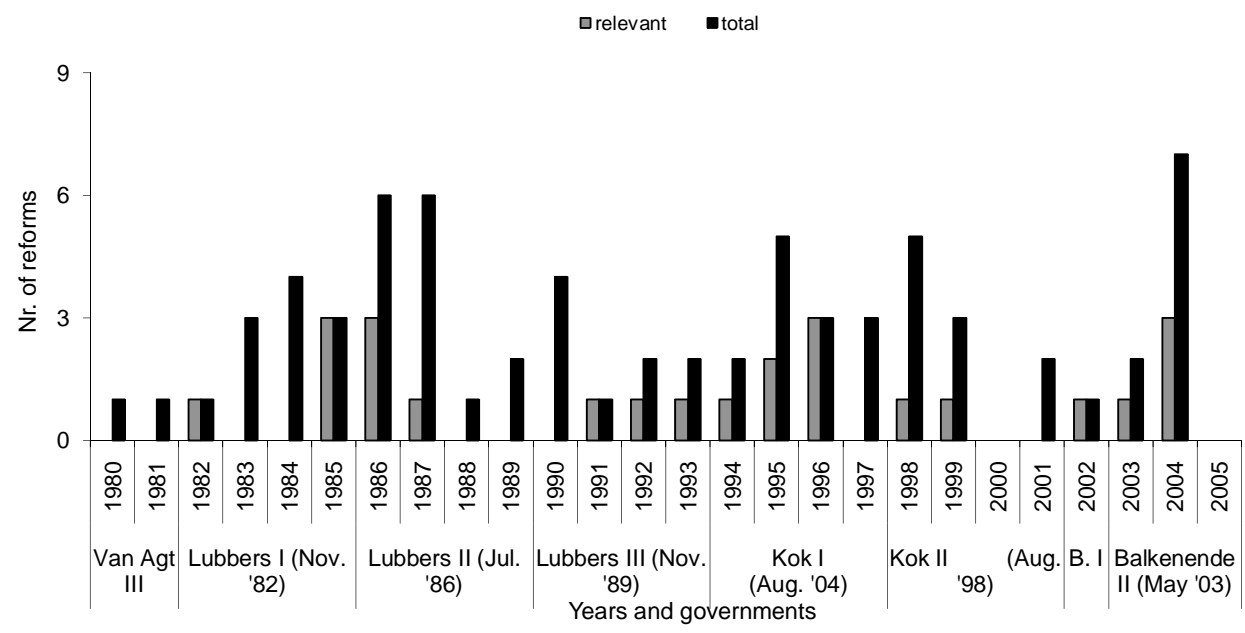

Source: Table 2.3

\footnotetext{
${ }^{13}$ The total of unemployment, disability, sickness, EPL and ALMP reforms.

${ }^{14}$ There was also a fifth reform wave in 1982/1983 when the Wassenaar agreement was signed. Compared to the other waves this wave is not as apparent from Figure 2.2 since the Wassenaar agreement is counted as one reform, while actually consisting of numerous reforms.
} 
Figure 2.2 does not show a clear pattern with regard to the relation between the total number of reforms in a specific period and the number of relevant reforms that would result from these. Periods of high total reform activity do not necessarily produce relatively more reforms that prove relevant, nor do they produce significantly more irrelevant reforms. Moving into more detail, Table 2.3 shows the amount of reforms initiated by year and by reform area. ${ }^{15}$ The left part of the table only counts the reforms that we found to be relevant. The right part of the table includes all other reforms. The distribution of reforms over time shows that unemployment has been on the mind of policy makers continuously, with (relevant) reforms occurring throughout the entire period. Examples of these include the 1982 Wassenaar agreement, which was centered on unions and industry agreeing to lower working hours in order to create additional jobs. The Wassenaar agreement is commonly regarded as one of the earliest manifestations of the Poldermodel, which is at the basis of the period of substantial job growth in the 1990s often referred to as the Dutch Miracle (Visser and Hemerijck, 1997). Another example is the 1991 PES (Public Employment Services) law which introduces the obligation for the PES to inform the institutions in charge of unemployment benefits of insufficient job search efforts by benefit claimants and increased sanctions for refusing a suitable job offer. Abbring et al. (2005) find that, using 1992-1993 data, 're-employment rates are significantly and substantially raised by imposition of a sanction' (p.628).

For disability reforms we observe that except for a few reforms in the early 1980s that were not found to be relevant (mainly involving changes in the taxation aspects of disability payments), and a two-stage reduction in disability replacement rates in 1985/1986, the focal period has been 1992 to present. An example of a relevant reform was the 1992 Act on Reducing Disability Volume (TAV), which entailed some measures such as a bonus-malus system and wage subsidies to reduce the number of disabled. An employer could be eligible for a bonus and subsidy for hiring a disabled worker, whereas he could be liable for a fine (malus) if one of his employees would become disabled. By estimating a model for changes in WAO inflow, Stegeman (2005) found a significant negative effect of TAV on WAO inflow. Another example is the 1993 Act on Reducing Disability Claims (TBA) that consisted of several measures amongst which were a new definition of disability and a corresponding reassessment of a large number of current WAO claimants. Several authors such as van Oorschot and Boos (2001) and Aarts et al. (2002) point to a significant positive effect of the TBA.

Sickness reforms and their timing are closely related to their disability siblings, although the number of pure sickness reforms is notably smaller. Reforms we found to be important include the 1985/1986 reduction in sickness replacement rate from $80 \%$ to $70 \%$ and the 1994 TZ/Arbo. An important element of this last reform was the

\footnotetext{
${ }^{15}$ Incidentally a reform was targeted at more than one area and we chose to include those in our reforms list in all of the relevant areas.
} 
Table 2.3: Reform areas and reform relevance.

\begin{tabular}{|c|c|c|c|c|c|c|c|c|c|c|}
\hline \multirow{4}{*}{$\begin{array}{l} \\
1980 \\
1981\end{array}$} & \multicolumn{5}{|c|}{ Relevant } & \multicolumn{5}{|c|}{ Total, including irrelevant reforms } \\
\hline & Sickne & sab & $\mathrm{LM}$ & $\mathrm{PL}$ & emp. & Sickn & Disability & $\overline{\mathrm{LM}}$ & $\mathrm{QPI}$ & lemp \\
\hline & & & & & & & 1 & & & \\
\hline & & & & & & & & 1 & & \\
\hline 1982 & & & & & 1 & & & & & 1 \\
\hline 1983 & & & & & & & & 1 & 1 & 1 \\
\hline 1984 & & & & & & & 1 & 1 & & 2 \\
\hline 1985 & 1 & 1 & & & 1 & 1 & 1 & & & 1 \\
\hline 1986 & 1 & 1 & & & 1 & 1 & 1 & 3 & & 1 \\
\hline 1987 & & & & & 1 & & 1 & 3 & 1 & 1 \\
\hline 1988 & & & & & & & & 1 & & \\
\hline 1989 & & & & & & & & 2 & & \\
\hline 1990 & & & & & & 1 & & 3 & & \\
\hline 1991 & & & & & 1 & & & & & 1 \\
\hline 1992 & & 1 & & & & & 1 & 1 & & \\
\hline 1993 & & 1 & & & & & 1 & 1 & & \\
\hline 1994 & 1 & & & & & 1 & & 1 & & \\
\hline 1995 & & 1 & 1 & & & & 2 & 2 & 1 & \\
\hline 1996 & 1 & & 1 & & 1 & 1 & & 1 & & 1 \\
\hline 1997 & & & & & & & & 2 & & 1 \\
\hline 1998 & & 1 & & & & & 2 & 2 & 1 & \\
\hline 1999 & & & & 1 & & & 1 & & 2 & \\
\hline 2000 & & & & & & & & & & \\
\hline 2001 & & & & & & & & & 1 & 1 \\
\hline 2002 & & 1 & & & & & 1 & & & \\
\hline 2003 & & & & & 1 & & & & 1 & 1 \\
\hline 2004 & 1 & 1 & & & 1 & 1 & 3 & 1 & & 2 \\
\hline
\end{tabular}

obligation for employers to continue a sick employee's wage payment during the first weeks of sickness. Van Oorschot and Boos (2001) conclude that ${ }^{16}$ 'The privatization of the first weeks of sickness benefit had an immediate and significant effect' (p.348).

Active labor market policies and employment protection legislation have been popular areas of reform predominantly from the late 1980s onwards, albeit with very limited verified success. For instance, De Koning et al. (2003) state with respect to ALMP reforms: 'There is little we know about the effectiveness of the measures. Evidently, evaluation is more complex when a large number of institutions are involved.' (p.32). The so called 'Melkert jobs' of the mid 1990s which provided subsidized jobs for long term unemployed that would otherwise have a very low chance of obtaining work have been among one of the more successful ALMP policies. Jansen (2001) finds that of those participants that have completed the program $73 \%$ eventually find regular paid employment. With regard to EPL the 1999 'Flexwet' (Flexibility and Security Law) is worth mentioning. This law attempts to introduce more flexibility in working contracts while giving more protection to workers on such contracts. The

\footnotetext{
${ }^{16}$ Based on data published by CTSV (a social security supervisory board).
} 
OECD Economic survey for the Netherlands (2000) refers to mixed experiences with the Flexwet amongst both employers and employees.

Another method of looking at the reforms of Table 2.3 is by classifying them according to reform type. This is elaborated in Table 2.4 where we classified the reforms into five types. ${ }^{17}$ Again, we also make the distinction between relevant reforms and total reforms. With respect to the types, level reforms change real money levels of income from benefits. An obvious example of a level reform would be a reduction in replacement rate. Responsibility refers to reforms that shift responsibilities from government to private sector or change responsibilities between employers and employees. ${ }^{18}$ An example is the 1996 WULBZ which states that employers became responsible for continuing wage payment the first few weeks an employee became ill. Access reforms change which specific groups of people are eligible for a certain benefit scheme. For example part of a 1983 unemployment reform was that 16 and 17 year olds would no longer have access to unemployment benefits. Duration reforms change the length of benefit entitlement and stimuli refers to reforms that provide financial or other incentives to employers and/or employees to seek out, create or accept work.

Most obvious from Table 2.4 is the concentration of level reforms in the early to mid 1980s. Among the ones we found to be relevant are the two-stage cuts in replacement rates from $80 \%$ to $70 \%$ in 1985/1986. Combined with a number of access and duration reforms, these level reforms aimed to reduce the costs of social security. Overall the table shows extensive reform activity in 1987 which was the already mentioned structural reform that affected all areas of social security. Although this was a system wide reform, we will not elaborate further on its specific details. In part because the expected effects of the reform were not observed in the immediate years thereafter (for example Aarts et al. (2002) and Bovenberg (2000)).

In the first half of the 1990s several reforms were implemented to reduce the volume of benefit claimants which include the abovementioned TAV, TBA and TZ/Arbo. These reforms combined stimuli (e.g. the bonus/malus aspect of the TAV) with access aspects (e.g. aforementioned reassessment of WAO claimants under TBA). The second half of the 1990s is characterized strongly by shifts in responsibilities, where for example the WULBZ signaled the first stage in privatizing the sickness insurance scheme by making employers responsible for the continued wage payments in the first few weeks of sickness of an employee. This privatization and corresponding shift in responsibility from government to market was continued in the new millennium with the full abandonment of the sickness insurance scheme, being replaced by a privatized

\footnotetext{
${ }^{17}$ Some reforms contain multiple types and are therefore counted in all these categories. This explains for example why in Table 2.3 in 1987 there is only one relevant reform but in Table 2.4 there are three. This particular unemployment reform thus consisted of a combination of three types.

${ }^{18}$ Responsibility reforms mostly entail reforms that change who bears a certain cost or which actor is the first to take a certain action. Responsibility reforms do not refer to reforms that only change the administrative nature or bureaucratic characteristics of policy.
} 
Table 2.4: Reform types and reform relevance.

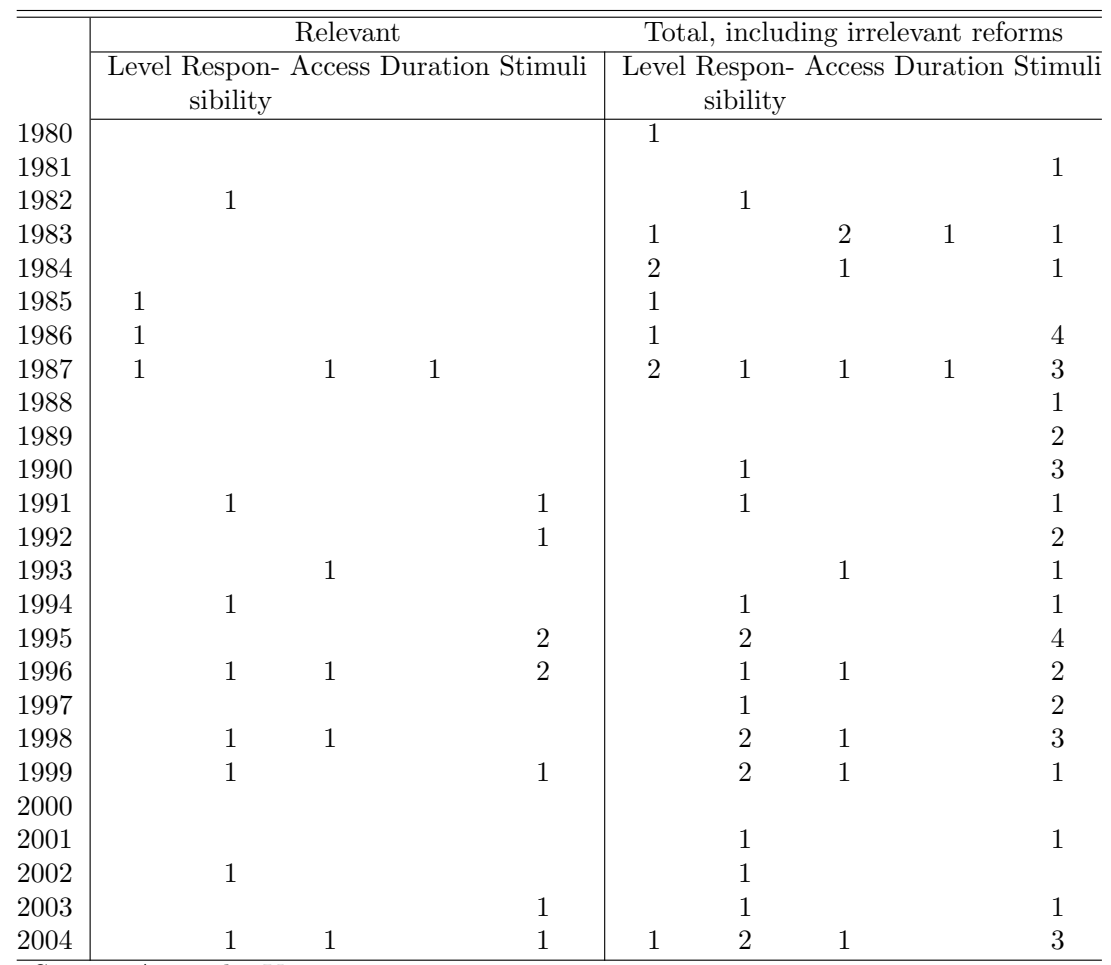

Source: Appendix V

version in which the employer is since 2004 responsible for paying up to the first 2 years of sickness. Also dominant in the late 1990s (but not a specific topic in this chapter) were the changes in the governing and administrative structure of the social security system, aimed at increasing the overall system efficiency. A final interesting observation from Table 2.4 is that pure duration reforms that change the length of benefit entitlements have sparsely been used.

Combining some of the insights from Figure 2.2 and Tables 2.3 and 2.4 leads to the observation that level reforms were used in the early 1980s to reduce the high costs associated with the large numbers of WW, WAO and ZW claimants. The late 1980 were relatively quiet in terms of reforms, likely a waiting period in anticipation of the first results of the extensive 1987 structural reform. Especially with regard to WAO and ZW these results did not show and as a consequence these became hot reform areas and the 1990s became riddled first with volume reforms targeted at WAO and ZW and after those with reforms shifting responsibilities through privatization and reorganization of administrative bodies. Unemployment has been under attention from policymakers continuously resulting in a number of reforms which we found to be relevant. In the 1990s when unemployment numbers were going down steadily and there were less 
specific targeted unemployment (WW) reforms, a shift in instrumentation to ALMP and EPL, and therewith from passive to active policies, can be observed. ALMP and EPL have tried to supplement the more specific targeted unemployment, disability and sickness reforms but their significance is difficult to establish. After reaching the lowest level of unemployment since decades in 2001, unemployment started to increase again. This led to a renewed attention to specific targeted unemployment reforms, with reforms implemented in 2001, 2003 and 2004.

An important conclusion from both Figure 2.2 and Tables 2.3 and 2.4 is that the overall amount of reforms that are relevant is substantially smaller than the overall total amount of reforms. This is illustrated in Table 2.5 below which depicts the ratios of relevant reforms to total reforms. EPL and ALMP seem to be policy areas in which

Table 2.5: Reform relevance ratios by area and type.

\begin{tabular}{lccccc}
\hline \hline & \multicolumn{5}{c}{ Reform relevance ratios by area } \\
& sickness & disability & almp & epl & unemployment \\
ratio & $5 / 6$ & $8 / 16$ & $2 / 26$ & $1 / 8$ & $8 / 14$ \\
$\%$ & $83 \%$ & $50 \%$ & $8 \%$ & $13 \%$ & $57 \%$
\end{tabular}

\section{Reform relevance ratios by type}

\begin{tabular}{lccccc} 
& level & responsibility & access & duration & stimuli \\
ratio & $3 / 9$ & $8 / 18$ & $5 / 9$ & $1 / 2$ & $9 / 38$ \\
$\%$ & $33 \%$ & $44 \%$ & $56 \%$ & $50 \%$ & $24 \%$ \\
\hline \hline
\end{tabular}

Source: Tables 2.3 and 2.4

most unfruitful reforms are conducted ${ }^{19}$ whereas the relatively few sickness reforms are considered to have been quite relevant. This result is confirmed by the low score for the stimuli type, of which a large number of ALMP reforms consist. Level reforms also score low. This is not unthinkable given that quite some reforms that attempt to change the benefit level of the social security system are countered by collective bargaining agreements. See for example Hartog (1999) who writes that: '. . legislated changes in the mandatory components are often countered by adjustments in collective bargaining (e.g. supplementing legal benefit entitlements)...' (p.472). Responsibility reforms do not score very low or very high. When a reform clearly assigns (financial) responsibilities to either government, individuals or employers, results shows that it can work. Good examples of this are the 1994 TZ, 1996 WULBZ and 2004 WVLZ reforms in sickness insurance, which each made employers increasingly financially responsible for employees that fall ill. These three reforms all turn out relevant in our content analysis. However, when it is not clear who bears certain responsibilities, actors tend to shift responsibilities to other actors. Research by TNS-NIPO (2003)

\footnotetext{
${ }^{19}$ Measurement problems in evaluation studies of EPL and ALMP reforms and the relative lack of evaluation studies might bias this outcome, although the difference is still striking.
} 
finds that when asked who is primarily responsible for the prevention of sickness and disability, employers think that employees are primarily responsible, while employees (whether healthy, sick or disabled) think that employers are primarily responsible). These conclusions about stimuli, responsibility and level reforms are supportive to the notion that only reform policies restricting access and duration seem to really make a difference, together with responsibility reforms that clearly assign responsibilities to specific actors. Reforms that reduce access to unemployment, sickness or disability benefits or cut the duration of entitlements are not easily circumvented as the rules simply state who is entitled to benefits and for how long.

\subsection{Econometric evidence}

In this section we want to test whether the reforms we found to be relevant based on our content analysis and ranking scheme also turn out to be significant in econometric analysis. To that end we estimate the effect of reforms in the areas of unemployment, sickness and disability. ${ }^{20}$ In section 2.2 we identified the policy reforms that were relevant and which will be the dummy variables in our regression analysis. In order to avoid spurious regressions we use a two-stage error correction model (Engle and Granger, 2001). ${ }^{21}$ Appendix III provides an overview of the dependent and control variables we used and Appendix IV presents an overview of our reform dummies over time. The first stage consists of the estimation of a long run equation using macroeconomic data on the relevant reform areas and a number of covariates and reform dummies that are relevant in long run analysis. There we estimate:

$$
\gamma_{t}=\alpha+\beta c_{t}+\delta d_{t}+\epsilon_{t}
$$

where $\gamma_{t}$ stands for either the unemployment rate, the sickness absence rate, or the disability rate (all of them as a percentage of labor input (in person years)), $c_{t}$ is a vector of covariates and $\beta$ the corresponding vector of coefficients, and $d_{t}$ is a vector of individual policy dummies with the corresponding coefficients in vector $\delta$. The second stage of the error correction model identifies the sensitivity of the variables to the business cycle ${ }^{22}$ and determines the adjustment speed to the long run. Thus we estimate in the second stage:

$$
\Delta \gamma_{t}=\alpha+\beta \Delta c_{t}+\delta \Delta d_{t}+\psi \Delta \hat{\epsilon}_{t-1}+\mu_{t}
$$

\footnotetext{
${ }^{20}$ The areas EPL and ALMP are left out because of data limitations. Moreover, the majority of EPL and ALMP reforms were found to be irrelevant in our ranking.

${ }^{21}$ Using a similar procedure Stegeman (2005) shows that there is a positive relation between economic upswings and sickness leave in the Netherlands in the period 1980-2003.

${ }^{22}$ See Appendix III for information on the business cycle variable
} 
where $\hat{\epsilon}$ represents the estimated error of the long run equation. ${ }^{23}$

Using dummy variables it is difficult to measure the effect of reforms that where implemented in subsequent years, as it is hard to distinguish between the impacts of dummies that are close to each other in time. Thus in order to reduce the density of dummies in the sample some dummies represent multiple reforms. For example the 'Exemption 57+' dummy is also measuring the effects of the Wassenaar agreement. ${ }^{24}$ This implies that for these 'multiple reform dummies' we can not attribute the coefficient to one specific reform. Furthermore as Appendix IV shows, in the long run all dummies will have value ' 1 ' at some point. This complicates the interpretation of the long run estimations as many dummies are active. Therefore, we are most interested in the effects of the short run estimations.

In Table 2.6 we analyze the effect of reforms on unemployment including welfare which is defined as the number of unemployment benefit claimants (UB, Dutch: WW) plus the number of welfare claimants (Dutch: WWB) as percentage of labor input. Welfare claimants are often those who have exhausted their rights at regular UB and as such represent the hardest to reintegrate unemployed. The regression results are not always what we logically expected. The Wassenaar, nABW and benefit duration dummies unexpectedly have positive signs a a number of estimations and although the latter two are insignificant, the Wassenaar dummy is significant. An explanation could lie in the fact that the total unemployment kept rising for the first few years after the Wassenaar agreement and only slowly started to decline after having peaked in 1985 . So by the time total unemployment was actually declining, our model already includes the next dummy, which is the 1987 structural reform that is significant and with the expected sign in estimation 1.4, which also corrects for the business cycle. Including the business cycle reduces the significance of the other control variables which are the female participation rate and the ratio of part-time workers. ${ }^{25}$ Most importantly the business cycle is negatively related (counter-cyclical) to total unemployment in both the long (1st stage) and short run (2nd stage) estimations. The Flexwet and PES reform are significant in at least the short run estimations and this holds across a wide range of model specifications, making the results for these reforms quite robust. Estimating these equations with only the welfare ratio as dependent variable does not lead to much different outcomes. As the number of welfare claimants is much higher than the number of UB claimants in almost every year this indicates that the welfare ratio dominates the outcomes of these regressions.

\footnotetext{
${ }^{23}$ Thus the first stage looks at 'levels' $\left(\gamma_{t}, \beta c_{t}\right.$, etc) while the second stage looks at 'changes' $\left(\Delta \gamma_{t}, \beta \Delta c_{t}\right.$, etc $)$

${ }^{24}$ Likewise, the '1998 package' in the disability estimations in Table 2.9 corresponds to the introduction of both PEMBA and REA; the '2004 package' represents the introduction of the WSW, the reform of the WAO and the introduction of the WIA.

${ }^{25}$ Note that the indicator we use differs from the business cycle indicator Stegeman used. The CPB business cycle indicator has been revised in 2003 and the new indicator has been in effect since MEV 2004, which is after Stegeman's paper.
} 
Table 2.6: The relation between institutional reforms and unemployment - 1980 to 2008.

\begin{tabular}{|c|c|c|c|c|}
\hline \multirow{2}{*}{$\begin{array}{l}\text { Dependent variable } \\
\text { Number of obs }\end{array}$} & \multicolumn{4}{|c|}{ Total unemployment } \\
\hline & 29 & 28 & 29 & 28 \\
\hline & 0.87 & 0.60 & 0.91 & 0.75 \\
\hline & 1st stage & 2nd stage & 1st stage & 2nd stage \\
\hline \multirow{2}{*}{ Exemption $57+$ and Wassenaar } & 0.043 & $0.021 *$ & $0.057 * *$ & $0.032 * * *$ \\
\hline & $(0.029)$ & $(0.011)$ & $(0.023)$ & $(0.009)$ \\
\hline \multirow[t]{2}{*}{1987 Structural reform } & -0.001 & -0.004 & -0.009 & $-0.017 * * *$ \\
\hline & $(0.014)$ & $(0.007)$ & $(0.008)$ & $(0.005)$ \\
\hline \multirow[t]{2}{*}{ PES reform } & -0.002 & $-0.016 * * *$ & -0.013 & $-0.013 * * *$ \\
\hline & $(0.015)$ & $(0.005)$ & $(0.011)$ & $(0.004)$ \\
\hline \multirow[t]{2}{*}{ nABW } & 0.003 & 0.005 & -0.007 & -0.001 \\
\hline & $(0.012)$ & $(0.004)$ & $(0.010)$ & $(0.003)$ \\
\hline \multirow[t]{2}{*}{ Red. of benefit duration } & -0.006 & 0.003 & -0.007 & 0.004 \\
\hline & $(0.014)$ & $(0.005)$ & $(0.015)$ & $(0.005)$ \\
\hline \multirow[t]{2}{*}{ Flexwet } & $-0.040 * * *$ & $-0.024 * * *$ & $-0.038 * * *$ & $-0.020 * * *$ \\
\hline & $(0.012)$ & $(0.005)$ & $(0.012)$ & $(0.004)$ \\
\hline \multirow[t]{2}{*}{ Unempl. replacement rate } & 0.004 & 0.004 & 0.004 & 0.002 \\
\hline & $(0.005)$ & $(0.003)$ & $(0.004)$ & $(0.002)$ \\
\hline \multirow[t]{2}{*}{ Participation rate women } & $-0.007 * *$ & -0.003 & -0.001 & 0.002 \\
\hline & $(0.003)$ & $(0.004)$ & $(0.002)$ & $(0.002)$ \\
\hline \multirow[t]{2}{*}{ PA Ratio } & $0.020 * *$ & $0.017 * * *$ & 0.007 & $0.008 *$ \\
\hline & $(0.007)$ & $(0.005)$ & $(0.006)$ & $(0.004)$ \\
\hline \multirow[t]{2}{*}{ CPB business cycle indicator } & & & $-0.011 * * *$ & $-0.010 * *$ \\
\hline & & & $(0.002)$ & $(0.003)$ \\
\hline \multirow[t]{2}{*}{ Residual } & & $-0.583 * *$ & & $-0.532 *$ \\
\hline & & $(0.203)$ & & $(0.252)$ \\
\hline Constant & $-2.333 * *$ & -0.001 & -1.051 & -0.005 \\
\hline Estimation number & 1.1 & 1.2 & 1.3 & 1.4 \\
\hline
\end{tabular}

Table 2.7 shows the results of the same type of regressions using only UB claimants. UB eligibility was at most 5 years until 2006 and has been reduced to 38 months afterwards, a reform captured by the reduction of benefit duration dummy which is insignificant in all estimations. The Flexwet is again significant in all estimations and the unemployment replacement rate is now also significant, both with expected signs. The problem of the positive and significant dummy for the Wassenaar agreement has been solved as we only look at the ratio of UB claimants here, which starts to decline two years earlier than if the social assistance ration was included as in Table 2.6. Hence there is less 'interference' with the next dummy of the 1987 structural reform which now has its own significant impact in estimations 2.3 and 2.4. The business cycle again has the expected negative coefficient. 
Table 2.7: The relation between institutional reforms and UB claimants - 1980 to 2008.

\begin{tabular}{|c|c|c|c|c|}
\hline \multirow{4}{*}{$\begin{array}{l}\text { Dependent variable } \\
\text { Number of obs } \\
\text { R-squared }\end{array}$} & \multicolumn{4}{|c|}{ Unemployment } \\
\hline & 29 & 28 & 29 & 28 \\
\hline & 0.76 & 0.68 & 0.89 & 0.85 \\
\hline & 1st stage & 2nd stage & 1st stage & 2nd stage \\
\hline Exemption $57+$ and Wassenaar & $\begin{array}{c}-0.004 \\
(0.012)\end{array}$ & $\begin{array}{c}-0.012 * * \\
(0.005)\end{array}$ & $\begin{array}{c}0.006 \\
(0.008)\end{array}$ & $\begin{array}{c}-0.003 \\
(0.003)\end{array}$ \\
\hline 1987 Structural reform & $\begin{array}{c}-0.004 \\
(0.008)\end{array}$ & $\begin{array}{c}-0.001 \\
(0.004)\end{array}$ & $\begin{array}{c}-0.009 * * \\
(0.004)\end{array}$ & $\begin{array}{c}-0.010 * * * \\
(0.003)\end{array}$ \\
\hline PES reform & $\begin{array}{c}0.014 \\
(0.011)\end{array}$ & $\begin{array}{c}-0.001 \\
(0.003)\end{array}$ & $\begin{array}{c}0.006 \\
(0.006)\end{array}$ & $\begin{array}{c}0.001 \\
(0.002)\end{array}$ \\
\hline nABW & $\begin{array}{c}0.011 \\
(0.007)\end{array}$ & $\begin{array}{l}0.010 * * * \\
(0.002)\end{array}$ & $\begin{array}{c}0.003 \\
(0.005)\end{array}$ & $\begin{array}{l}0.005 * * * \\
(0.001)\end{array}$ \\
\hline Red. of benefit duration & $\begin{array}{c}-0.001 \\
(0.008)\end{array}$ & $\begin{array}{c}0.004 \\
(0.003)\end{array}$ & $\begin{array}{c}-0.001 \\
(0.008)\end{array}$ & $\begin{array}{c}0.003 \\
(0.004)\end{array}$ \\
\hline Flexwet & $\begin{array}{c}-0.020 * * * \\
(0.007)\end{array}$ & $\begin{array}{c}-0.012 * * * \\
(0.003)\end{array}$ & $\begin{array}{c}-0.018 * * * \\
(0.006)\end{array}$ & $\begin{array}{c}-0.009 * * * \\
(0.002)\end{array}$ \\
\hline Unempl. replacement rate & $\begin{array}{c}0.005 * \\
(0.002)\end{array}$ & $\begin{array}{l}0.004 * * * \\
(0.001)\end{array}$ & $\begin{array}{l}0.005 * * * \\
(0.001) \\
\end{array}$ & $\begin{array}{l}0.003 * * * \\
(0.001)\end{array}$ \\
\hline Participation rate women & $\begin{array}{c}-0.003 \\
(0.002)\end{array}$ & $\begin{array}{c}-0.003 \\
(0.002)\end{array}$ & $\begin{array}{c}0.001 \\
(0.001)\end{array}$ & $\begin{array}{c}0.001 \\
(0.001)\end{array}$ \\
\hline PA Ratio & $\begin{array}{l}0.013 * * * \\
(0.003)\end{array}$ & $\begin{array}{l}0.011 * * * \\
(0.003)\end{array}$ & $\begin{array}{c}0.004 \\
(0.002)\end{array}$ & $\begin{array}{l}0.005 * * * \\
(0.002)\end{array}$ \\
\hline CPB business cycle indicator & & & $\begin{array}{c}-0.008 * * * \\
(0.001)\end{array}$ & $\begin{array}{c}-0.007 * * * \\
(0.002)\end{array}$ \\
\hline Residual & & $\begin{array}{c}-0.622 * * * \\
(0.161)\end{array}$ & & $\begin{array}{c}-0.636 * * \\
(0.292)\end{array}$ \\
\hline Constant & $-1.772 * * *$ & 0.002 & -0.846 & -0.001 \\
\hline Estimation number & 2.1 & 2.2 & 2.3 & 2.4 \\
\hline
\end{tabular}

In Table 2.8 we present our estimation results for the sickness absence rate. Comparing the results from these estimations with our qualitative results for sickness in the third section of this chapter, we find proof for the importance we found earlier for TZ/Arbo, Wulbz and the extension of sickness payments. These dummies are all significant except for the Wulbz in estimation 3.1. Introducing the business cycle in estimations 3.3 and 3.4 does not reduce the significance of the reforms dummies whilst at the same time the explanatory power $\left(R^{2}\right)$ of the short term model rises substantially. The business cycle is weakly significant in the long run estimation and highly significant in the short run estimation. Its positive coefficient points to a procyclical relation to the sickness ratio which is in line with Stegeman (2005).

Table 2.9 presents the estimation results for the disability rate. In the first stage estimation (4.1) all variables with the exception of the TBA/TAV reform package 
Table 2.8: The relation between institutional reforms and sickness benefit claimants 1980 to 2008 .

\begin{tabular}{|c|c|c|c|c|}
\hline \multirow{4}{*}{$\begin{array}{l}\text { Dependent variable } \\
\text { Number of obs } \\
\text { R-squared }\end{array}$} & \multicolumn{4}{|c|}{ Sickness } \\
\hline & 29 & 28 & 29 & 28 \\
\hline & 0.75 & 0.69 & 0.80 & 0.75 \\
\hline & 1st stage & 2nd stage & 1st stage & 2nd stage \\
\hline Wulbz & $\begin{array}{c}-0.003 \\
(0.002)\end{array}$ & $\begin{array}{c}-0.008 * * * \\
(0.001)\end{array}$ & $\begin{array}{c}-0.004 * \\
(0.002)\end{array}$ & $\begin{array}{c}-0.008 * * * \\
(0.001)\end{array}$ \\
\hline $\mathrm{TZ} /$ Arbo & $\begin{array}{c}-0.011 * * * \\
(0.002)\end{array}$ & $\begin{array}{l}-0.012 * * * \\
(0.001)\end{array}$ & $\begin{array}{c}-0.009 * * * \\
(0.001)\end{array}$ & $\begin{array}{c}-0.010 * * * \\
(0.001)\end{array}$ \\
\hline WVP & $\begin{array}{c}-0.002 \\
(0.004)\end{array}$ & $\begin{array}{c}0.001 \\
(0.003)\end{array}$ & $\begin{array}{c}0.000 \\
(0.003)\end{array}$ & $\begin{array}{c}0.003 \\
(0.003)\end{array}$ \\
\hline WVLZ Extension sickness payments & $\begin{array}{c}-0.008 * * \\
(0.003)\end{array}$ & $\begin{array}{c}-0.008 * * * \\
(0.001)\end{array}$ & $\begin{array}{c}-0.009 * * \\
(0.003)\end{array}$ & $\begin{array}{c}-0.008 * * * \\
(0.001)\end{array}$ \\
\hline sickness replacement rate & $\begin{array}{c}0.043 \\
(0.026)\end{array}$ & $\begin{array}{c}0.035 \\
(0.025)\end{array}$ & $\begin{array}{c}0.038 * \\
(0.020)\end{array}$ & $\begin{array}{c}0.053 * \\
(0.029)\end{array}$ \\
\hline Participation rate women & $\begin{array}{l}0.002 * * * \\
(0.000)\end{array}$ & $\begin{array}{c}0.001 * \\
(0.001)\end{array}$ & $\begin{array}{l}0.001 * * * \\
(0.000)\end{array}$ & $\begin{array}{c}0.001 \\
(0.001)\end{array}$ \\
\hline PT Ratio & $\begin{array}{c}-0.003 * * * \\
(0.001)\end{array}$ & $\begin{array}{c}-0.002 * \\
(0.001)\end{array}$ & $\begin{array}{c}-0.002 * * \\
(0.001)\end{array}$ & $\begin{array}{c}-0.001 \\
(0.001)\end{array}$ \\
\hline CPB business cycle indicator & & & $\begin{array}{c}0.002 * \\
(0.001)\end{array}$ & $\begin{array}{l}0.002 * * * \\
(0.001)\end{array}$ \\
\hline Residual & & $\begin{array}{c}-0.849 * * \\
(0.290)\end{array}$ & & $\begin{array}{c}-0.862 * * * \\
(0.297)\end{array}$ \\
\hline Constant & $0.273 * * *$ & 0.000 & $0.172 * *$ & 0.001 \\
\hline Estimation number & 3.1 & 3.2 & 3.3 & 3.4 \\
\hline
\end{tabular}

and the 1998 package turn out to be significant and with the expected sign. As the introduction of the TBA coincided with a break in the sickness data series (Stegeman, 2005) this might play a role here. In the short run estimation (4.2) only the Amber reform is still significant as well as the control variables. Our explanation for this is that reforms in disability insurance and legislation typically have a long outside lag. This means that after a reform has been decided upon, it takes much time before the actual number of claimants goes down. This is due to the time-consuming process of re-evaluating every person's rights to disability benefits with respect the new reform's rules. A similar effect can be seen from estimations 4.3 and 4.4 in which the business cycle is included. Although the reform dummies hardly lose in significance from the long run (4.3) to the short run (4.4), their coefficient sizes are all reduced, pointing to the lower impact these reforms have in the short run, compared to the long run. In these final two estimations the TBA/TAV reforms dummy turns out to be significant and with the expected sign. 
Table 2.9: The relation between institutional reforms and disability benefit claimants - 1980 to 2008 .

\begin{tabular}{|c|c|c|c|c|}
\hline \multirow{4}{*}{$\begin{array}{l}\text { Dependent variable } \\
\text { Number of obs } \\
\text { R-squared }\end{array}$} & \multicolumn{4}{|c|}{ Disability } \\
\hline & 29 & 28 & 28 & 28 \\
\hline & 0.91 & 0.59 & 0.95 & 0.73 \\
\hline & 1st stage & 2nd stage & 1st stage & 2nd stage \\
\hline TBA/TAV & $\begin{array}{c}-0.004 \\
(0.003)\end{array}$ & $\begin{array}{c}-0.003 \\
(0.005)\end{array}$ & $\begin{array}{c}-0.014 * * * \\
(0.003)\end{array}$ & $\begin{array}{c}-0.012 * * * \\
(0.002)\end{array}$ \\
\hline Amber & $\begin{array}{c}-0.020 * * * \\
(0.003)\end{array}$ & $\begin{array}{c}-0.013 * * * \\
(0.002)\end{array}$ & $\begin{array}{c}-0.018 * * * \\
(0.002)\end{array}$ & $\begin{array}{c}-0.012 * * * \\
(0.001)\end{array}$ \\
\hline 1998 package & $\begin{array}{c}0.004 \\
(0.003)\end{array}$ & $\begin{array}{c}0.001 \\
(0.002)\end{array}$ & $\begin{array}{c}0.005 * \\
(0.002)\end{array}$ & $\begin{array}{c}0.001 \\
(0.002)\end{array}$ \\
\hline WVP & $\begin{array}{c}-0.011 * * * \\
(0.003)\end{array}$ & $\begin{array}{r}-0.004 \\
(0.002)\end{array}$ & $\begin{array}{c}-0.015 * * * \\
(0.002)\end{array}$ & $\begin{array}{c}-0.010 * * * \\
(0.002)\end{array}$ \\
\hline 2004 package & $\begin{array}{c}-0.009 * * \\
(0.003)\end{array}$ & $\begin{array}{c}-0.000 \\
(0.001)\end{array}$ & $\begin{array}{c}-0.009 * * * \\
(0.002)\end{array}$ & $\begin{array}{c}-0.003 * * * \\
(0.001)\end{array}$ \\
\hline Participation rate women & $\begin{array}{c}-0.003 * * * \\
(0.001)\end{array}$ & $\begin{array}{c}-0.002 * * * \\
(0.001)\end{array}$ & $\begin{array}{r}-0.001 * \\
(0.000)\end{array}$ & $\begin{array}{c}-0.001 * * \\
(0.001)\end{array}$ \\
\hline $\mathrm{PT}$ ratio & $\begin{array}{l}0.009 * * * \\
(0.002)\end{array}$ & $\begin{array}{c}0.004 * * \\
(0.001)\end{array}$ & $\begin{array}{l}0.005 * * * \\
(0.001)\end{array}$ & $\begin{array}{c}0.003 * * \\
(0.001)\end{array}$ \\
\hline CPB business cycle indicator & & & $\begin{array}{c}-0.004 * * * \\
(0.001)\end{array}$ & $\begin{array}{c}-0.004 * * * \\
(0.001)\end{array}$ \\
\hline Residual & & $\begin{array}{c}-0.505 * * \\
(0.203)\end{array}$ & & $\begin{array}{c}-0.686 * * * \\
(0.149)\end{array}$ \\
\hline Constant & $-0.786 * * *$ & 0.001 & $-0.468 * * *$ & 0.001 \\
\hline Estimation number & 4.1 & 4.2 & 4.3 & 4.4 \\
\hline
\end{tabular}

The results of the econometric analysis in this section confirm that many reforms that were determined to be relevant in Section 2.2.1 indeed have a significant impact on reducing the relevant number of claimants. At least for sickness and disability the results are close to our expectations. However, the results on unemployment and welfare benefits are much less pronounced. Not all relevant unemployment reforms that were summarized in Table 2.2 turned out significant and some unexpectedly had the wrong sign. This shows that whilst this two stage error correction method may have worked fine for Stegeman (2005) on sickness and also for our own sickness and disability analyses, it is somewhat sensitive when applied to a related variable such as unemployment. Nevertheless, this section provides empirical evidence for the role of the business cycle in long run levels of unemployment, sickness and disability as well as short run adjustments in these. A factor we did not take into account is the possibility of spill-over effects and interactions between unemployment, sickness and disability and their respective reforms. Although the pro-cyclical nature of sickness paired with the counter-cyclical nature of unemployment hints at the existence of these spill-overs. 


\subsection{Conclusions}

In this chapter we analyzed 25 years of Dutch reform history in the areas of unemployment, disability, sickness, employment protection legislation and active labor market policy. We conducted a literature study to show why some reforms are relevant and others are not. Using the method of content analysis we find that not all reforms are relevant to the same extent. Most notably the reforms in sickness seem to have been relatively successful, compared to the reforms in other areas which were often less relevant. Out of the five relevant reforms in sickness, three (the 1994 TZ, 1996 WULBZ and 2004 WVLZ) made employers more financially responsible for the benefits paid to employees that fall ill and these three have shown to be effective in our econometric analysis. Hence, responsibility reforms can be effective as long as they clearly assign (financial) responsibilities.

Furthermore, we find that reforms that employ access or duration restrictions are most effective. An example includes the TBA/TAV which, based on reassessment of disabled persons, declared disabled persons (partially) fit for work again, restricting their access to disability benefits. Such reforms simply change the rules of entitlement and as such are difficult to circumvent. Conversely, reform types that attempt to reduce social security dependency through use of stimuli and level changes perform worse. Especially reforms that change benefit levels are often circumvented by collective bargaining agreements, rendering the reform irrelevant.

In addition, the analysis of Figure 2.2 shows that the political business cycle also left a distinct mark on the reform history, generally showing higher reform activity in the first two years of new governments and lower reform activity in the years leading up to elections. Lastly, we confirm the counter-cyclical relation between the business cycle and unemployment and disability and the pro-cyclical relation between the business cycle and sickness. 


\section{Appendix I: Overview of our sources}

\begin{tabular}{|c|c|c|c|c|c|}
\hline & Kroniek & Brandt et al & FRDB & LABREF & OECD surveys \\
\hline $\begin{array}{l}\text { 1. Year of pub- } \\
\text { lication /last up- } \\
\text { date }\end{array}$ & 2008 & 2005 & $\begin{array}{l}2006, \text { thereafter } \\
\text { continued as } \\
\text { FRDB-IZA } \\
\text { database }\end{array}$ & $\begin{array}{l}\text { Continuous } \\
\text { updates }\end{array}$ & $\begin{array}{l}\text { Continuous } \\
\text { (yearly) } \\
\text { updates }\end{array}$ \\
\hline $\begin{array}{l}\text { 2. Time period } \\
\text { that it covers }\end{array}$ & $\begin{array}{l}\text { From the intro- } \\
\text { duction of social } \\
\text { welfare to } 2007\end{array}$ & 1984 to 2003 & 2000 to 2006 & 2000 to 2007 & 1979 to 2010 \\
\hline $\begin{array}{l}\text { 3. Authors or } \\
\text { publishing insti- } \\
\text { tute }\end{array}$ & $\begin{array}{l}\text { UWV The } \\
\text { executive organ } \\
\text { that supervises } \\
\text { and runs the } \\
\text { social insurances }\end{array}$ & $\begin{array}{l}\text { OECD officials; } \\
\text { summarizing } \\
\text { the information } \\
\text { provided by the } \\
\text { country surveys }\end{array}$ & $\begin{array}{l}\text { The Fondazione } \\
\text { Rodolfo } \\
\text { DeBenedetti } \\
\text { a widely } \\
\text { renown Italian } \\
\text { foundation }\end{array}$ & $\begin{array}{l}\text { The European } \\
\text { Commissions } \\
\text { department } \\
\text { of Economic } \\
\text { and Financial } \\
\text { Affairs }\end{array}$ & The OECD \\
\hline $\begin{array}{l}\text { 4. Main purpose } \\
\text { of document }\end{array}$ & $\begin{array}{l}\text { Discuss the } \\
\text { history of the } \\
\text { organization, } \\
\text { which } \\
\text { administrates the } \\
\text { social security } \\
\text { system }\end{array}$ & $\begin{array}{l}\text { Academic arti- } \\
\text { cle on reforms } \\
\text { in OECD coun- } \\
\text { tries }\end{array}$ & $\begin{array}{l}\text { Labor market } \\
\text { reforms } \\
\text { database (thus, } \\
\text { collection) }\end{array}$ & $\begin{array}{l}\text { Labor market } \\
\text { reforms } \\
\text { database } \\
\text { (thus, } \\
\text { collection) }\end{array}$ & $\begin{array}{l}\text { Following up } \\
\text { on what is } \\
\text { happening in } \\
\text { the country }\end{array}$ \\
\hline $\begin{array}{l}5 . \quad \text { Types of } \\
\text { reforms } \quad \text { covered } \\
(\text { EPL, ALMP, } \\
\text { UB, SICK, WAO) }\end{array}$ & UB, SICK, WAO & $\begin{array}{l}\text { EPL, ALMP, } \\
\text { UB }\end{array}$ & $\begin{array}{l}\text { EPL, ALMP, } \\
\text { UB }\end{array}$ & $\begin{array}{l}\text { EPL, ALMP, } \\
\text { UB }\end{array}$ & $\begin{array}{ll}\text { EPL, } & \text { ALMP, } \\
\text { UB, } & \text { SICK, } \\
\text { WAO } & \end{array}$ \\
\hline $\begin{array}{l}\text { 6. Used method } \\
\text { of collecting re- } \\
\text { forms }\end{array}$ & $\begin{array}{l}\text { Side product of } \\
\text { recollecting the } \\
\text { institutions } \\
\text { historical } \\
\text { development }\end{array}$ & $\begin{array}{l}\text { Not following } \\
\text { up }\end{array}$ & Unknown & See footnote $*$ & $\begin{array}{l}\text { Following } \\
\text { up what is } \\
\text { happening in } \\
\text { the country }\end{array}$ \\
\hline $\begin{array}{l}\text { 7. Used method } \\
\text { of ranking/rating } \\
\text { reforms (if any) }\end{array}$ & $\begin{array}{l}\text { Argue that some } \\
\text { reforms may be } \\
\text { more important } \\
\text { than others }\end{array}$ & $\begin{array}{l}\text { Pre-selection of } \\
\text { the reforms pre- } \\
\text { sented in the } \\
\text { country studies }\end{array}$ & $\begin{array}{l}\text { Distinguishing } \\
\text { structural } \\
\text { and marginal } \\
\text { reforms }\end{array}$ & none & $\begin{array}{l}\text { Argue that } \\
\text { some reforms } \\
\text { may be more } \\
\text { important than } \\
\text { others }\end{array}$ \\
\hline $\begin{array}{l}\text { 8. Language in } \\
\text { which it is pub- } \\
\text { lished }\end{array}$ & Dutch & English & English & English & English \\
\hline
\end{tabular}

* The construction process of the LABREF database is outlined in a special Guide (European Commission (2005): 'Sources used to compile the LABREF database include the International Labor Organization (ILO) 'Conditions of work and Employment' database, the comparative information on Member States' developments published by the European Industrial Relations Observatory (EIRO) of the European Foundation for the Improvement of Living and Working Conditions, the country reports by the Organization for the Economic Cooperation and Development (OECD) and International Monetary Fund (IMF), the National Action Plans for employment annually set-up in the framework of the European Employment Strategy, national legislation and other information publicly available on the websites of the Ministries for Employment and Social Affairs of the EU-25.' 


\section{Appendix II: The ranking scheme table}

\begin{tabular}{|c|c|c|}
\cline { 2 - 3 } \multicolumn{1}{c|}{} & \multicolumn{2}{|c|}{ Mentioned } \\
\cline { 2 - 3 } Sources & yes & no \\
\hline Brandt et al (2005) & 0 & -1 \\
\hline FRDB (2000-2006) & 0 & -1 \\
\hline LABREF (1994-2004) & 0 & -1 \\
\hline FRDB calls the reform structural (1987-2005) & +1 & 0 \\
\hline OECD country surveys (1979-2007) & +1 & 0 \\
\hline General literature review & +1 & 0 \\
\hline Evidence of effect & -2 to +2 \\
\hline Theoretical consideration & +1 \\
\hline
\end{tabular}




\section{Appendix III: Our dependent variables and the business cycle}

This Appendix presents the dependent variables we use on unemployment, sickness and disability, as well one of our independent variables, the business cycle. Our dependent variables are all expressed as rates, constructed as the number of benefit recipients as percentage of labor input, where labor input is in person years and is a measure for the labor force. The data come mainly from the Netherlands Bureau for Economic Policy Analysis (CPB (2010)).

\section{Unemployment}

There are many definitions of unemployment, each with their own data. Figure 2.3 shows that the various definitions develop very similar over time and move opposite to the business cycle. For the analyses in this chapter we used the number of unemployment benefit recipients as percentage of labor input.

Figure 2.3: Unemployment in the Netherlands

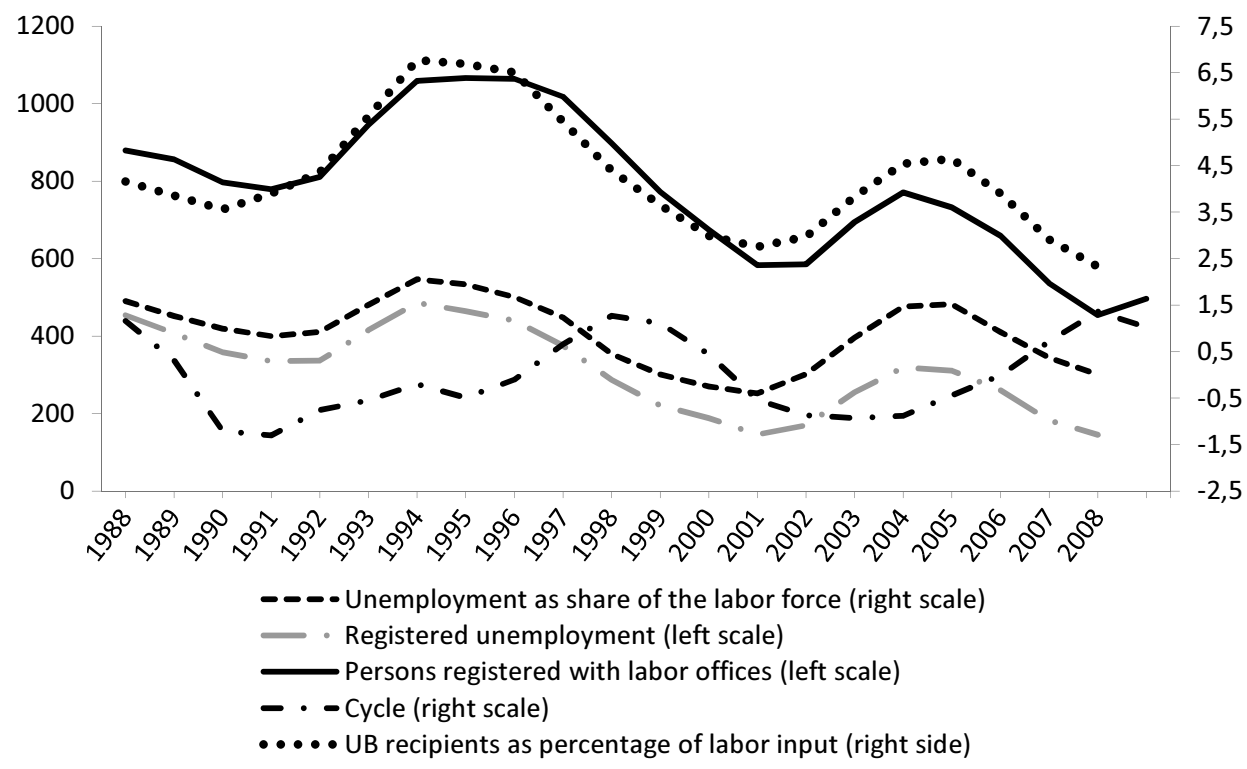

Source: Statistics Netherlands (CBS) and CPB 


\section{Sickness}

Figure 2.4 presents the development of the sickness rate. Sickness seems related to the business cycle.

Figure 2.4: The sickness rate and the business cycle

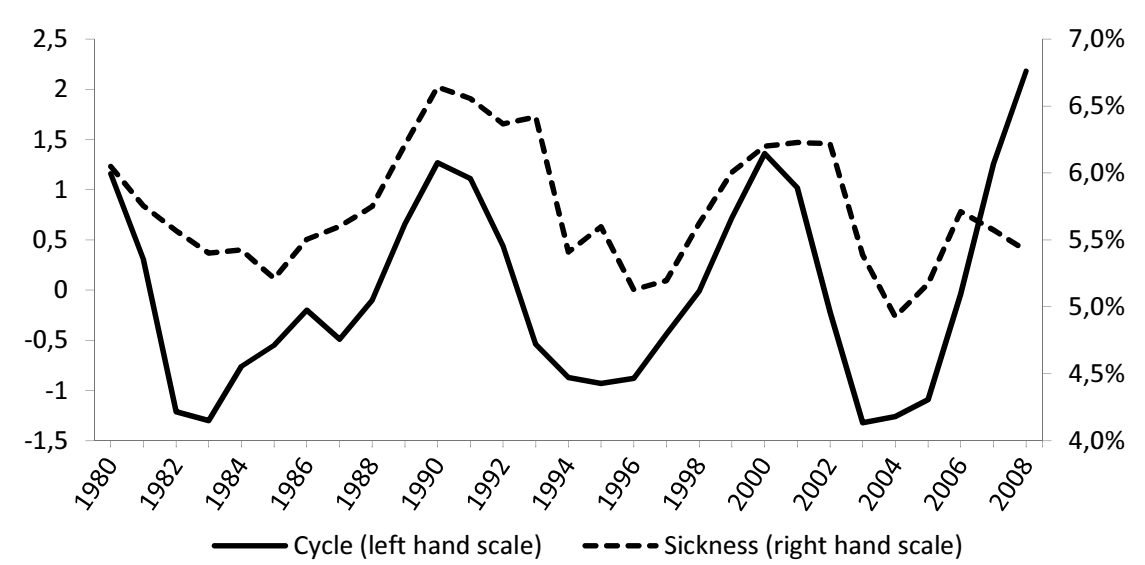

Source: CPB

\section{Disability}

Figure 2.5 shows that the disability rate, after peaking in the early eighties, declined gradually from $15 \%$ in 1985 to $11 \%$ in 2007 .

Figure 2.5: The disability rate and the business cycle

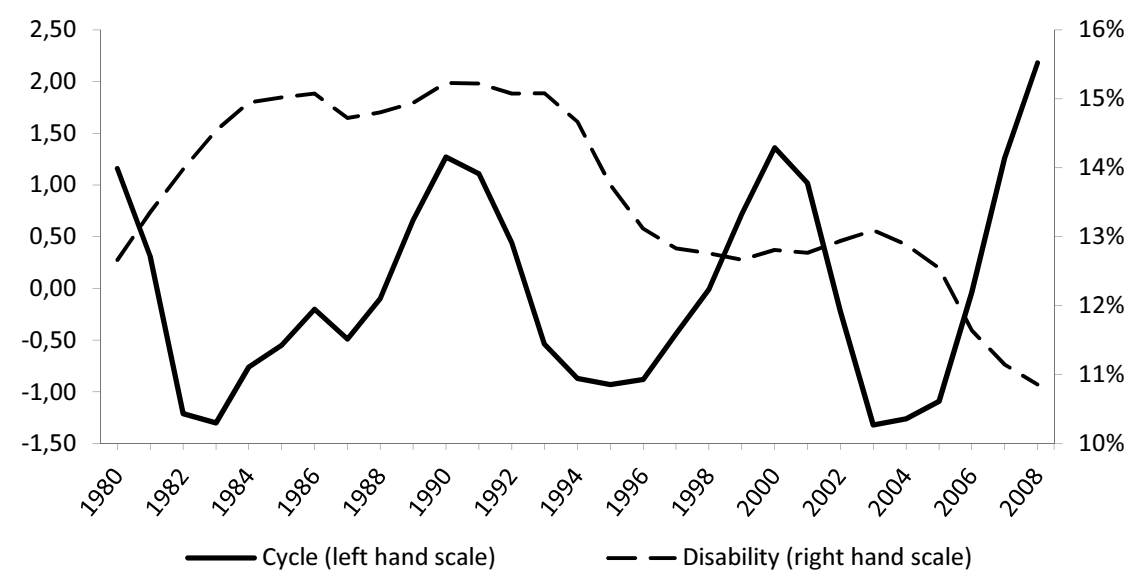

Source: CPB 


\section{CPB Business cycle indicator}

In 2004, the CPB collaborated with the German IFO institute to generate a business cycle indicator using IFO data. The CPB business cycle indicator is composed of 25 separate composite data series, none of which is related to unemployment. This special feature of the data series allows using it in regressions of unemployment. According to the authors, the indicator "performs quite well in describing the economic cycle of the GDP, in indicating the upturns and downturns, and in telling the story behind the business cycle.' (Kranendonk et al. (2004)) 


\section{Appendix IV: Our reform dummies over time}

\begin{tabular}{l|llllllllllll|llll}
\hline & \multicolumn{10}{c}{ Sickness } \\
\hline year & ex57 & struct.87pes & nabw dura & flex & wulbz & tz & wvp & extension & tba/tav & amber ref1998 & wvp & ref2004 \\
\hline \hline 1980 & 0 & 0 & 0 & 0 & 0 & 0 & 0 & 0 & 0 & 0 & 0 & 0 & 0 & 0 & 0 \\
1981 & 0 & 0 & 0 & 0 & 0 & 0 & 0 & 0 & 0 & 0 & 0 & 0 & 0 & 0 & 0 \\
1982 & 0 & 0 & 0 & 0 & 0 & 0 & 0 & 0 & 0 & 0 & 0 & 0 & 0 & 0 & 0 \\
1983 & 0 & 0 & 0 & 0 & 0 & 0 & 0 & 0 & 0 & 0 & 0 & 0 & 0 & 0 & 0 \\
1984 & 1 & 0 & 0 & 0 & 0 & 0 & 0 & 0 & 0 & 0 & 0 & 0 & 0 & 0 & 0 \\
1985 & 1 & 0 & 0 & 0 & 0 & 0 & 0 & 0 & 0 & 0 & 0 & 0 & 0 & 0 & 0 \\
1986 & 1 & 0 & 0 & 0 & 0 & 0 & 0 & 0 & 0 & 0 & 0 & 0 & 0 & 0 & 0 \\
1987 & 1 & 1 & 0 & 0 & 0 & 0 & 0 & 0 & 0 & 0 & 0 & 0 & 0 & 0 & 0 \\
1988 & 1 & 1 & 0 & 0 & 0 & 0 & 0 & 0 & 0 & 0 & 0 & 0 & 0 & 0 & 0 \\
1989 & 1 & 1 & 0 & 0 & 0 & 0 & 0 & 0 & 0 & 0 & 0 & 0 & 0 & 0 & 0 \\
1990 & 1 & 1 & 0 & 0 & 0 & 0 & 0 & 0 & 0 & 0 & 0 & 0 & 0 & 0 & 0 \\
1991 & 1 & 1 & 1 & 0 & 0 & 0 & 0 & 0 & 0 & 0 & 0 & 0 & 0 & 0 & 0 \\
1992 & 1 & 1 & 1 & 0 & 0 & 0 & 0 & 0 & 0 & 0 & 0 & 0 & 0 & 0 & 0 \\
1993 & 1 & 1 & 1 & 0 & 0 & 0 & 0 & 0 & 0 & 0 & 0.4 & 0 & 0 & 0 & 0 \\
1994 & 1 & 1 & 1 & 0 & 0 & 0 & 0 & 1 & 0 & 0 & 1 & 0 & 0 & 0 & 0 \\
1995 & 1 & 1 & 1 & 0 & 0 & 0 & 0 & 1 & 0 & 0 & 1 & 1 & 0 & 0 & 0 \\
1996 & 1 & 1 & 1 & 1 & 0 & 0 & 0.6 & 1 & 0 & 0 & 1 & 1 & 0 & 0 & 0 \\
1997 & 1 & 1 & 1 & 1 & 0 & 0 & 1 & 1 & 0 & 0 & 1 & 1 & 0 & 0 & 0 \\
1998 & 1 & 1 & 1 & 1 & 0 & 0 & 1 & 1 & 0 & 0 & 1 & 1 & 1 & 0 & 0 \\
1999 & 1 & 1 & 1 & 1 & 0 & 1 & 1 & 1 & 0 & 0 & 1 & 1 & 1 & 0 & 0 \\
2000 & 1 & 1 & 1 & 1 & 0 & 1 & 1 & 1 & 0 & 0 & 1 & 1 & 1 & 0 & 0 \\
2001 & 1 & 1 & 1 & 1 & 0 & 1 & 1 & 1 & 0 & 0 & 1 & 1 & 1 & 0 & 0 \\
2002 & 1 & 1 & 1 & 1 & 0 & 1 & 1 & 1 & 0.8 & 0 & 1 & 1 & 1 & 0.8 & 0 \\
2003 & 1 & 1 & 1 & 1 & 0 & 1 & 1 & 1 & 1 & 0 & 1 & 1 & 1 & 1 & 0 \\
2004 & 1 & 1 & 1 & 1 & 1 & 1 & 1 & 1 & 1 & 1 & 1 & 1 & 1 & 1 \\
2005 & 1 & 1 & 1 & 1 & 1 & 1 & 1 & 1 & 1 & 1 & 1 & 1 & 1 & 1 & 1 \\
2006 & 1 & 1 & 1 & 1 & 1 & 1 & 1 & 1 & 1 & 1 & 1 & 1 & 1 & 1 & 1 \\
2007 & 1 & 1 & 1 & 1 & 1 & 1 & 1 & 1 & 1 & 1 & 1 & 1 & 1 & 1 \\
2008 & 1 & 1 & 1 & 1 & 1 & 1 & 1 & 1 & 1 & 1 & 1 & 1 & 1 & 1 & 1 \\
\hline
\end{tabular}


Appendix V: Reforms database 


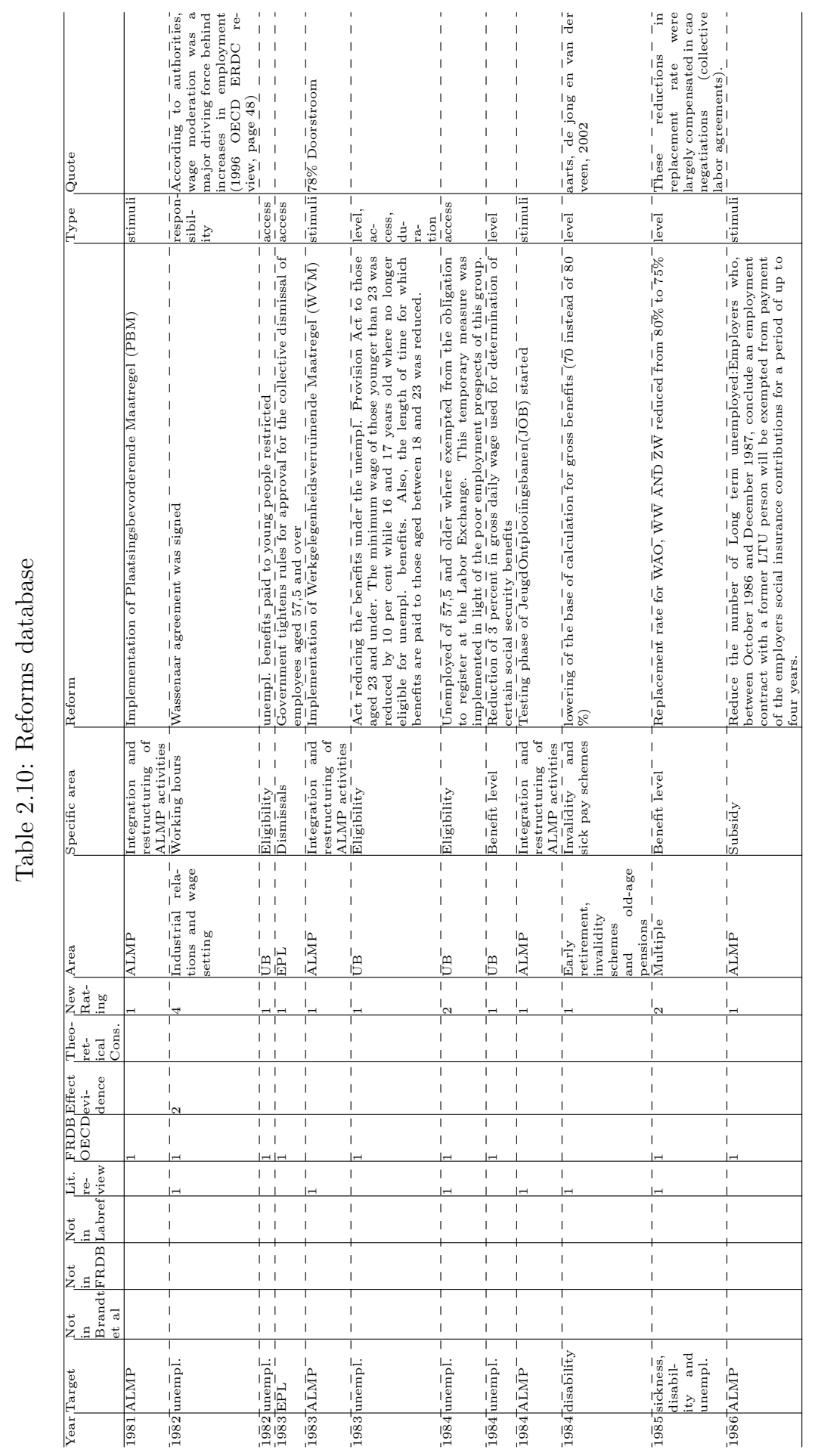




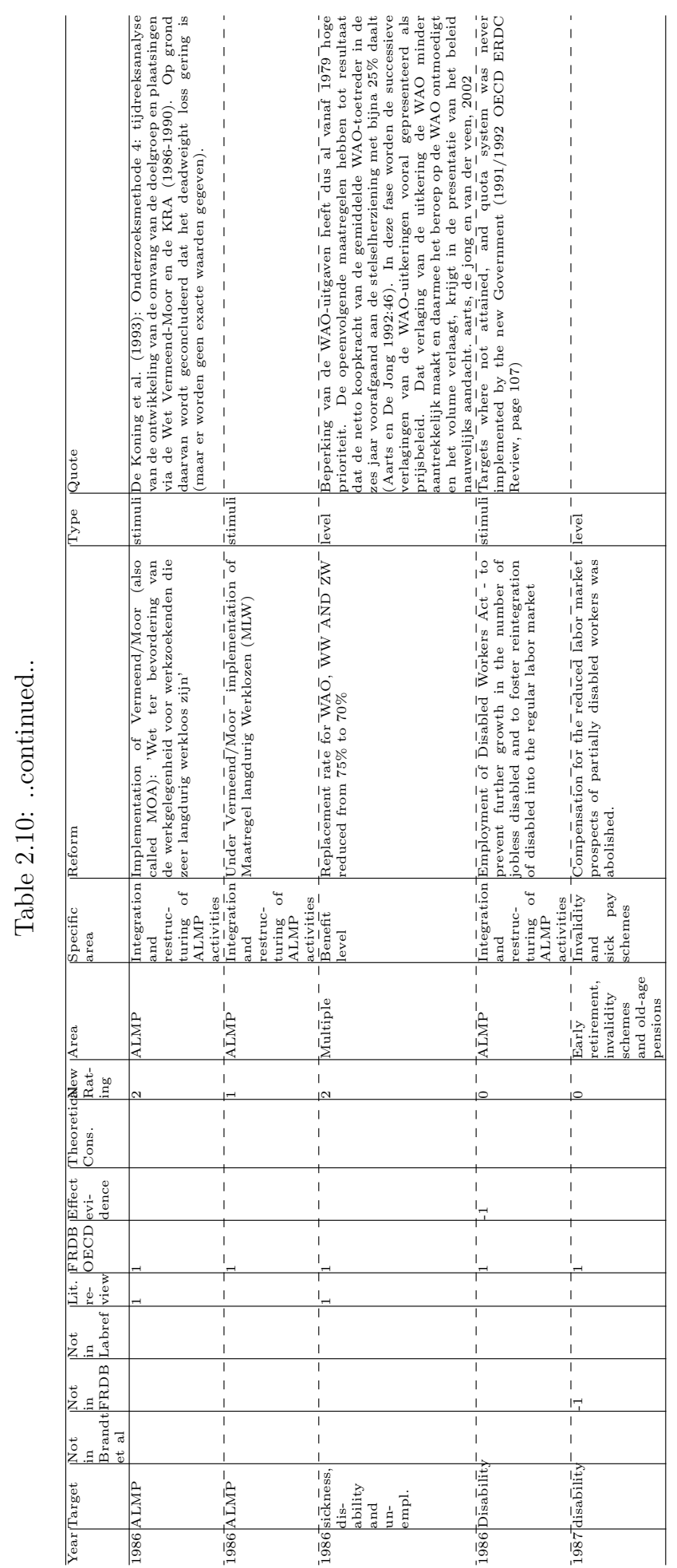




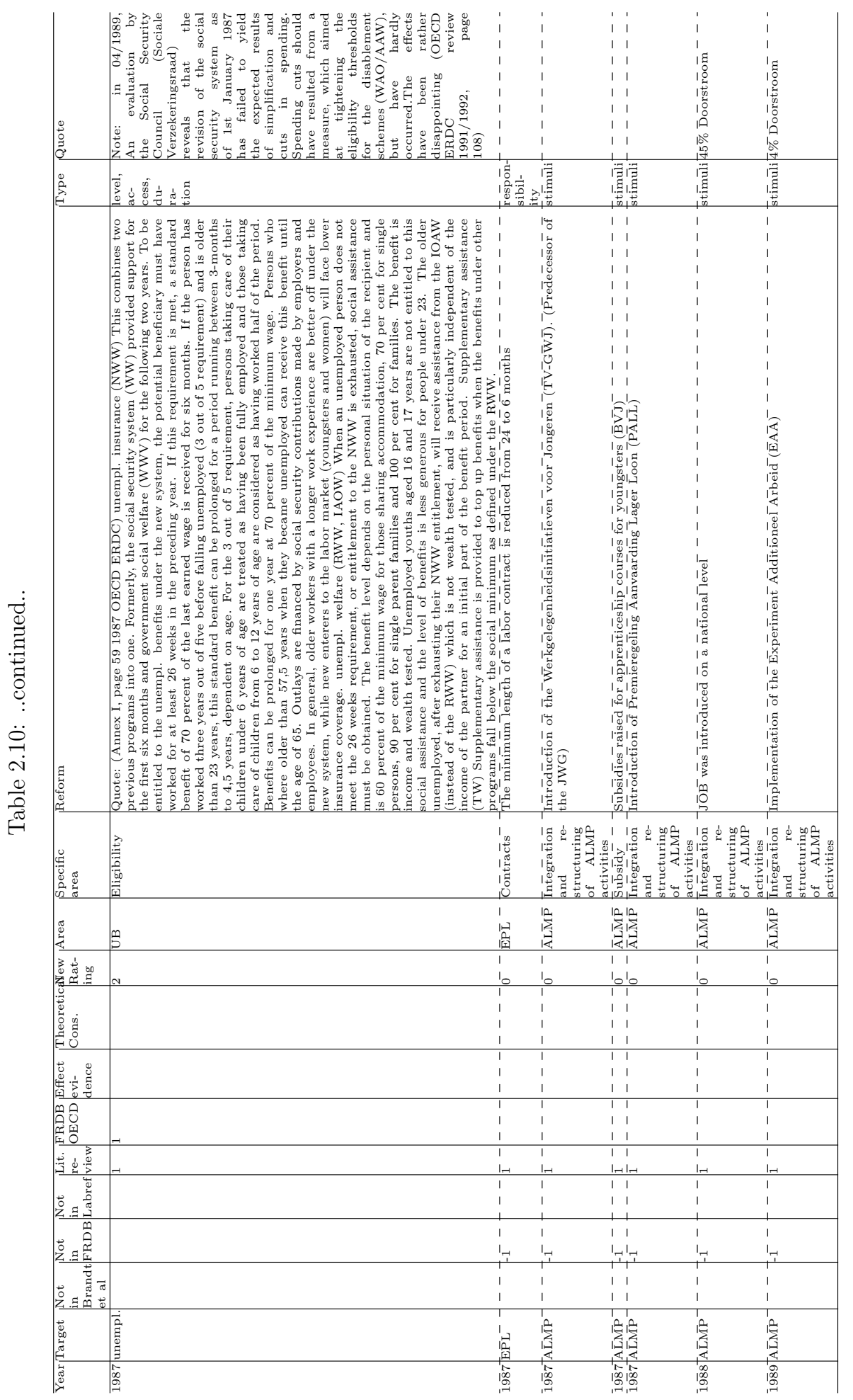




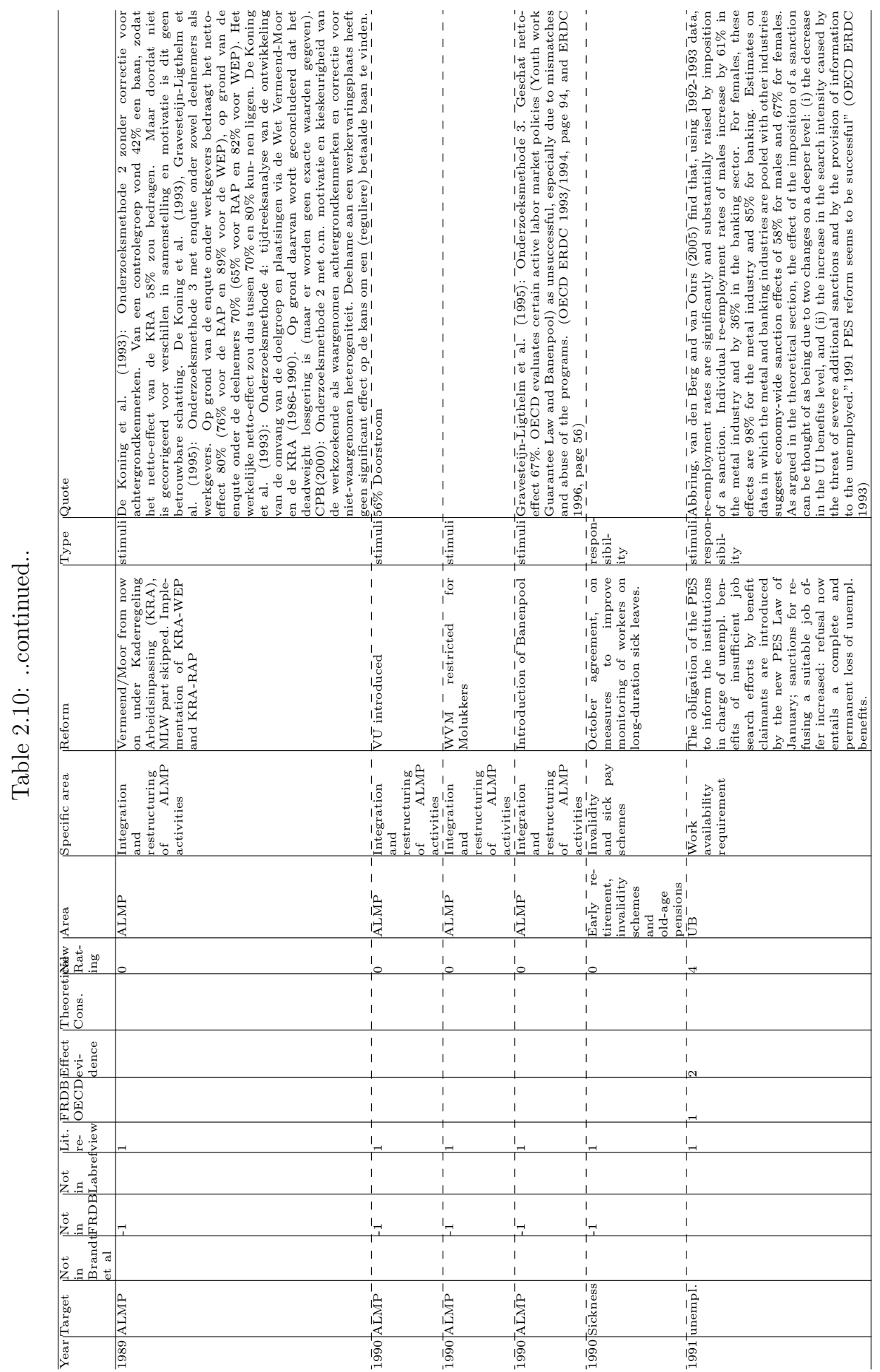




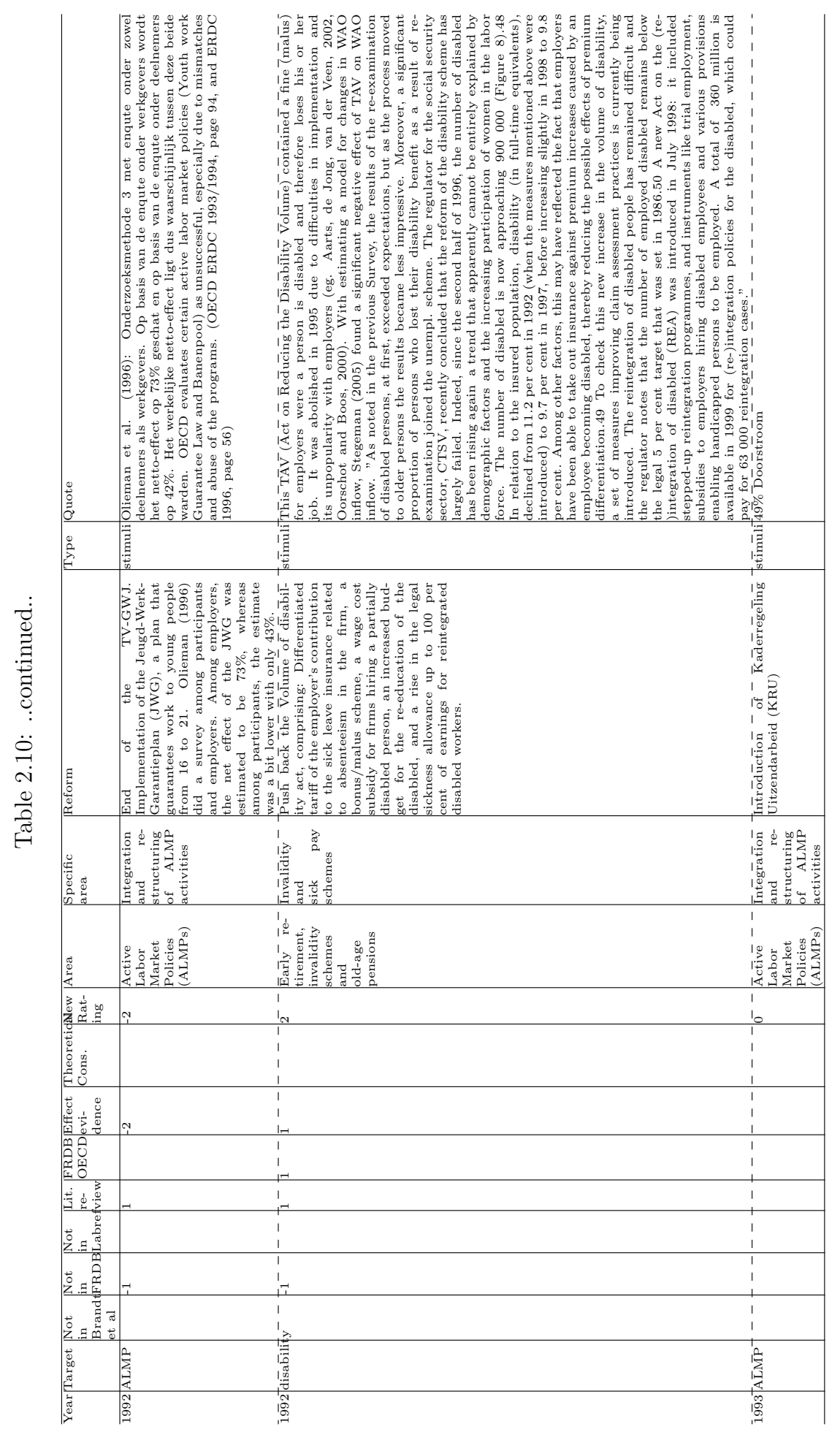




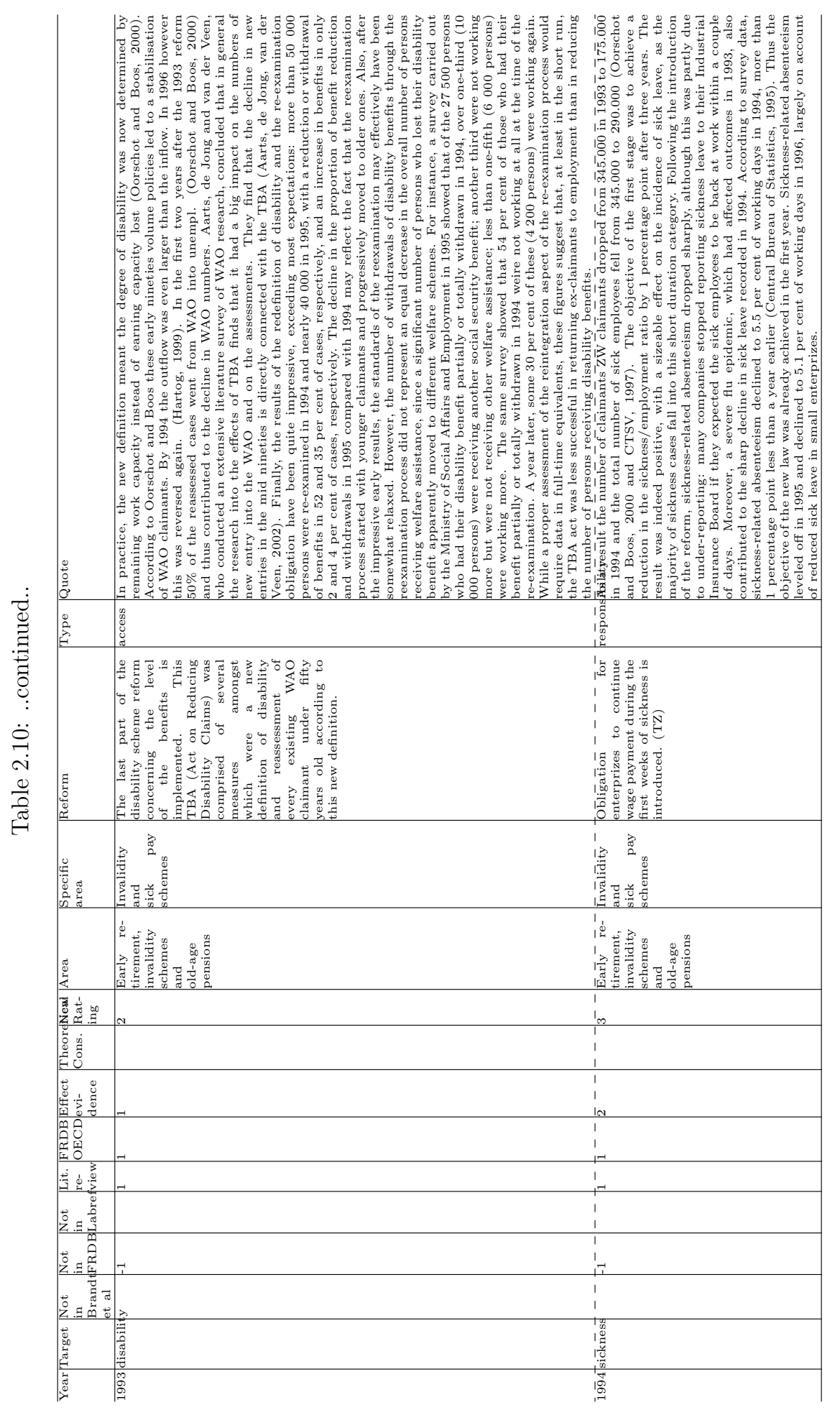




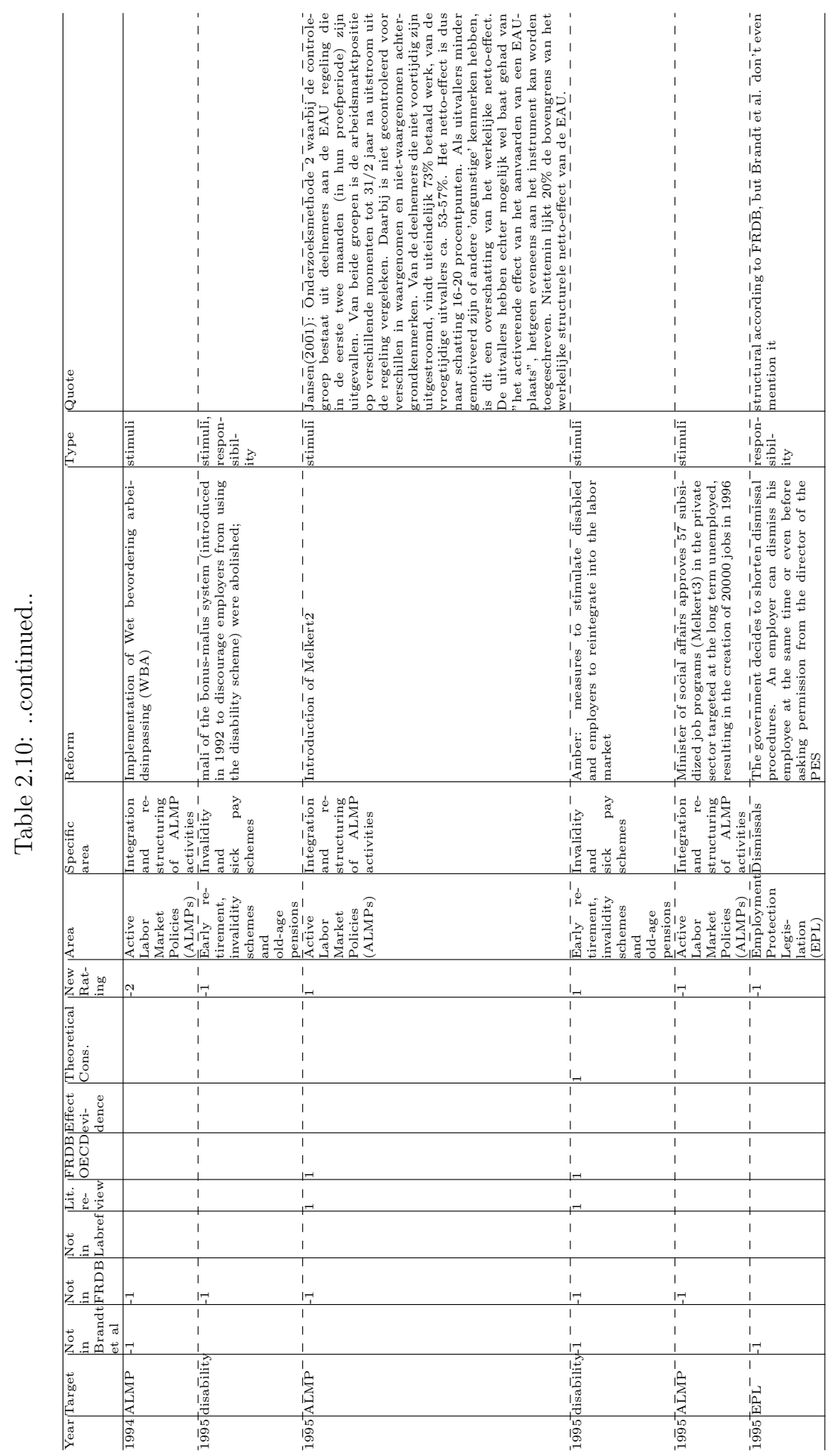




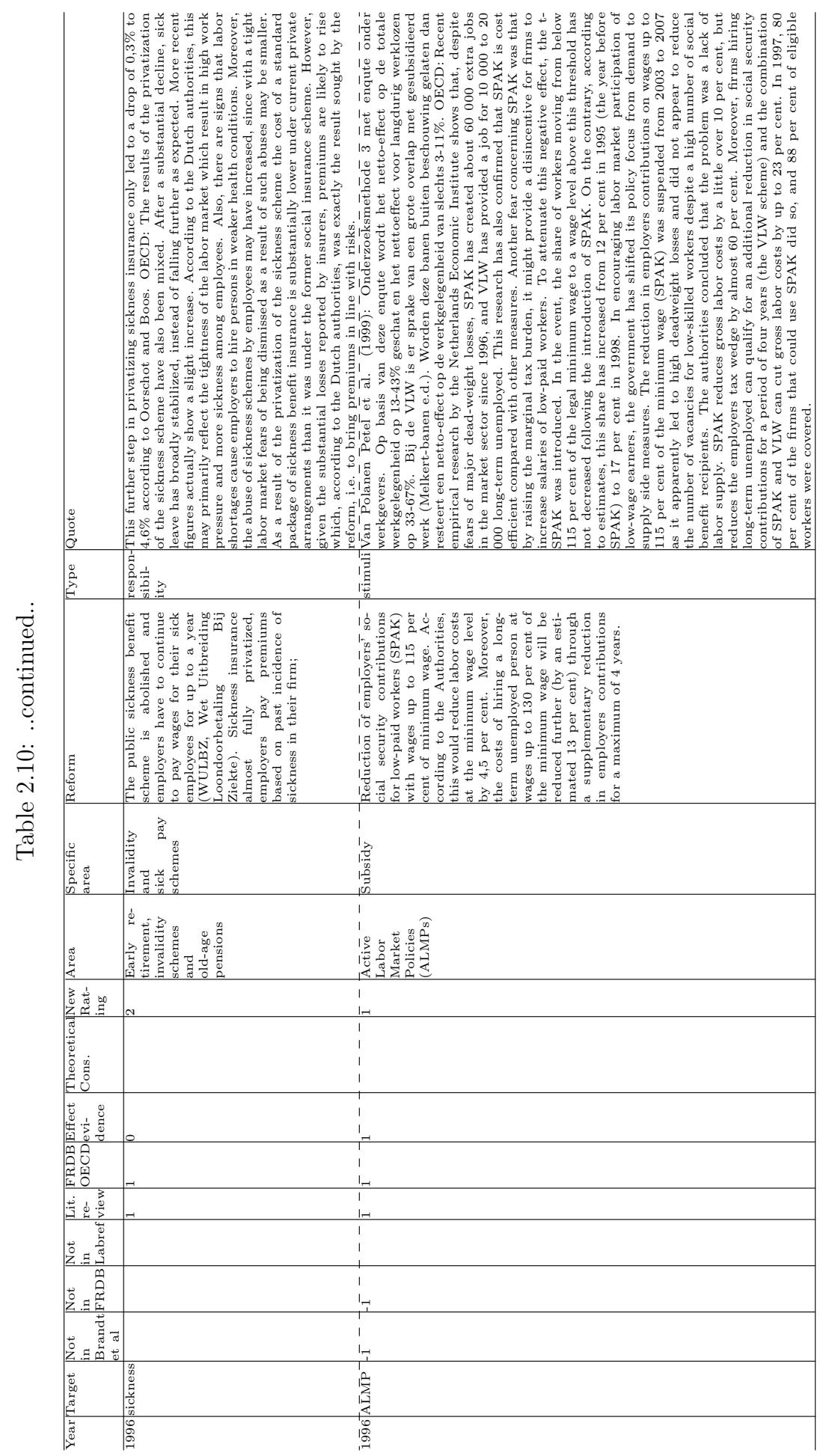




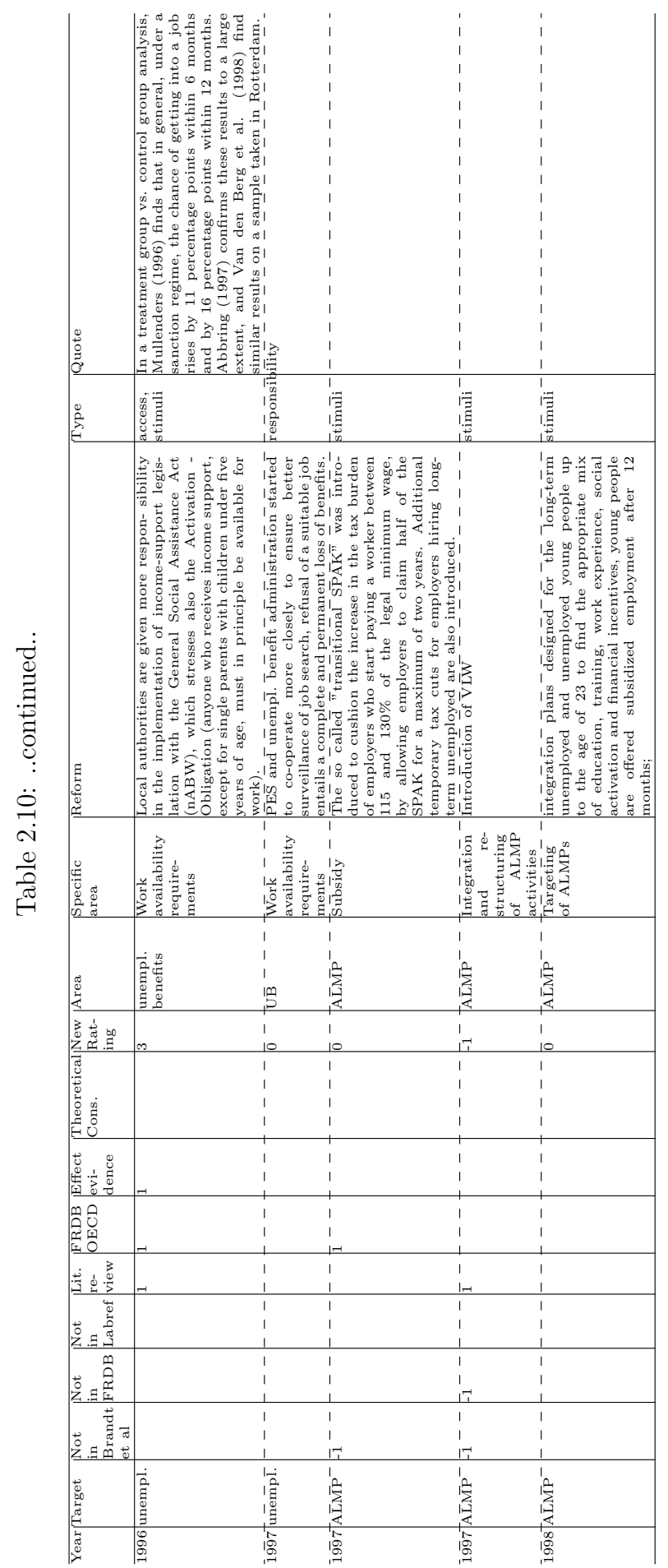




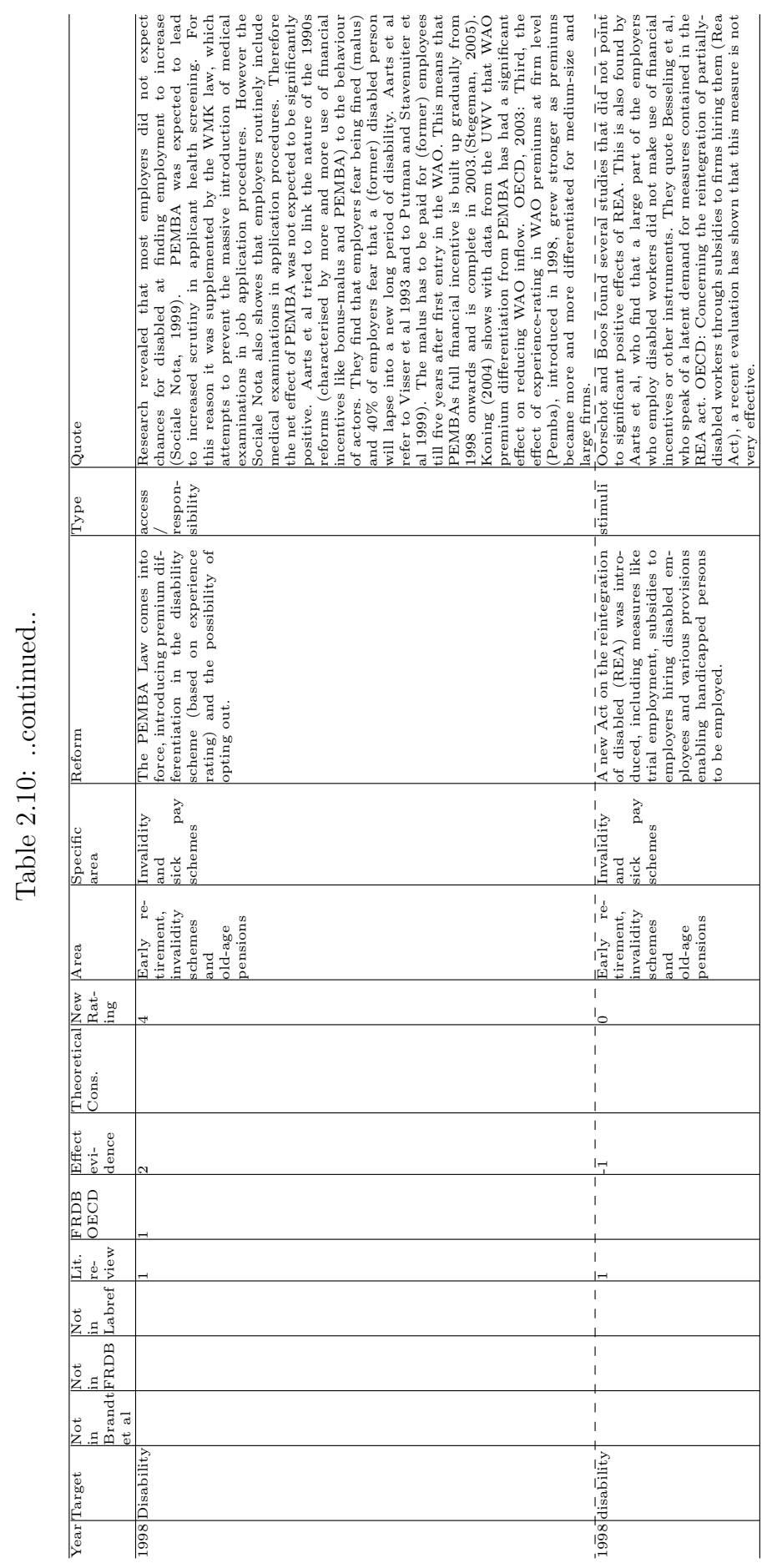




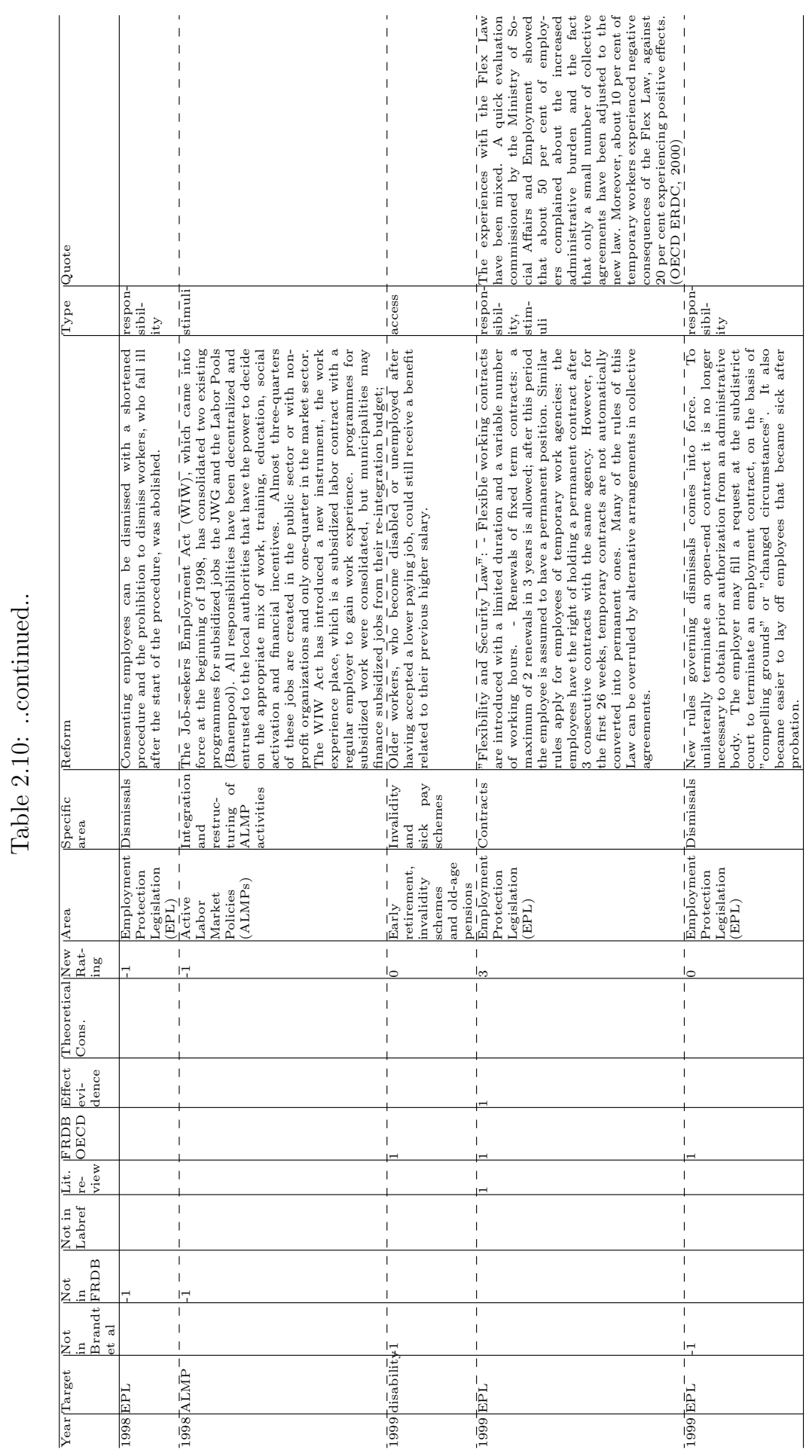




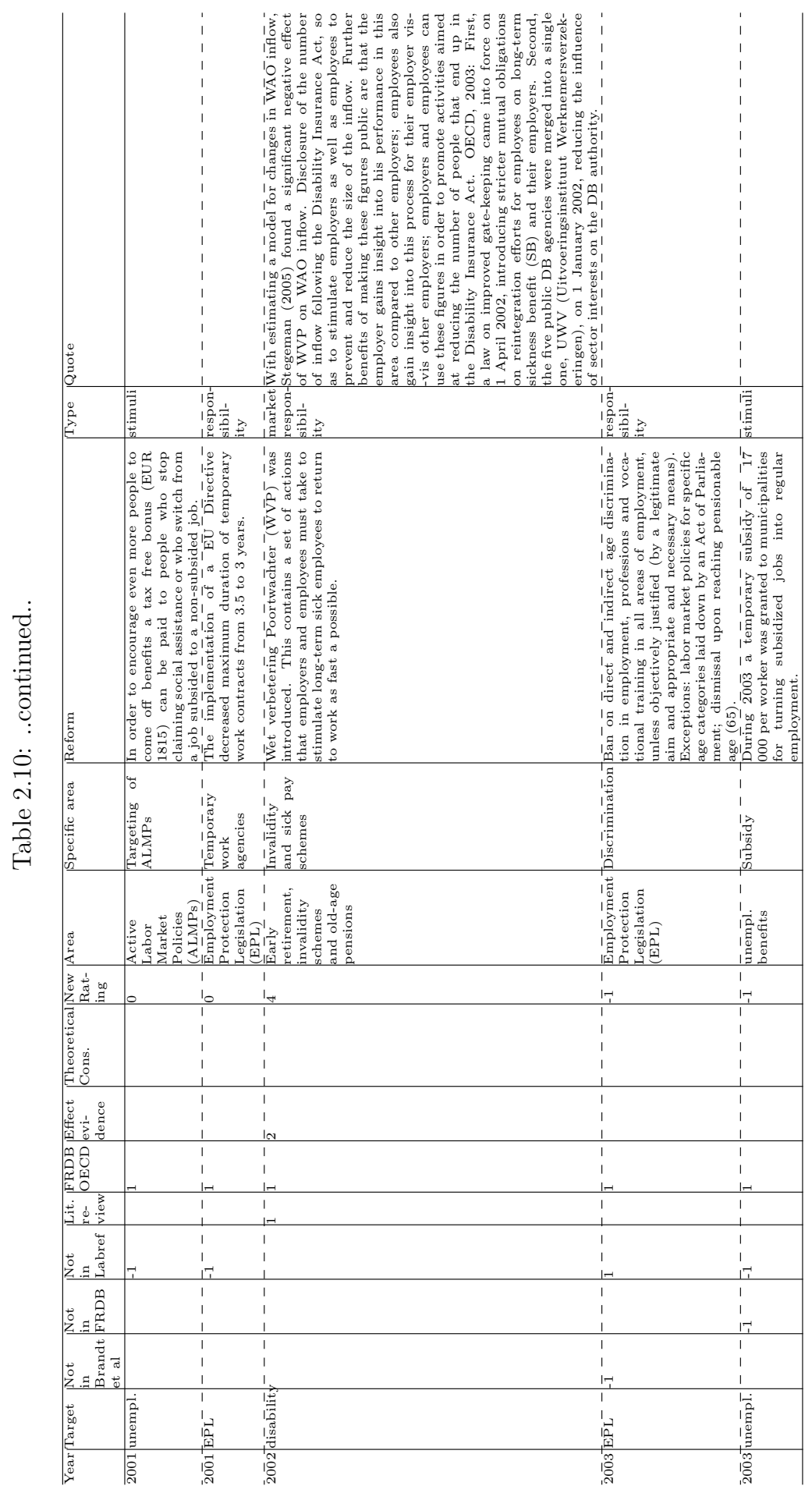




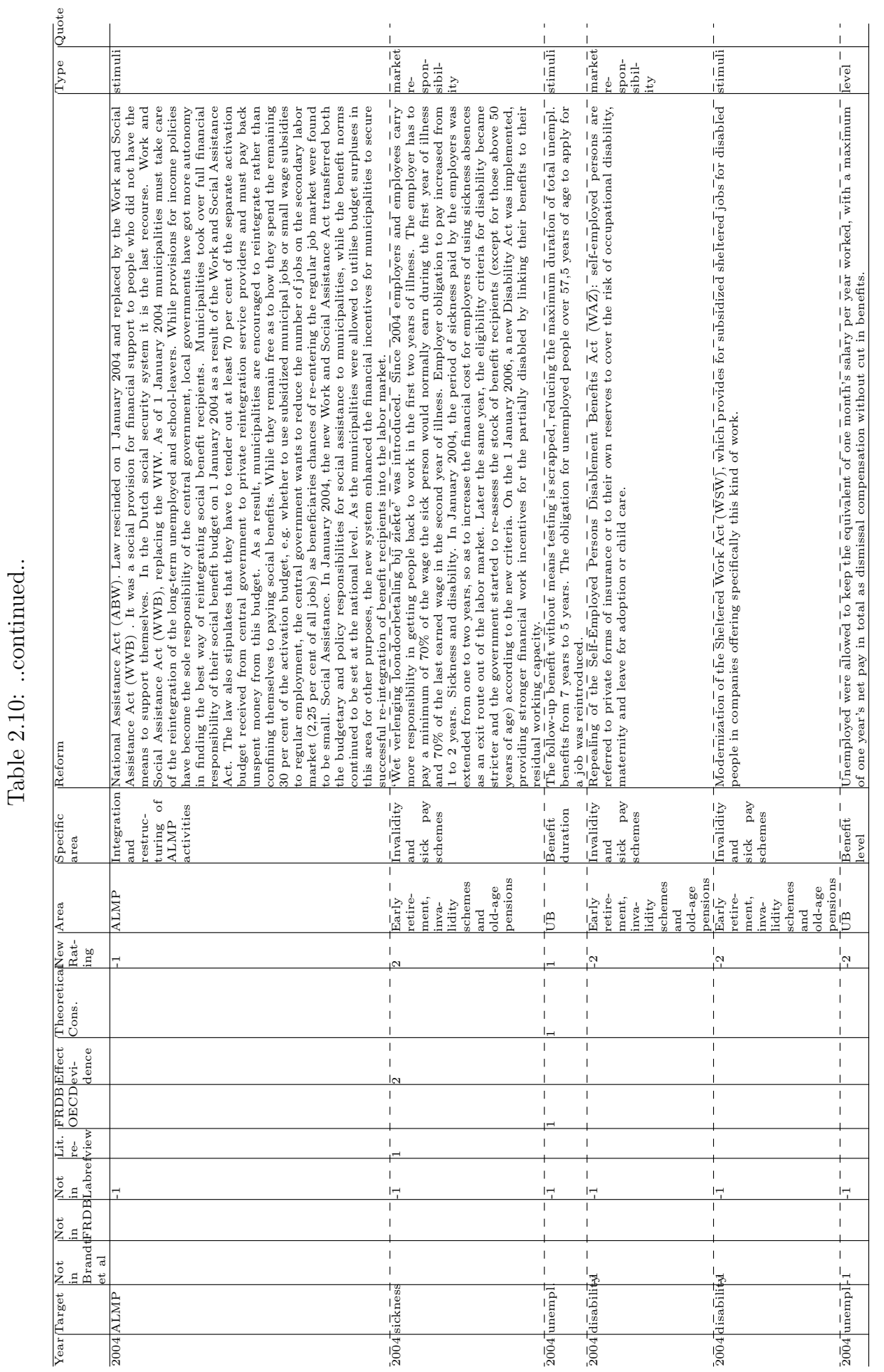




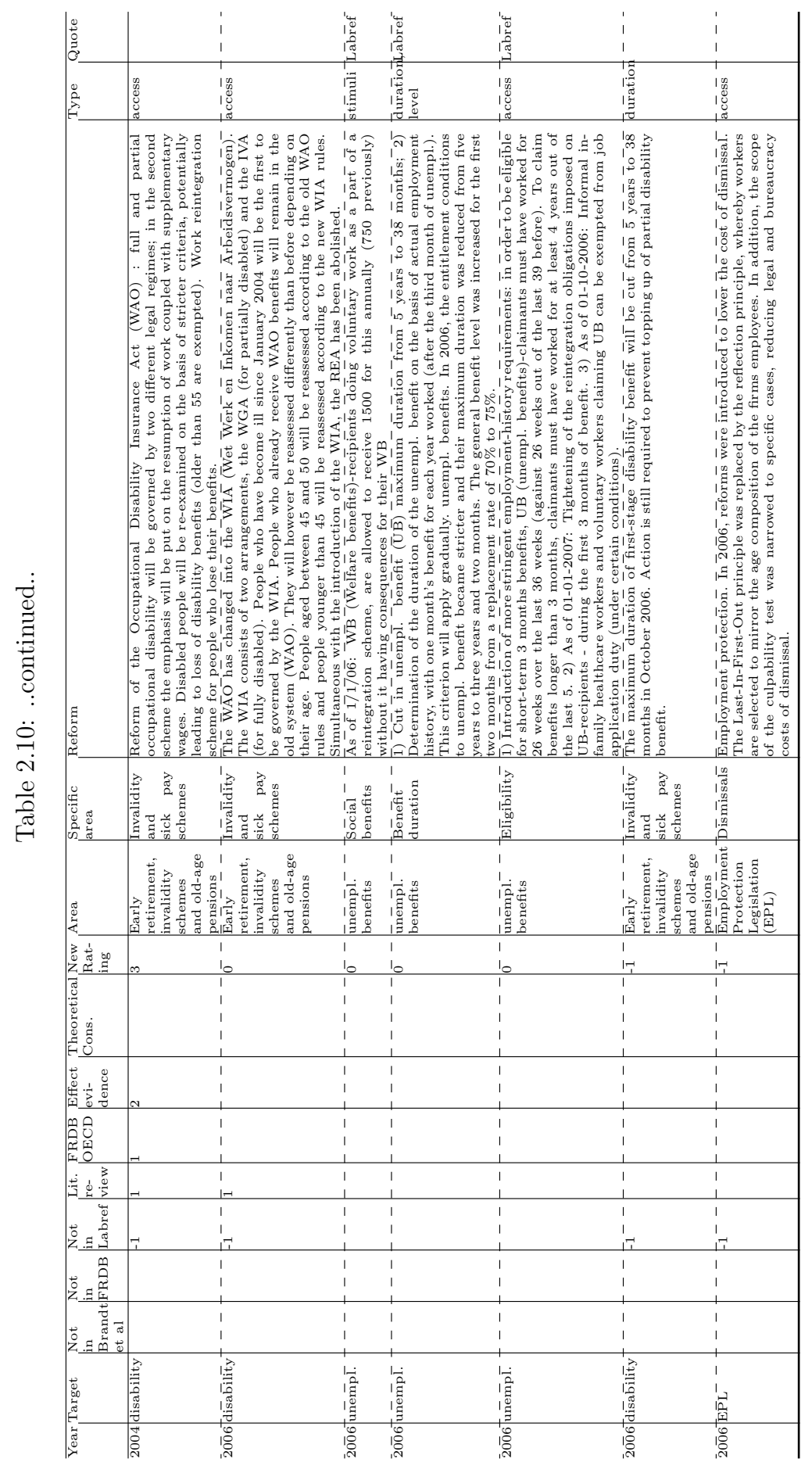





\section{Active Labor Market Policy by a Profit Maximizing Firm}

\subsection{Introduction ${ }^{1}$}

It is well documented that subsidized private sector employment programs (SPSEPs) in which the government pays firms to provide experience to unemployed workers, seem to perform relatively well in bringing unemployed back to work. ${ }^{2}$ This chapter investigates the effectiveness of a pure private employment program to find out whether such a program can also be beneficial for both unemployed workers and firms. We explore this question by analyzing the effectiveness of a large Dutch firms' employment program, based on a unique data set covering a period of 23 years and data on one thousand participating persons. We find that this pure private program performs markedly better than public programs.

One of the private components that give SPSEPs an advantage over other forms of Active Labor Market Policy (ALMP), is that SPSEPs more closely resemble a regular work environment and hence facilitate the build up of relevant human capital (Sianesi, 2008). Other advantages of private involvement are that participation in a SPSEP works as positive signalling towards future employers (Gerfin et al., 2005) and similarly it is a very direct way of demonstrating one's abilities to employers (Graversen, 2004). Although these benefits can be ascribed to private sector involvement, these programs are still initiated, designed, administrated and evaluated by the public sector. Several aspects of this program setup create scope for cream-skimming. First, since these programs are mostly evaluated based on their post-program effects, caseworkers have an incentive to select the most employable - which are not always those who stand to

\footnotetext{
${ }^{1}$ This chapter is joint work with Joan Muysken and Riccardo Welters.

${ }^{2}$ See for instance Kluve (2010), Card et al. (2009) for metastudies confirming this or Jaenichen and Stephan (2009), Sianesi (2008), Graversen and Jensen (2010) and Carling and Richardson (2004) for microeconometric evaluation studies confirming this.
} 
benefit most from it. (Aakvik et al., 2005). Second, Martin and Swank (2004) show that persuading firms to participate in AMLP entails more than just a wage subsidy and, somewhat related, Martin and Grubb (2001) present results that suggest that firms' participation in these programs is positively linked to the quality of participants they can expect. Thus even if caseworkers were able to identify flawlessly those who would benefit most from participation, they would need to think twice before actually selecting them, as these participants might not satisfy the firms expected quality.

In case of a pure private program there is obviously no need to persuade the firm to participate since it is their own program. Hence the delicate balancing act is no longer required. A pure private program would still enjoy the advantages already mentioned. In addition, it may be attractive for a firm to run a private ALMP for reasons we will investigate.

The remainder of this chapter is structured as follows. We elaborate on the program we study in Section 3.2. In Section 3.3 we analyze the outflow data of the program and in Section 3.4 we discuss the performance of the WGP. In Section 3.5 we present a number of benefits for the firm when running a pure private labor market program. Section 3.6 concludes.

\subsection{A private initiative: The Philips Employment Scheme (WGP)}

The unemployment rate in the Netherlands rose dramatically in the early eighties peaking at a record high of $10.2 \%$ in 1983 (CPB, 2009). Among the unemployed were a large number of youngsters, below age 23. This development induced the government and unions to agree on a package of reforms called the Wassenaar agreement in 1982. An important element of this agreement was an economy-wide reduction in working hours to split the same amount of work into more jobs. However, Philips Electronics, the Dutch multinational known for amongst others its household appliances and lighting products, preferred a different approach to combat unemployment and make its contribution in these times of need. Since it was one of the largest employers in the Netherlands, it was able to implement its own course of action. Instead of reducing working hours, Philips created the 'Youth Work Plan' (JWP). The JWP offered unemployed youngsters one year of work and training with Philips and had 639 participants by the end of 1983 - its inaugural year (van der Bruggen and van Schagen, 2001). The JWP ran successfully until 1986 at which time the number of youth unemployed had declined substantially. According to van der Bruggen and van Schagen (2001) the apparent success of the JWP led unions to embrace it, which in turn led Philips and the unions to incorporate the JWP into the centralized wage agreement. This meant that part of Philips's wage budget was allocated to the program. At the same time the scope of the program was expanded to include other groups of unemployed; the JWP morphed into the Philips Employment Scheme 
(WGP). To avoid confusion with the commonly used abbreviation PES for Public Employment Services, we will abbreviate Philips Employment Scheme to 'WGP' (based on 'Werkgelegenheidsplan', the Dutch name of the program). The basic setup however, remained largely unchanged and still entailed one year of full-time employment and training at Philips. Participants receive the legal minimum wage and the training component's objective is to obtain a vocational qualification and therefore includes a substantial theoretical component. However, the WGP goes beyond vocational education. It comprises a considerable amount of on-the-job training and also job counselling services are provided, including job interview training and personal development training. The WGP therefore can be considered as an active labor market policy comparable to the subsidized private sector employment programs mentioned in the introduction.

By design, employment in the WGP is not conflicting with existing (regular) employment at Philips. If there were no WGP, the tasks performed by WGP participants would simply not be performed. Moreover, strict monitoring by independent auditors ensures that the target group of disadvantaged unemployed is indeed reached. Each year the HRM department of Philips allocates WGP jobs over the various Philips establishments. The main consideration for this allocation are the future job prospects of participants. Since Philips has plants and offices operating in various industrial sectors and regions throughout the Netherlands, the future job prospects differ per region and subsequently the choice as to which outlets are assigned to open WGP jobs matters (Welters, 2005). Due to this regional and sectoral variation, this allocation process turns out to be an interactive process between the central HRM department and local HRM staff. Philips aims at a yearly WGP inflow of one percent of total employment at Philips.

Figure 3.1 shows the number of participants entering the WGP compared to total Philips employment and unemployment. On average Philips attains the one percent target, but the inflow varies substantially over time, which several WGP managers attribute to the difficulty to attract suitable candidates during economic upswings. The figure corroborates this finding since the periods in which the one percent target is not attained feature low unemployment.

The data used to construct the figures in this section originate from WGP annual reports from 1987 to 2008 . Table 3.1 presents summary statistics of the most important variables in this dataset. The most striking feature of the data is the job finding rate of almost $70 \%$ measured one year after WGP exit. Judging by this gross measure of effectiveness the WGP seems to perform admirably, but ultimately we need to assess its net effectiveness. This necessitates a more subtle and in depth analysis of the performance of the WGP. This performance crucially depends on three stages: selection of the participants, treatment and outflow counseling. In the subsequent section we elaborate on the design of each of these stages. 
Figure 3.1: WGP inflow

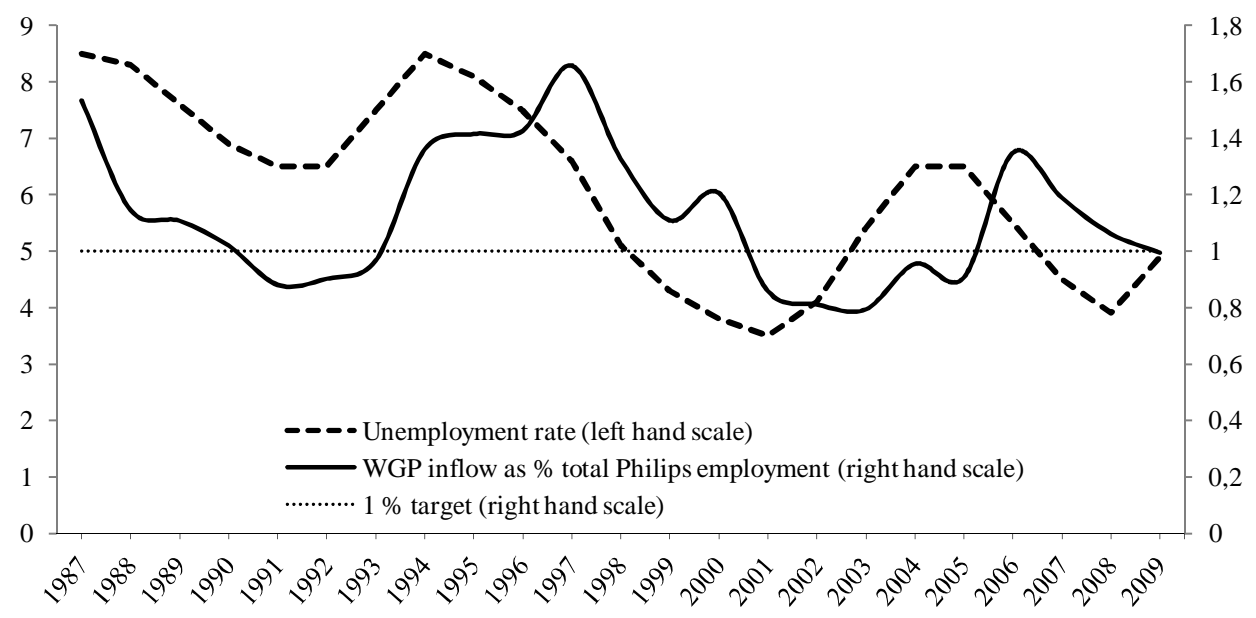

Based on annual data from the WGP yearly reports

Table 3.1: Summary of annual data

\begin{tabular}{l|cccc}
\hline \hline Variable (N=23 years) & Years & Mean & Min & Max \\
\hline & & & & \\
Total employment PhilipsNL & $1987-2010$ & 36,202 & 14,217 & 70,942 \\
Total inflow & $1987-2009$ & 427 & 143 & 768 \\
$\%$ males in inflow & $1988-2009$ & 57.1 & 38 & 76 \\
Average age of inflow & $1988-2009$ & 31.2 & 23.5 & 35.8 \\
Job finding rate 6 weeks after WGP exit & $1987-2007$ & 60.7 & 40 & 79 \\
Job finding rate 1 year after WGP exit & $1995-2007$ & 69.6 & 50 & 84 \\
& & & & \\
\hline \hline
\end{tabular}

\subsubsection{Selection}

Four selection criteria apply to be eligible to participate in the WGP. First, a candidate must be formally registered as unemployed. ${ }^{3}$ The WGP then explicitly targets those unemployed with the largest distance to the labor market, which is the second criterion: that is, long term unemployed, early school leavers, unemployed from ethnic minorities, refugees, persons with a disability and higher educated persons with weak ties to the labor market. Third, a candidate should have the potential to successfully complete the practical and theoretical training component that is part of the WGP treatment. Philips cooperates with public and private sector intermediaries (both paid by government agencies) to find candidates that match these three criteria. It is anticipated that a candidate should possess a certain level of willingness to participate

\footnotetext{
${ }^{3}$ An exception to this rule was made for three groups: women reentering the labor market, early school leavers and disabled.
} 
and this constitutes the fourth criterion, which is tested at the relevant Philips outlet. In principle, all four criteria have to be satisfied.

We compare the characteristics of the inflow into the WGP to the characteristics of the total population of unemployed in Figures 3.2 and 3.3. For Figure 3.2 we use information from a dataset on about 8,900 WGP participants - see Appendix I for details. The only available information is age, education, gender and start year and duration of WGP. For Figure 3.3 we use a different dataset on about 1,000 individuals, described in more detail in Section 4.2 and Appendix I.

Figure 3.2: Education level of WGP inflow compared to total population of unemployed

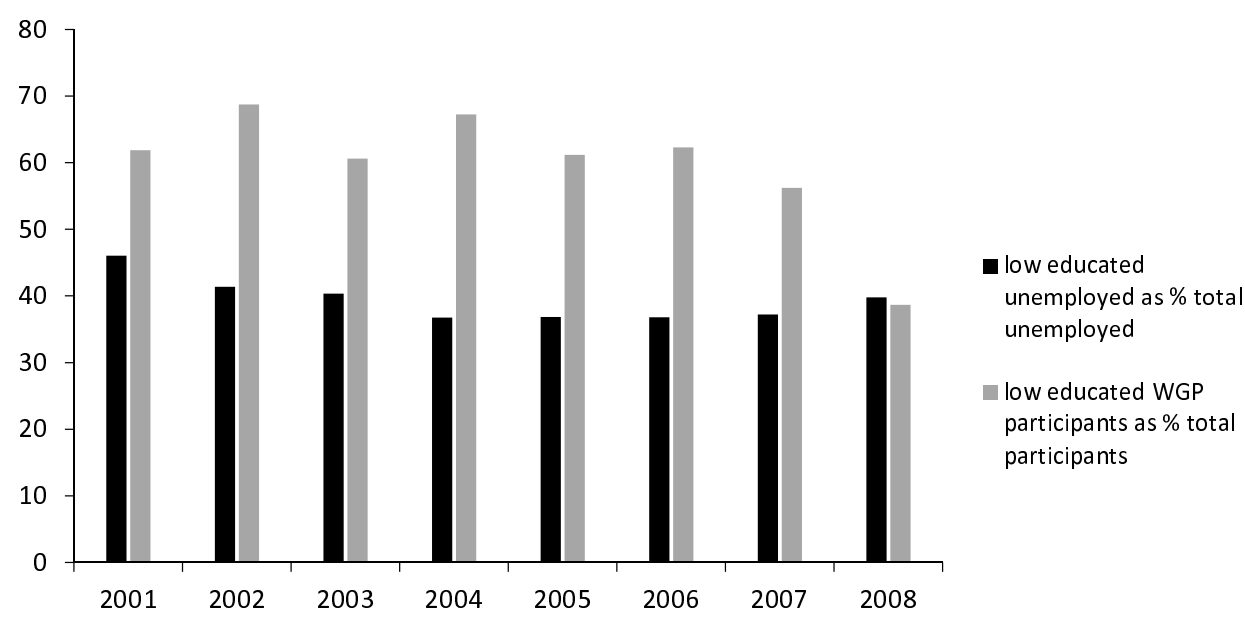

Unemployment data from Statistics Netherlands labor force research (EBB)

Compared to the total population of unemployed, Figure 3.2 shows that low educated unemployed are over-represented in the WGP and Figure 3.3 shows that long term unemployed are generally over-represented in the WGP. This exemplifies that the inflow of the WGP does not represent the -a priori- most employable unemployed available.

Additionally, Table 3.2 provides further evidence of the (un)employability of participants. Until several years ago, the public employment services assigned the unemployed to degrees of employability, where degree one indicated an easily employable person and degree four a hardly employable person. Table 3.2 is based on the only available sample of our data that contains this labeling. The participants in this sample have been positioned throughout different Philips outlets between August 2002 and April 2003. Therefore this sample implicitly includes the efforts of various intermediaries and various Philips floor managers and WGP coordinators. Over ninety percent of participants in this sample are considered to be 'legitimate' program participants (degrees, 2, 3 and 4) and almost seventy percent of the participants in 
Figure 3.3: Unemployment duration of WGP inflow compared to total population of unemployed

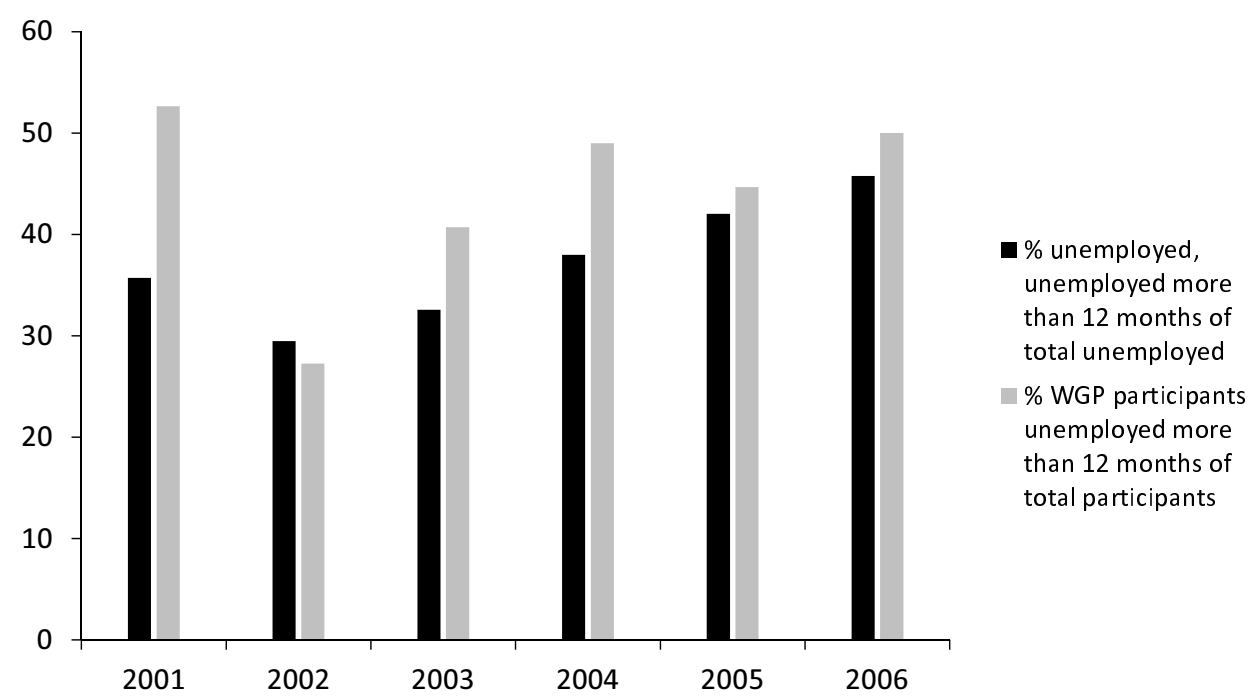

Unemployment data from Statistics Netherlands labor force research (EBB)

this sample are considered tough or virtually impossible to reintegrate as they belong to degrees three and four. Less than nine percent of participants are from the most employable segment of unemployed.

A final observation is that the participants of the WGP are relatively young and male when compared to the average unemployed. As we will elaborate in Section 3.4, this is in favor of their employability.

Table 3.2: Employability of WGP inflow: a sample of August 2002 - April 2003

\begin{tabular}{lllll}
\hline \hline Degree & Definition & In sample & $\%$ & Cum. \\
\hline
\end{tabular}

$4 \quad$ Unemployable

$\begin{array}{lll}10 & 10.9 & 10.9\end{array}$

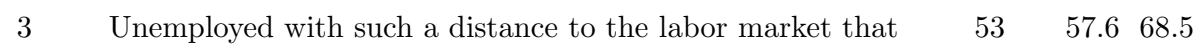
job-finding chances have been reduced significantly

2 Unemployed who are less easily employable but are able to

$21 \quad 22.8 \quad 91.3$

find a job within a year with support of schooling or subsidy

1 Unemployed who are easily employable and can find a job

$\begin{array}{lll}8 & 8.7 & 100\end{array}$

\begin{tabular}{lll}
\hline Total & 92 & 100 \\
\hline \hline
\end{tabular}




\subsubsection{Treatment and outflow counseling}

The treatment in the WGP consists of one year of work experience combined with formal training that leads to a vocational qualification. Since the end of the nineties, half of the WGP participants start with a five month pre-program because their initial qualifications are too low to enter the WGP directly. They would not be able to attain the vocational qualification within the standard WGP time frame of one year. After this pre-program they enter the WGP proper (van der Bruggen, 2004). Many participants are also not able to complete the entire WGP treatment in one year and are offered a 6 or 12 month extension. These developments exemplify the large distance to the labor market of many candidates.

The type of training that a participant receives depends on the nature of the particular WGP job. Many of the WGP participants still complete the VaPro degree, which is a widely recognized qualification in the Dutch process industry. However, due to changes in the labor market and in the qualifications of participants, there has been an increase in the number of participants that complete a degree in other fields such as administrative, secretarial and ICT skills. The knowledge and skills acquired during the training are brought into practice on the job. Throughout the entire WGP period the participant receives regular supervision, counseling and guidance primarily from within Philips but occasionally also from the intermediary.

Outflow counseling starts three to six months before the end of the WGP period and is provided by the intermediary that proposed the participant for the program. Specific counseling activities vary but generally include individual job interview training and personal development training. After exiting the WGP all participants are contacted twice to answer a number of questions about their participation and their current situation. First, six weeks after exiting the participants are sent a large paper questionnaire, which is completed by on average 59 percent. One question, asked in this questionnaire, is whether the former WGP participant is currently employed. Since 1995, this question is asked again one year after exiting the WGP and this time, participants who do not respond to the question in writing, are also contacted by telephone. This extra effort helps bring the total response to this question to on average 88 percent. The answers have been aggregated by Philips and were used in the annual reports about the WGP. Figure 3.4 shows the aggregate job finding rate over the history of the WGP.

On average sixty percent of respondents report to be employed when asked six weeks after exiting the WGP whereas this increases to seventy percent after one year. On average $15 \%$ of respondents were employed by Philips at completion of the WGP period, while this figure has varied from 11 to 34 percent. ${ }^{4}$ When asked about their general opinion on their WGP period, on average seventy percent of respondents answer 'satisfied' or 'very satisfied' (on a five point scale).

\footnotetext{
${ }^{4}$ In Section 3.3 we present estimates showing that young and academically qualified participants are more likely to be employed by Philips after completing the WGP than others.
} 
Figure 3.4: Aggregate job success of WGP

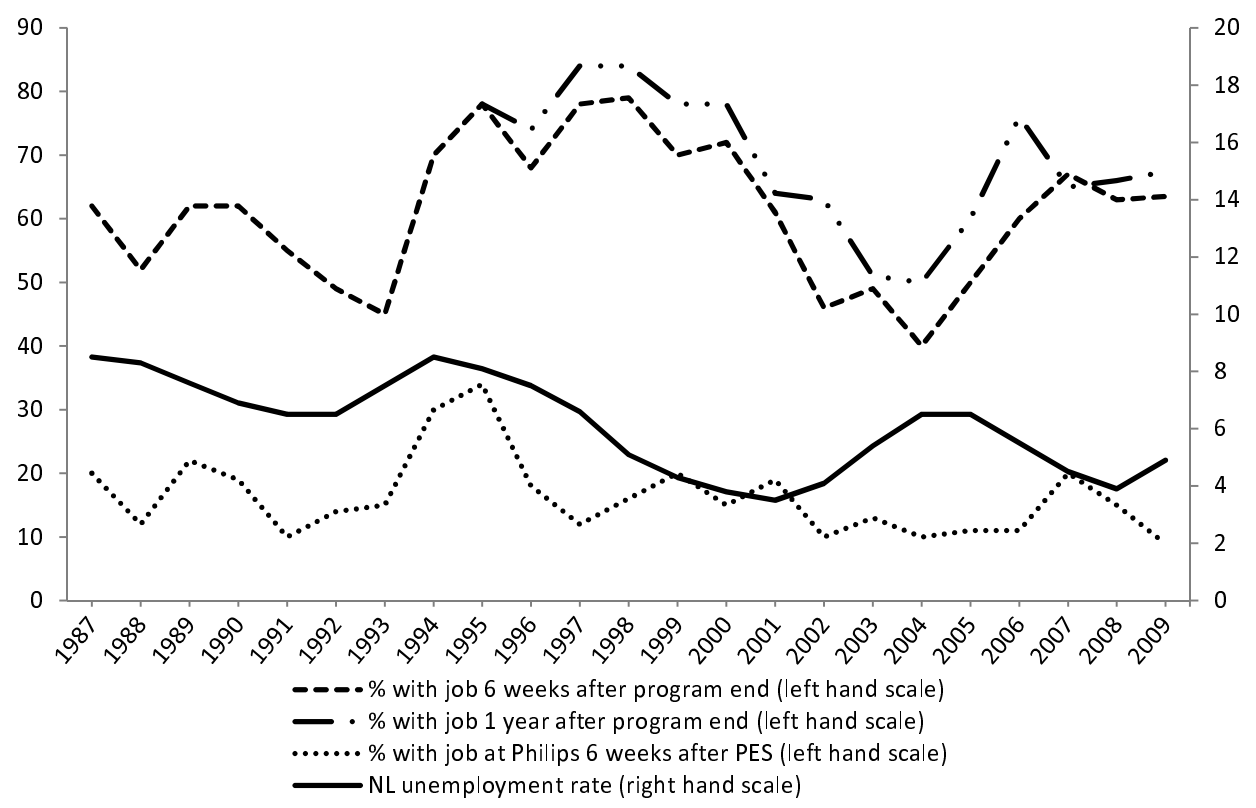

Based on annual data from the WGP yearly reports and on unemployment data from Statistics Netherlands

\subsection{The gross effect of the WGP}

In Section 3.2 we found that on average seventy percent of participants hold a job when interviewed one year after leaving the WGP. In this section we take a closer look at the WGP to investigate what factors influence its job finding rate and the quality of its participants.

\subsubsection{Who get a job after the WGP?}

To analyze the determinants of the job finding rate of the WGP participants, we use both aggregate annual data (see Table 3.1 for a description) and individual questionnaire data. Although the questionnaires have been in use since 1987 and their results are still available in aggregate form, the participants' individual answer sheets are only available for the period 1999-2007. (See Appendix I for more information.)

Table 3.3 presents the results of two models that shed light on job finding chances after the WGP. The aggregate model uses the job finding rate (6 weeks after program exit, as shown in Figure 3.4) as dependent variable and the individual model uses a job finding dummy. Both models show a positive relation between the job finding rate/dummy and unemployment at time of inflow and a negative relation with unemployment at time of outflow. This second relation suggests that 
Table 3.3: Explaining participants' job finding chances

\begin{tabular}{|c|c|c|c|c|}
\hline $\begin{array}{l}\text { Data used } \\
\text { Period } \\
\text { Regression }\end{array}$ & \multicolumn{2}{|c|}{$\begin{array}{c}\text { Yearly aggregates } \\
\text { 1988-2007 } \\
\text { OLS }\end{array}$} & \multicolumn{2}{|c|}{$\begin{array}{c}\text { Individual } \\
\text { 1999-2007 } \\
\text { Probit } \\
\end{array}$} \\
\hline Dependent variable & \multicolumn{2}{|c|}{ Job finding rate } & \multicolumn{2}{|c|}{ "Job finding dummy } \\
\hline $\begin{array}{l}\text { Unemployment at time of inflow } \\
\text { Unemployment at time of outflow } \\
\text { Age } \\
\text { Gender }\end{array}$ & $\begin{array}{r}7.00 * * * \\
-9.22 * * *\end{array}$ & $\begin{array}{l}(1.99) \\
(1.87)\end{array}$ & $\begin{array}{r}0.30 * * * \\
-0.50 * * * \\
-0.03 * * * \\
0.06\end{array}$ & $\begin{array}{l}(0.09) \\
(0.09) \\
(0.01) \\
(0.08)\end{array}$ \\
\hline $\begin{array}{l}\text { Prior education: } \\
\text { Average educational attainment } \\
\text { Primary school } \\
\text { Low level vocational/secondary } \\
\text { Middle level vocational/secondary } \\
\text { High level vocational } \\
\text { University }\end{array}$ & $0.10 * * *$ & $(0.02)$ & $\begin{aligned} & \text { refe } \\
&-0.01 \\
&-0.03 \\
& 0.06 \\
& 0.28\end{aligned}$ & $\begin{array}{l}\text { ace } \\
(0.17) \\
(0.16) \\
(0.18) \\
(0.20)\end{array}$ \\
\hline $\begin{array}{l}\text { Unemployment status } \\
\text { Unemployment duration: } \\
\text { 0-6 months } \\
\text { 6-12 months } \\
12-24 \text { months } \\
24-48 \text { months } \\
48+\text { months }\end{array}$ & & & $\begin{array}{l}-0.44 * * * \\
\text { refe } \\
0.05 \\
-0.13 \\
0.19 \\
-0.05\end{array}$ & $\begin{array}{l}(0.15) \\
\text { ace } \\
(0.12) \\
(0.13) \\
(0.15) \\
(0.16)\end{array}$ \\
\hline $\begin{array}{l}\text { If unemployed, what age: } \\
\text { Age 16-30 } \\
\text { Age } 31-40 \\
\text { Age } 41-50 \\
\text { Age } 51+\end{array}$ & & & $\begin{array}{l}\text { refe } \\
0.37 * * \\
0.33 \\
0.26\end{array}$ & $\begin{array}{l}(0.14) \\
(0.22) \\
(0.31)\end{array}$ \\
\hline Constant & -0.25 & $(0.18)$ & $1.70 * * *$ & $(0.40)$ \\
\hline $\begin{array}{l}\mathrm{N} \\
R^{2} \\
\text { Durbin-Watson D-statistic } \\
\text { Correctly classified by probit model }\end{array}$ & $\begin{array}{r}20 \\
0 \\
2\end{array}$ & & \multicolumn{2}{|c|}{$61.35 \%$} \\
\hline
\end{tabular}

${ }^{* * *}=$ significant at $1 \%,{ }^{* *}=$ significant at $5 \%,{ }^{*}=$ significant at $10 \%$

${ }^{a}$ Average number of years of schooling

Standard errors in parentheses

higher unemployment at time of outflow means a lower chance to find a job. This seems logical as more job seekers compete for the same number of jobs. The first relation indicates that participants who enter the WGP when unemployment is high, 
have a higher chance to find a job after their treatment than participants who enter the program in a low unemployment period. This is consistent with findings from for instance Kluve (2010) and Lechner and Wunsch (2009). Lechner and Wunsch (2009) show that 'all else equal' higher unemployment at time of inflow into (training) programs correlates positively with the programs' effects. ${ }^{5}$ However, even though our individual model corrects for some participant characteristics, we suspect that the positive relation between unemployment at time of inflow and the program success is also driven by unobserved participant characteristics which are more favorable when the pool of unemployed is large. Evidence of this is given in the discussion of Table 3.5 .

With regard to educational background the aggregate model shows that a higher average educational attainment corresponds with a higher average job finding rate, whereas the individual model which distinguishes between education levels shows no significant effect. The variable 'Unemployment status' is a dummy variable that distinguishes participants that entered the WGP without having been formerly registered as unemployed (dummy $=0$, remember from Section 3.2.1 that these consist of women reentering the labor force, early school leavers and disabled) from those that had a registered unemployment history (dummy=1). We observe that participants without a registered unemployment history have a higher chance to find a job after the WGP. A possible explanation for this could be that these participants are more intrinsically motivated to get back to work (in the case of women reentering the labor force because they make the deliberate choice to re-enter the labor force) and that they have not suffered from a discouraged worker effect.

Age and gender have no significant impact on the aggregate model or its robustness and were left out. However, the individual model shows that an increase in age has a negative effect on the chances of finding a job. Interacting age-groups with the 'unemployment status dummy' shows that participants between age 31 and 40 have a higher chance of finding a job after the WGP than the reference group of 16 to 30 year old's. Both the duration of unemployment and gender are not significant in the individual model. This suggests the WGP is quite successful, given the intrinsic qualities of the candidates. ${ }^{6}$

\subsubsection{A closer look at the inflow of the WGP}

To further investigate if higher unemployment leads to better qualified participants we zoom in on the (dynamics of the) inflow quality in the WGP. In Table 3.4 we present OLS estimates of the effect of 'unemployment at time of inflow', gender and age on

\footnotetext{
${ }^{5}$ One explanation they provide is that in times of high unemployment, non-participants experience fewer job matches or worse matches than when unemployment is low and this reflects negatively on their future prospects, whereas program participants enjoy a stable program situation and do not incur unfavorable matches.

${ }^{6}$ We tested this model on several levels of geographical aggregation for unemployment -i.e. also looking at regional and municipal unemployment. However, the results remain qualitatively the same.
} 
the quality of participants. ${ }^{7}$ The quality of participants is measured as the ratio of the participant's years of schooling to the labor force average years of schooling in the year of inflow. We constructed this ratio to correct for possible bias that might arise due to the rising trend in the labor force's overall education level. The first

Table 3.4: Effect of labor market conditions on participants quality, 1987-2006

\begin{tabular}{|c|c|}
\hline & Educational attainment $^{a}$ \\
\hline Unemployment at time of inflow & $0.04(0.00) * * *$ \\
\hline \multicolumn{2}{|l|}{ Gender: } \\
\hline Male & reference \\
\hline Female & $-0.04(0.01) * * *$ \\
\hline \multicolumn{2}{|l|}{ Age groups: } \\
\hline $16-30$ years & reference \\
\hline 31 - 40 years & $-0.02(0.01) * *$ \\
\hline 41 - 50 years & $-0.04(0.01) * * *$ \\
\hline$>50$ years & $-0.06(0.03) * *$ \\
\hline Constant & $0.74(0.02) * * *$ \\
\hline$R^{2}$ & 0.06 \\
\hline $\mathrm{N}$ & 6611 \\
\hline \multicolumn{2}{|c|}{${ }^{* * *}=$ significant at $1 \%,{ }^{* *}=$ significant at $5 \%,{ }^{*}=$ significant at $10 \%$} \\
\hline \multicolumn{2}{|c|}{${ }^{a}$ Participant's years of schooling to labor force average years of schooling ratio } \\
\hline \multicolumn{2}{|c|}{ Standard errors in parentheses } \\
\hline \multicolumn{2}{|c|}{ Based on our dataset on 8,928 participants } \\
\hline
\end{tabular}

result we observe is that, the higher the unemployment rate at time of inflow, the higher the educational attainment of participants entering the WGP. Whether this results from self-selection or selection by intermediaries/Philips cannot be answered with certainty. Albeit neither gratifying nor original to argue, it's most likely a combination of both. We also find that, relative to participants from the age group of 16 - 30 year, participants from older age groups have a lower educational attainment relative to the labor force average. This is not surprising since recent generations stay in education longer and hence the average educational attainment of the labor force has risen steadily during the last decades. Finally we observe that female WGP participants appear to have a lower educational attainment.

By analyzing the time participants spent in the WGP we can provide an alternative analysis which more clearly shows the business cycle effect on the quality of inflow. ${ }^{8}$ A 'bread-and-butter' WGP treatment takes twelve months. Thus when a person takes more than twelve months to complete he or she apparently needs more time to be

\footnotetext{
${ }^{7}$ Again we also looked at various levels of geographical aggregation for unemployment and again we found qualitatively the same results.

${ }^{8}$ As presented in Appendix I, our '8900 dataset' contains a variable measuring the time spent in the WGP. This is measured as duration in months.
} 
deemed ready for outflow, and is likely to have been relatively less qualified at time of inflow. ${ }^{9}$ Based on this assumption we construct a dummy variable equal to ' 0 ' when participants spent at most twelve months in the WGP, and equal to ' 1 ' for participants who spent more than twelve months in the WGP. ${ }^{10}$ We tested the sensitivity of this dummy to the business cycle and the characteristics of the inflow with a probit model. Table 3.5 contains the results.

Table 3.5: Effect of business cycle and inflow characteristics on time spent in WGP, 1987-2006

\begin{tabular}{l|c}
\hline \hline & Duration dummy \\
\hline Unemployment at time of inflow & $-0.20(0.02) * * *$ \\
Gender: & reference \\
Male & $-0.40(0.05) * * *$ \\
Female & reference \\
Age groups: & $0.12(0.05) * *$ \\
Age 16-30 & $0.27(0.07) * * *$ \\
Age 31-40 & $0.23(0.15)$ \\
Age 41-50 & \\
Age 51+ & reference \\
Prior education: & $0.08(0.07)$ \\
Primary school & $-0.10(0.08)$ \\
Low level vocational & $-0.05(0.07)$ \\
Low level secondary & $-0.16(0.11)$ \\
Middle level vocational & $-0.17(0.16)$ \\
Middle level secondary & $-0.37(0.10) * * *$ \\
Top level secondary & $-0.46(0.12) * * *$ \\
High level vocational & $0.03(0.11)$ \\
University & \\
Constant & $91.45 \%$ \\
\hline Correctly specified by probit model & 6611 \\
\hline N & \\
\hline \hline St** significant at $1 \%, * *=$ significant at $5 \%, *$ & $=$ significant at $10 \%$ \\
Stand errors in parentheses &
\end{tabular}

We observe that women are less likely to spend more than twelve months in the WGP and that middle aged participants are more likely to stay longer in the WGP than the youngest participants. Furthermore both high level vocational and university educated participants are less prone to spend more than twelve months in the WGP. The business cycle effect manifests itself as the negative relation between

\footnotetext{
${ }^{9}$ In Section 4.2 we already mentioned that less qualified participants are regularly offered a 6 or 12 months extension.

${ }^{10}$ Since an extension lasts a fixed 6 or 12 months there is hardly any variation in the duration so we used a dummy variable instead of actual duration in months.
} 
unemployment at time of inflow and the duration dummy. When the labor market is tight and unemployment is low at time of inflow, participants have a higher chance to spend more than twelve months in the WGP and are likely to be less qualified. Thus participants are 'locked-in' the WGP longer when unemployment was low at time of inflow. However, our explanation (a person needs more time in the WGP to be qualified enough to successfully exit the WGP) differs from the usual explanation that 'locking-in' occurs due to reduced job search efforts on behalf of the participant. Thus even though we correct for several significant participant characteristics we still find that the unemployment rate at time of inflow matters for the duration spent in the WGP. This supports our impression from Table 3.3 that unobserved participant characteristics vary with the size of the pool of unemployed.

\subsection{Performance of the WGP}

We now turn to assessing the performance of the WGP. To assess the performance, we need to conduct a counterfactual analysis, i.e. what would have happened - in terms of labor market outcome - to participants if they had not joined the WGP? To conduct such a counterfactual analysis we apply the nearest neighbor matching technique - see Dehejia and Wahba (2002) for its theoretical validity.

We use data from the Labor supply panel, which is collected bi-annually by the Netherlands Institute for Social Research since 1985. The labor supply panel is a representative sample of the Dutch labor force - see Fouarge et al. (2006). Since it is rotating, we can track respondents and trace changes in their labor market position. Information on gender, age, residence, unemployment duration and educational attainment is readily available. Moreover, this information is consistently available for the period for which we have information on WGP participants. We therefore decide to exploit this data to conduct the matching estimator analysis.

First, we need to establish the length of the period between start of the WGP program and the time at which the WGP participant is interviewed about their job find success. We find that the mean treatment period for WGP participants is 12.6 months. The small standard error (0.19 months) indicates that variation in program participation length is rather small. Consequently, we assume that every WGP participant will stay in the program for 12.6 months. Since Philips interviews program participants six weeks (equivalent to 1.4 months) after concluding the program, the average time between starting program participation and the job find interview is 14 months. Therefore, to ensure accurate matching, we simulate this time window for our control group, i.e. respondents from the labor supply panel exploiting retrospective information in the questionnaire. We conduct this procedure for the labor supply panels for the years 1994, 1996, 1998, 2000, 2002, 2004, 2006 and 2008 (using 2008 to establish transition rates only, discarding any panels prior to 1994), to collect a group of unemployed who can serve as a control group in our analysis. We ensure that 
respondents from the labor supply panel can only enter once in our control group (we select the first entry and discard any subsequent entries).

We end up with a group of 384 unemployed who constitute our control group, while we have 780 WGP participants, who have been exposed to the treatment. Table 3.6 gives descriptive statistics of the variables we will use in our matching estimator. We note that WGP participants experience slightly longer uncompleted spells of unemployment, have slightly higher educational attainments, are concentrated in southern Netherlands and are more likely male and younger. Finally, we note that the average job find rate of WGP participants is higher.

Table 3.6: Descriptive statistics of matching variables (mean values)

\begin{tabular}{l|cc}
\hline \hline Matching variables & WGP participants & Non WGP participants \\
\hline Unemployment duration: & & \\
6 months or less & 0.26 & 0.33 \\
6 months - 1 year & 0.26 & 0.19 \\
1 year - 2 years & 0.21 & 0.20 \\
more than 2 years & 0.26 & 0.28 \\
& & \\
Educational attainment: & & 0.11 \\
Primary school & 0.08 & 0.40 \\
Lower vocational & 0.28 & 0.28 \\
Middle vocational & 0.37 & 0.14 \\
Higher vocational & 0.17 & 0.08 \\
University & 0.10 & \\
& & 0.16 \\
Spatial identifier: & & 0.22 \\
Northern Netherlands & 0.22 & 0.36 \\
Eastern Netherlands & 0.16 & 0.26 \\
Western Netherlands & 0.01 & \\
Southern Netherlands & 0.62 & 0.39 \\
Gender: & & \\
Male & & \\
Female & 0.55 & 0.59 \\
Age: & 0.45 & \\
Average & & \\
Job find rate: & & \\
After 14 months & 0.55 & \\
& & \\
\hline \hline
\end{tabular}

To perform this matching estimator, we need to impose the number of matches (in the control group) for each treated respondent. This choice is a trade off between similarity of respondents in the control group to the treated respondents and robustness 
of the comparison. That is, a high number of required matches ensures robustness of the comparison, but we may start including control group respondents who are not that similar any more to the treated respondents as the nearest neighbor is. We follow Abadie and Imbens (2002) and set the number of matches equal to 4. Since the sample size of the treatment group is larger than the sample size of the control group, we also tried lower levels of required matches. Lower level of required matches do not change our results in a significant manner. Finally, since we are testing the success of an existing program, we present the sample average treatment effect.

Table 3.7 contains the results, in which we progressively add matching variables. We start with the vacancy rate (to control for business cycle differences over time) and year dummies (to control for potential institutional changes throughout the time window). Adding more matching variables to the matching procedure gives some expected effects:

- Program participants are more often male, which in those years made them more employable, ceteris paribus, lowering the treatment effect.

- Program participants are younger, which made them more employable, ceteris paribus, lowering the treatment effect.

Table 3.7: Measuring WGP treatment effect using nearest neighbor matching technique

\begin{tabular}{l|lc}
\hline \hline Matching variables & \multicolumn{2}{|l}{ Sample average treatment effect } \\
\hline (1) Vacancy rate and year & $0.30 * * *$ & $(0.04)$ \\
$(2):(1)+$ unemployment duration & $0.29 * * *$ & $(0.041)$ \\
$(3):(2)+$ educational attainment & $0.31 * * *$ & $(0.037)$ \\
$(4):(3)+$ regional identifier & $0.29 * * *$ & $(0.038)$ \\
$(5):(4)+$ gender & $0.23 * * *$ & $(0.040)$ \\
$(6):(5)+$ age & $0.18 * * *$ & $(0.041)$ \\
Sample size (WGP participants) & \multicolumn{2}{|c}{$1,164(780)$} \\
\hline \hline
\end{tabular}

Once we include the complete set of control variables, we note a statistically significant positive average treatment effect of 0.18. Since our outcome variable is: [0] unsuccessful in finding employment; [1] successful in finding employment, the coefficient is the percentage point difference to find employment between participation 
and non-participation in the WGP program. Consequently, we find that the WGP lifts the job find rate of participants by 18 percentage points.

The above analysis refers to persons in the control group who may have benefitted from public treatment programs other than (public) employment, such as job search assistance, job counseling and training. Groot et al. (2008) show that if public reintegration treatment for unemployed persons is started in the first year, the job find probability within 1.5 years increases by 0.9 percentage points. This implies that our finding of an increased probability of finding a job of 18 percentage points due to participation in the WGP is not seriously affected by the composition of the control group with respect to participation in a reintegration program. It also implies that the impact of the WGP is much larger than the impact of participating in a public reintegration program - see also the discussion in the introduction.

\subsection{What are the benefits to the firm?}

There are a number of possible benefits for the firm running a private employment program. The first possible benefit to the firm is that the WGP might serve as a fruitful recruitment channel. Table 3.8 provides some quantitative evidence that supports this notion. We constructed a subset of participants who found a job after their WGP treatment and added a dummy with value ' 1 ' if this was a job with Philips, or a value of ' 0 ' for a job elsewhere. This allows us to identify which type of participants Philips favors to offer a regular job. In terms of independent variables we use a similar structure as in Table 3.3.

We find that the unemployment rate at time of inflow negatively correlates with employment prospects at Philips. To understand this finding, we need to go back to Figure 3.4, which among others depicts the share of participants that find a job at Philips over time. We note that this share is fairly stable (especially for the 1999 - 2007 period, which is the relevant time window for the regression above), while the share of participants that find employment elsewhere fluctuates heavily. We therefore assume that Philips has a policy of recruiting a stable share of WGPparticipants. We know from Tables 3.4 and 3.5 that if unemployment at time of inflow is high, participants have higher educational levels and experience lower unemployment duration. Consequently, they should have better job prospects regardless of program participation. Therefore, the share of participants that find a job elsewhere (i.e. not with Philips) will increase when the unemployment rate at time of inflow increases. This in turn implies, that the share of participants who find a job with Philips in total participants who find a job, decreases when the unemployment rate at time of inflow increases.

Further, we note that Philips is less likely to employ participants whose highest level of education is primary school. Other variables including age, gender and unemployment duration do not play a major role in the firm's decision to recruit 
Table 3.8: Who stay with Philips?, 1999 - 2007

\begin{tabular}{|c|c|c|}
\hline & Job wit & Philips \\
\hline $\begin{array}{l}\text { Unemployment at time of outflow } \\
\text { Unemployment at time of inflow } \\
\text { Age } \\
\text { Gender }\end{array}$ & $\begin{array}{l}0.02 \\
-0.26 * \\
-0.02 \\
-0.04\end{array}$ & $\begin{array}{l}(0.14) \\
(0.14) \\
(0.01) \\
(0.12)\end{array}$ \\
\hline $\begin{array}{l}\text { Prior Education: } \\
\text { Primary School } \\
\text { Low level vocational / secondary } \\
\text { Middle level vocational / secondary } \\
\text { High level vocational } \\
\text { University }\end{array}$ & $\begin{array}{l}\text { reference } \\
\quad 0.56 * \\
0.50 * \\
0.19 \\
0.80 * * *\end{array}$ & $\begin{array}{l}(0.29) \\
(0.28) \\
(0.31) \\
(0.31)\end{array}$ \\
\hline $\begin{array}{l}\text { Unemployment status } \\
\text { Unempl. duration (if unempl.): } \\
\text { 0-6 months } \\
\text { 6-12 months } \\
12-24 \text { months } \\
24-48 \text { months } \\
48+\text { months }\end{array}$ & $\begin{array}{l}-0.19 \\
\text { reference } \\
0.14 \\
-0.24 \\
-0.03 \\
-0.07\end{array}$ & $\begin{array}{l}(0.18) \\
(0.22) \\
(0.22) \\
(0.25)\end{array}$ \\
\hline $\begin{array}{l}\text { Age group (if unemployed): } \\
\text { Age 16-30 } \\
\text { Age } 31-40 \\
\text { Age } 41-50 \\
\text { Age } 51+\end{array}$ & $\begin{array}{l}\text { reference } \\
0.20 \\
0.26 \\
0.93 * *\end{array}$ & $\begin{array}{l}(0.22) \\
(0.33) \\
(0.47)\end{array}$ \\
\hline Constant & 0.00 & $(0.59)$ \\
\hline Sample size & \multicolumn{2}{|c|}{552} \\
\hline
\end{tabular}

participants subsequent to program completion. Consequently, Philips uses educational attainment to select participants for post program employment, whereas age, gender en unemployment duration play only minor roles. Obviously, since Philips is able to monitor participants for a year, it may use other indicators (like motivation) which remain unobserved in our analysis.

Another benefit is that running a private program for unemployed fits perfectly in today's era of corporate social responsibility and as such brings the firm some positive externalities. This proposition featured amongst others, in a questionnaire we sent to 69 Human Resource Managers of Philips Netherlands. We asked to what extent corporate social responsibility, the added recruitment channel and improved 
union relations are perceived as reasons why Philips runs the WGP. The results are summarized in Table 3.9, which shows that the distribution for all three reasons is left-skewed.

Table 3.9: Reasons important to run the WGP

\begin{tabular}{l|ccccc}
\hline \hline N=33 & \multicolumn{5}{|c}{ Very unimp. Unimportant Neutral Important Very important } \\
\hline & & & & & \\
Corp. social responsibility & $0 \%$ & $0 \%$ & $3 \%$ & $27 \%$ & $70 \%$ \\
Added recruitment channel & $6 \%$ & $18 \%$ & $18 \%$ & $48 \%$ & $9 \%$ \\
Improved union relations & $15 \%$ & $9 \%$ & $39 \%$ & $33 \%$ & $3 \%$ \\
& & & & & \\
\hline
\end{tabular}

This suggests that the WGP benefits the firm in terms of showing corporate social responsibility, improved unions relations and an added recruitment channel, underscoring the finding from Table 3.8. Especially in the Netherlands with its culture of centralized wage bargaining, the value of good union relations is vital. A last benefit of this program is that it is used to dampen productivity losses through the so called 'combi-project'. This means that the participant can temporarily replace a regular employee at times when the latter is away for training. This also implies that the work experience the participants gets is as close to regular as can be.

\subsection{Concluding remarks}

The chapter explored whether a pure private employment program is beneficial to both unemployed workers and firms. To this end we analyzed the effectiveness of a large Dutch firms' employment program: the Philips employment scheme (WGP). We find an average treatment effect of 18 percent, which means that the average program participant has a 18 percentage point higher job find probability than an unemployed person who did not participate in the program, but otherwise similar characteristics. The private program uses a carefully designed selection process, in which the focus on the unemployed who need the treatment most is securely anchored. Additionally, the treatment itself entails various private components of which the relative effectiveness has already been established in the literature and confirmed by this chapter. The most important of these is that the work experience gained during the treatment resembles a regular job as closely as possible which provides a direct way of signaling one's capabilities to future employers. Interesting from both a business and policymaker's perspective is that running a private employment program also brings benefits to the firm. Evidence presented in Section 3.5 shows that the program serves as a fruitful recruitment channel, contributes to the firm's image of corporate social responsibility, helps improve union relations and can dampen productivity losses that occur when regular staff receives off-the-job training. 


\section{Appendix I: Data on individuals in the WGP}

In this chapter we use three datasets. One dataset based on yearly aggregates as summarized in Table 3.1 and two datasets with individual data. We describe the two latter datasets in this appendix. The first dataset contains data on 8928 individual participants of the WGP. This dataset was originally extracted from Philips' administrative systems and is the most integral collection of WGP participants available, containing 75 percent of all WGP participants ever. On the other hand we obtained data on 1038 former WGP participants surveyed six weeks after the end of their WGP treatment in the period 1997-2007. Both datasets are described briefly below.

\section{'8900 dataset'}

This large sample size comes with a trade-off since the information we have per participant is limited to a number of 'bread and butter' variables. Table 3.10 summarizes the most important variables in this dataset. Looking at the various

Table 3.10: Summary of main variables '8900 dataset'.

\begin{tabular}{lcccrr}
\hline \hline Variable (N=8928) & N & Mean & Std. Dev. & Min & Max \\
Startyear WGP treatment & & & & & \\
Endyear WGP treatment & 8928 & & & 1983 & 2009 \\
Duration WGP treatment (months) & 8712 & & & 1983 & 2009 \\
Age & 8712 & 10.0 & 4.5 & 0 & 24 \\
Level of prior education (years of school) & 8928 & 28.5 & 8.2 & 16 & 60 \\
& 7150 & 10.3 & 2.9 & 6 & 16 \\
\hline & $\mathrm{N}$ & Male & Female & & \\
Gender & 8928 & 5187 & 3741 & & \\
Residential address & 8928 & & & & \\
\hline
\end{tabular}

statistics in the table, especially the means and standard deviations, we can state that the WGP inflow is quite heterogeneous. Moreover, although this was never recorded accurately enough to be used as a variable, we know from working with the data and from qualitative sources that there is also a large variation in ethnicity of participants. The level of prior education was originally defined in eight categories specific to the Dutch education system. Table 3.11 provides the number of WGP participants from each educational background. For later analysis we translated these categories into 'years of school' as shown in the last column.

\section{'Questionnaire dataset'}

The most detailed information on individuals who have participated in the WGP comes from the 'Questionnaire dataset'. This dataset stems from Philips databases in which 
Table 3.11: Prior education level of WGP participants.

\begin{tabular}{llrrr}
\hline \hline Prior education & N & \multicolumn{1}{c}{ Years of school } \\
\hline LO (Primary school) & \multirow{2}{*}{ LO + LBO: Primary } & 1280 & 17.9 & 6 \\
LBO (Low level vocational) & 1581 & 22.1 & 9 \\
MAVO (low level secondary) & & 1022 & 14.3 & 10 \\
MBO (middle level vocational) & \multirow{2}{*}{ MAVO - VWO: Secondary } & 1302 & 18.2 & 10.5 \\
HAVO (middle level secondary) & & 466 & 6.5 & 11 \\
VWO (top level secondary) & & 183 & 2.6 & 12 \\
HBO (high level vocational) & \multirow{2}{*}{ H HBO + WO: Tertiary } & 813 & 11.4 & 15 \\
WO (university) & & 503 & 7.0 & 16 \\
\hline
\end{tabular}

the returned questionnaires are stored. It contains the answers of 1038 former WGP participants surveyed six weeks after the end of their WGP treatment. We observe 1038 participants since we could only retrieve the individual questionnaires sent out in the years 2000 to 2007. This includes persons who started their WGP treatment in 1997 and ended it in 1999. The average response to the questionnaire was 59 percent. Table 3.12 summarizes the main variables.

Table 3.12: Summary of main variables 'Questionnaire dataset'.

\begin{tabular}{|c|c|c|c|c|c|c|c|}
\hline$\overline{\text { Variable }(\mathrm{N}=1038)}$ & $\mathrm{N}$ & Mean & Std. Dev. & Min & Max & & \\
\hline Startyear WGP & 1038 & & & 1997 & 2006 & & \\
\hline Endyear WGP & 1038 & & & 1999 & 2007 & & \\
\hline Age & 1038 & 35.2 & 9.6 & 17 & 58 & & \\
\hline Prior education (years of school) & 1012 & 11.6 & 2.8 & 6 & 16 & & \\
\hline Unemployment before WGP & $\begin{array}{c}\mathrm{N} \\
1025 \\
\end{array}$ & $\begin{array}{c}\text { n.r. } \\
18.2 \% \\
\end{array}$ & $\begin{array}{c}<6 \mathrm{~m} \\
21.7 \% \\
\end{array}$ & $\begin{array}{l}6-12 \mathrm{~m} \\
20.6 \%\end{array}$ & $\begin{array}{c}12-24 \mathrm{~m} \\
17.6 \% \\
\end{array}$ & $\begin{array}{c}24-48 \mathrm{~m} \\
11.7 \% \\
\end{array}$ & $\begin{array}{l}>48 \mathrm{~m} \\
10.2 \% \\
\end{array}$ \\
\hline Job 6 weeks after WGP & $\begin{array}{c}\mathrm{N} \\
1022\end{array}$ & $\begin{array}{c}\text { Yes } \\
\text { Philips } \\
13.6 \%\end{array}$ & $\begin{array}{c}\text { Yes } \\
\text { Elsewhere } \\
20.6 \%\end{array}$ & $\begin{array}{c}\text { Yes } \\
\text { Temp } \\
21.8 \% \\
\end{array}$ & $\begin{array}{c}\text { No } \\
\text { Study } \\
3.0 \%\end{array}$ & $\begin{array}{c}\text { No } \\
\text { No } \\
41.0 \%\end{array}$ & \\
\hline Gender & $\begin{array}{c}\mathrm{N} \\
1038\end{array}$ & $\begin{array}{c}\text { Male } \\
55.6 \%\end{array}$ & $\begin{array}{c}\text { Female } \\
44.4 \%\end{array}$ & & & & \\
\hline WGP location/Philips outlet $^{a}$ & 1035 & & & & & & \\
\hline
\end{tabular}

The substantial variations in age, prior education and unemployment duration confirm the heterogeneity of participants observed in Table 3.10. In addition to the variables reported in the table, the 'Questionnaire dataset' contains data on participant satisfaction with the WGP treatment and answers to questions that enquire about the intensity of supervision participants received from both Philips as well as the Labor Office.

In Gerards et al. (2010) we show that this can be considered a representative sample of the large '8900 dataset' as it displays very similar movements in gender and 
age composition of participants. Due to differences in how prior education was defined in both datasets, we could not construct a reasonable comparison of this characteristic (even though we managed to translate them both into 'years of education'). In the '8900 dataset', prior education was classified in 8 levels whereas the classification in the 'Questionnaire dataset' contained only 5 levels. Especially the lower education levels were more compressed into aggregates in the 'Questionnaire dataset', leading to less accuracy there. 



\section{The effects of firm sponsored general training on low skilled workers}

\subsection{Introduction}

Low skilled workers have been facing a growing wage inequality compared to high skilled workers for the past 25 years (Machin, 2008) as well as a higher risk of becoming unemployed (eg. Oesch (2010) and Gesthuizen, Solga and Kunster (2010)). Low skilled workers need to be trained in order to improve their labor market position. Based on seventeen years of panel data from administrative company records, this article estimates the effects on wage, job promotions, job performance and involuntary job separations of a firm sponsored vocational training program for low skilled workers. Using an Instrumental Variables (IV) approach exploiting variation in training supply I find significant positive effects of training completion on wages and job promotions and a negative relation between training completion and the chance of an involuntary job separation (getting fired).

There is a substantial body of literature on the effects of firm sponsored training on wages (for instance Goux and Maurin (2000), Kuckulenz and Zwick (2004), Leuven and Oosterbeek (2008) and Dostie (2010)). However, as noted in 2004 by Asplund and Salverda and again in 2009 by Cuesta and Salverda, there are only very few papers that focus on the effects of firm sponsored training on low skilled workers.

This chapter adds to this small literature on the effects of firm sponsored (general) training for low skilled workers. The data I have exhibit a number of interesting features. First, it is administrative company data. The main advantages and disadvantages of the use of company data are outlined by Bartel (1995). An advantage of using (administrative) company data is that it eliminates problems of self-reported information because the training participation and further details are recorded systematically. Moreover, by studying a specific training program within one firm, a bias stemming from different definitions of training across firms is avoided. 
However, the main drawback of a company study is that generalization of the results to other companies may be limited (Bartel, 1995).

The second distinguishing feature of this chapter is that the data cover a comparatively long time-span. They include seventeen years of wage information (1995-2011) and eleven years of job performance information (2001-2011) allowing me to study the effects of training on these outcome variables over time. Furthermore, seventeen years of data on the job-level of the included workers is available, which makes it possible to study the effect of training on job promotion within the firm.

Third, I measure training completion. Most papers distinguish 'training' from 'not training', whereby it is usually not defined whether 'training' means participation in training (and possibly dropping out at some point) or the successful completion of training. Participants that complete the training obtain a vocational qualification which is widely recognized.

The remainder of this chapter is structured as follows. Section 4.2 presents a short literature background followed in section 4.3 by a description of the training program I analyze. This program is the Philips Vocational Qualification Program (VQP), run by Philips Electronics Netherlands. Section 4.4 describes the data and the analysis methods are discussed in section 4.5. The results of the estimations are presented in section 4.6. Section 4.7 concludes.

\section{$4.2 \quad$ Literature}

\subsubsection{Training, wages, job performance and employability}

Most articles that study the effects of training focus on wages/earnings as dependent variable of interest. Articles that study the effects of training on job promotions, job performance and job separations are much less common although some studies that analyze the effects of training on wages, also incorporate one or more of these other outcome variables. In general, a positive relation between training and wages has been shown in several papers such as Bartel (1995), Booth and Bryan (2002), Kuckulenz and Zwick (2004) and more recently Dostie (2010). A positive effect of training on job performance is found in for instance Bartel (1995), Krueger and Rouse (1998) and Jones, Jones, Latreille and Sloane (2009). With regard to the effects of training on firm-internal mobility, Pfeifer, Janssen, Yang and Backes-Gellner (2011) who use personnel data of a sample of a German firm's blue collar workers, find a positive relation between (longer) training spells and internal promotions. Sanders and de Grip (2004) analyze two waves of the Dutch OSA Labor Force Survey and find that training increases employability of low skilled workers in firm internal labor markets. Finally, Picchio and van Ours (2011) show that training lowers the probability of being out of the workforce in the period after training. Thus training is often shown to be positively related to the trained workers' wages, job performance and employability.

As noted in the introduction, there is little literature that specifically analyzes the 
effects of training for low skilled workers. For low skilled workers, Cuesta and Salverda (2009) show that human capital investment through formal education and on-the-job training increases the chances to get a higher paid job and reduces the chance of moving to a non-employment situation. Pavlopoulos, Muffels and Vermunt (2009) use data from the Dutch Socio-Economic Panel (SEP) and find similar outcomes as Cuesta and Salverda (2009). Unfortunately their data did not allow to distinguish between firm sponsored or employee paid training, nor between general or specific training. Krueger and Rouse (1998) is one of the few papers that use company data to study a workplace education program for low skilled workers. Although they find a positive relation between training and wage growth, a causal relation could not be proven and the training is argued to be specific in nature. Finally, the above mentioned papers by Sanders and de Grip (2004) and Pfeifer et al. (2011) focus on low skilled workers.

Based on the findings from the articles outlined above, I expect to find positive effects of training on wages, job promotions, job performance and firm internal employability, for workers who complete the VQP training.

\subsubsection{General vs. specific training and the focus on low skilled workers}

As the training program I analyze leads to a widely recognized vocational qualification, it is at odds with the predictions of Becker (1962) that the firm sponsors this training and that workers have to pay no part of it. Becker distinguishes between general and specific training, which is one of the basic tenets of human capital theory. The skills acquired through specific training are assumed to be useful only in the firm where the training takes place, whereas the skills acquired through general training are transferable to other firms. The standard theory predicts that firms are not willing to pay for general training, as the trained worker could quit and take their new and transferable skills with them to another firm (Becker, 1962).

However, research over the past decades has provided ample empirical evidence and accompanying theoretical explanations of firms investing in general training. Most of this later research has focussed on models with varying forms of imperfectly competitive labor markets as opposed to the assumption of perfectly competitive labor markets by Becker (eg. Katz and Ziderman (1990), Stevens (1994), Acemoglu and Pischke (1998, 1999a and 1999b), Lazear (2009), Booth and Katic (2010). Overviews are available in e.g. Leuven (2005) and Asplund (2005)). ${ }^{1}$ Given all this evidence, the existence of firm sponsored general training appears to be a well established phenomenon. However, most of these studies focus on training of high skilled workers

\footnotetext{
${ }^{1}$ One example of imperfect competition: Katz and Ziderman (1990) discuss the possibility of information asymmetry between the employer that offers the worker training and other firms. Other firms (that may want to recruit the worker) may not be able to exactly assess how much training and of what type the worker has received. Therefore their wage offer will not fully incorporate the value of this training and will reduce the likelihood that the worker can be enticed to switch employer. Thus the worker's current firm who is fully aware of the worker's increased marginal productivity gets to keep the worker at a wage between below the marginal product but above what an outside firm would offer.
} 
or on a panel of workers containing all skill levels, not specifically on low skilled workers. This chapter adds to this literature by confirming that firm sponsored general training also exists when the general training is focussed only on low skilled workers.

\subsection{The Vocational Qualification Program}

Since 1983, Philips (a Dutch multinational known amongst others by its household appliances, lighting products and medical systems) has run the Philips Employment Scheme (PES) in which long-term unemployed are offered a year of training and workexperience within the Philips organization, after which their employability is greatly improved (see Gerards, Muysken and Welters (2010) for a detailed analysis of the PES). The Vocational Qualification Program (VQP) builds on the knowledge and experiences from training unemployed in the PES and was initially (in the year 2000) aimed at roughly 2,400 low skilled employees. Many of these workers have more than a decade of experience but they lack a formal qualification or have a qualification which is too low to be competitive in the current labor market. In specific (Dutch) terms, they lack a 'start-qualification'. For a better understanding of the VQP I elaborate shortly on the concept of 'start-qualification' and present some statistics pertaining to the Dutch situation.

The concept of 'start-qualification' is used in the Netherlands to provide a formal classification of when someone is adequately skilled for the labor market. The startqualification is defined as the minimum level of education required to fully sustain oneself in the labor market or to continue in higher education. This is set to a successfully completed education on level 2 of the 'WEB' education legislation ('Dutch: Wet Educatie en Beroepsonderwijs (WEB)'), which corresponds to the international standard classification of education 'ISCED 3C short'. The number of years one must spend in school without flunking to reach this level varies from 11 to 12 years depending on the education type. Moreover, almost 23 percent of the labor force in the Netherlands has no start-qualification as of 2010 (Statistics Netherlands (2010)).

Figure 4.1 illustrates the relatively weak labor market attachment of those without a start-qualification. It shows the percentages of persons that are unemployed within those parts of the labor force with and without a start-qualification for the period 20022010. In this period, the unemployment rate for persons without a start-qualification is on average 3.6 percentage points higher than for those who have a start-qualification. This means the probability of being unemployed is almost twice as high without a startqualification. Additionally, the dotted line shows that when unemployment rises, it rises faster among those without a start-qualification. This means that the relative labor market position of these workers worsens during recessions. This is confirmed by De Vries, Wolbers and van der Velden (2004) who find that during recessions the start-qualification shifts from WEB level 2 to level 3 (ISCED 3C short to ISCED $3 \mathrm{C}$ long). In addition, they conclude that persons without a start-qualification more 
frequently find themselves in jobs with a relatively low job security and little new job opportunities (De Vries et al., 2004).

Figure 4.1: Unemployment rate for workers without and with start-qualification.

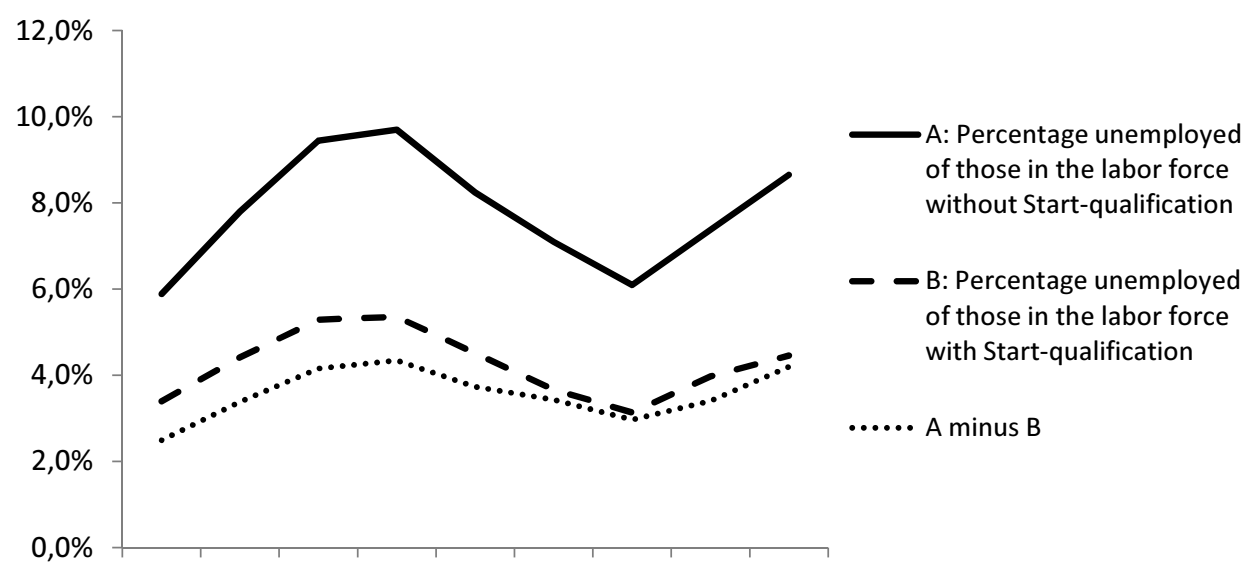

200220032004200520062007200820092010

Source: Statistics Netherlands, Labor Force Survey (EBB)

The goal of the VQP is to train the low skilled but experienced workers within Philips to meet the current skills demands of Philips as well as from the external labor market. Ultimately, all targeted workers should obtain a training certification on at least start-qualification level. From the start of the VQP in 2002 till June 2010, 1,508 employees gained a start-qualification and 525 workers were still in training or slated to start and finish before Summer 2011. The program is supported by the trade unions and a program framework is anchored in the collective labor agreement between Philips and the unions. Within the scope of this framework, local Philips plants can tailor the program to the specific training needs of their low skilled workers. The program is sponsored by Philips and receives partial funding from the European Social Fund ${ }^{2}$. All employees without a start-qualification were automatically eligible for the VQP. Local plant managers were responsible for the practical implementation of the VQP in their plant. Therefore there is no uniform policy how to determine which workers are trained first when training capacity is limited. In some cases workers will have had a pro-active role in being among the first to be trained, in other cases management has allocated the workers into training on a variety of managerial grounds. As I observe participants from all outlets there is no dominant selection mechanism present in the data. Furthermore, I attempt to avoid selectivity issues by using an IV approach to estimate the training participation as explained in section 4.5.

\footnotetext{
${ }^{2}$ The European Social Fund is one of the EU's Structural Funds aiming to promote employment in Europe. It is one of the instruments with which the EU supported the 2000-2006 Lisbon Strategy and for 2007-2013 one of the the ESF's goals is to increase lifelong learning (Hale, 2007).
} 
The training is tailored to the needs and abilities of the individual workers and consists of both on-the-job training and classroom training. Training takes place during normal working hours, with the exception of some theoretical homework. As the exact details of training vary between workers, the duration of the training also varies. Some workers have their training spread over two years to obtain the skills and knowledge required to graduate with a certificate on start-qualification level. On the other hand, workers with at least two years of work experience are often eligible for a pre-training assessment using 'Accreditation of Prior Learning' (APL). This method tests both onthe-job and theoretical skills to determine if a worker can be exempted from certain training modules. For a limited number of workers (4.3\%) the APL method led to an instant certification on start-qualification level without any further training, as their experience and knowledge was on par with the formal diploma requirements.

\subsection{Data}

The data originate from two sources. Training details such as start date, end date and details on completion of the training are recorded by the outlets where participants were trained. Further data such as age, gender and wage development are obtained from the centralized personnel administration. Wages are available on a yearly basis since 1995. Therefore I am able to construct a panel dataset consisting of 973 individuals up to seventeen years. This panel is unbalanced, as not all individuals have been working at Philips since 1995. For several reasons the data do not include the entire population of workers that were identified as low skilled in 2000. First, between 2000 and the actual start of the VQP in 2002 (and from 2002 onwards), the size of the population has continuously changed. The sale of parts of the company such as the sale of the Philips Semiconductors branch to NXP in 2006, involving in total 6.000 workers, and plant closures have led to a decline in the number of workers at Philips across all layers of the organization, including some of the initially identified low skilled workers. Second, due to the plant level tailoring of the program, training details had to be collected and aggregated from numerous reports and databases which were quite heterogeneous in their content and not always usable for analysis. These reductions in sample size are not selective with respect to individual workers' characteristics. Therefore, there is no reason to assume that the final sample of 973 workers is biased by selective dismissals or selective data availability ${ }^{3}$.

\footnotetext{
${ }^{3}$ Another possible source of selection bias can originate from the fact that we only observe and compare workers who train and subsequently stay with the company and workers who do not train and stay with the company. We do not analyze workers who train and shortly thereafter leave the company or persons who do not train and leave the company shortly after the first opportunity at training was offered (in 2002). However, analysis of job separations shows that more than $90 \%$ of the trained workers stay with the company for the entire length of our dataset and another $6.5 \%$ of the trained workers stay with the company for at least several years and are thus included in our analysis. The remaining $2.5 \%$ of the trained workers that do leave the company shortly after finishing the training have largely similar characteristics as the observed $6.5 \%$ that leave several years after
} 


\subsubsection{Descriptives}

Table 4.1: Descriptive statistics of sample

\begin{tabular}{|c|c|c|c|c|c|}
\hline Variable & $\mathrm{N}$ & Mean & Std. Dev. & Min & Max \\
\hline Yearly wage* & 973 & 21,123 & 3,929 & 5,360 & 50,215 \\
\hline Job-level* & 973 & 27.2 & 5.62 & 0 & 50 \\
\hline Performance rating* & 956 & 3.17 & 0.70 & 1 & \\
\hline Year & 973 & 2004 & 4.73 & 1995 & 2011 \\
\hline Gender & 973 & 0.23 & 0.41 & 0 (male) & 1 (female) \\
\hline Age (in 2002) & 852 & 38.75 & 6.64 & 19 & 56 \\
\hline Years of education & 973 & 9.39 & 1.01 & 8 & 13 \\
\hline Marital status & 973 & 0.64 & 0.48 & non-married) & 1 (married) \\
\hline Tenure (in 2002) & 852 & 13.75 & 8.36 & 0 & 35 \\
\hline Part-time factor & 973 & 88.77 & 12.90 & 37.5 & 100 (full-time) \\
\hline Shift work dummy & 973 & 0.53 & 0.50 & 0 (regular) & 1 (shift work) \\
\hline
\end{tabular}

*Average over time per individual

For variables that increase with one step yearly (age and tenure) I present the 2002 value. Some individuals only work at Philips since 2002, therefore $\mathrm{N}$ is smaller for age and tenure.

Table 4.1 summarizes the main variables. These descriptive statistics depict the average individual in this sample as middle aged, predominantly male, with substantial tenure and more often than not working in shifts. The mean education level is 9.4 years which correspond to ISCED level 2. This is two to three years less than the startqualification at 'ISCED 3C short', which takes 11 to 12 years of education to reach. The mean of the average yearly wage between 1995 and 2011 amounts to 21,123 euro which is significantly below the average yearly wage of 27,687 euro for an 'Average Joe' over the same period in the Netherlands. ${ }^{4}$ These characteristics confirm that the VQP targets those in danger of being economically marginalized (see for example Gesthuizen and Wolbers (2010), Gesthuizen and Scheepers (2010) and Gesthuizen et al. (2010) for recent studies on vulnerability of low educated workers in the Netherlands and Europe.)

Table 4.2 shows the status of the individuals in our sample with respect to the VQP training. Fifty percent of the individuals in our sample had completed the training and obtained a vocational qualification. The age, gender and tenure statistics of this group are quite representative of the average individual as portrayed by the bottom row of the table which provides the overall means. Noteworthy are the above average wage, age, percentage of males and tenure in the group that directly obtained a

finishing the training and are thus not likely to cause selectivity problems. Of the untrained workers, none left the company shortly after 2002 thus there are no unobserved workers here.

${ }^{4}$ Calculated from Netherlands Bureau for Policy Analysis (CPB): Macro Economic Outlook 2011 (CPB, 2010). 
Table 4.2: Training status of sample

\begin{tabular}{|c|c|c|c|c|c|c|c|c|}
\hline Training status & $\mathrm{N}$ & $\%$ & $\begin{array}{c}\text { Mean } \\
\text { wage in } \\
2002\end{array}$ & $\begin{array}{l}\text { Mean } \\
\text { age in } \\
2002\end{array}$ & $\begin{array}{c}\% \\
\text { males }\end{array}$ & $\begin{array}{c}\text { Mean } \\
\text { years of } \\
\text { educ. }\end{array}$ & $\begin{array}{c}\text { Mean } \\
\text { tenure } \\
\text { in } 2002\end{array}$ & $\begin{array}{c}\text { Mean } \\
\text { part-time } \\
\text { factor }\end{array}$ \\
\hline 1. Completed & 486 & 50.0 & 20,014 & 38.3 & 75.3 & 9.5 & 13.1 & 89.8 \\
\hline 2. Direct diploma by APL & 55 & 5.7 & 22,187 & 40.7 & 96.4 & 9.0 & 16.7 & 93.8 \\
\hline 3. Dropped out & 106 & 10.9 & 20,174 & 38.2 & 87.7 & 9.2 & 13.1 & 88.1 \\
\hline 4. Currently in training & 194 & 19.9 & 20,265 & 37.7 & 78.9 & 9.6 & 12.4 & 86.9 \\
\hline 5. Does not want to & 52 & 5.3 & 20,539 & 40.6 & 65.4 & 9.0 & 16.1 & 87.7 \\
\hline 6. Has no qualification & 80 & 8.2 & 20,842 & 41.4 & 58.8 & 8.9 & 17.0 & 84.7 \\
\hline Total / Mean & 973 & 100 & 20,310 & 38.8 & 76.7 & 9.4 & 13.8 & 88.8 \\
\hline
\end{tabular}

vocational qualification by way of an APL procedure. This makes intuitive sense as an APL procedure assesses competencies an individual has developed and acquired over time and hence older more experienced workers (which are often males due to their traditionally stronger labor market attachment than women) are more likely to have developed all the competencies for a direct certification. Two other groups that deviate from the averages are those who do not want to train and those without qualification. Both groups are older and have more tenure and wage than average and these groups consist of relatively more women and exhibit a higher frequency of less than full-time work than the groups that have completed training. Finally, consider the drop-outs who are slightly younger than average, have the somewhat less tenure than average and a slightly below average amount of contractual working hours. Details on the reasons for dropping out are not available (on the individual level).

\subsubsection{Dependent variables}

\section{Wages}

I observe yearly wages from 1995 to 2011. Every year wages at Philips are collectively adjusted with an official wage increase percentage resulting from the collective bargaining negotiations. For analyses performed in section 5.4, I derived real wages, using the official yearly wage increases as a deflator. As I only analyze Philips employees, using the actual collective wage bargaining percentage increase is a more accurate correction for yearly trends in wages than using the Dutch inflation rate. This procedure makes all wages comparable to 1995.

\section{Job-level}

The second dependent variable I observe over time is the job-level of the job the individual performs. Job-levels range from 0 to 90 and the higher the number the higher the job. To reach job-level 50 and onwards, one needs to have tertiary education. 
Within each job-level there is a range of wages a worker can earn, usually depending on experience or tenure in that job. This type of structure is common in many public and private sector organizations where there are several 'salary-scales' each with many wage positions (steps) on the scale. In many such cases workers rise through these positions with tenure but only jump to a higher 'salary scale' when they get promoted. A common feature which is also present in our case, is that two neighboring salary scales (in our case job-levels) have a largely overlapping structure of wage positions, but that the higher of the two job-levels offers higher wages in the top positions within that level. Figure 4.3 in Appendix II graphs the relevant part of the wage structure at Philips. The increases in job-level present in the data, represent real promotions with a higher possible end salary as tenure continuous to grow. In the case of the low-skilled workers that are subject of this chapter, even a move from job-level 25 to 27 (an increment of 2 is the smallest possible) is considered a serious promotion and comes with increased status and higher wages in the top wage steps. This information can be used to analyze the relation between workers' training and their firm internal mobility.

\section{Performance rating}

In addition to wages and job-level the data also contains the performance rating of individuals over time. Individuals are assessed annually which results in a score between 1 (worst possible performance) and 5 (excellent performance). The data includes these annual ratings from 2001 onwards. Analyses that incorporate this variable thus include less years as it does not run back to 1995.

\section{Job separations}

The data contain information on the date a worker leaves the firm and the reason for this. This information can be used to analyze the relation between a worker's training status and their external mobility. Many reasons for leaving the firm are recorded in the data and I recoded these categories to capture the pivotal distinction between voluntary and involuntary separations. The categories are: Quit (voluntary, $\mathrm{n}=4$ ); fired (involuntary, $\mathrm{n}=141$ ); and still at Philips (individuals still work at the firm, $\mathrm{n}=809$ ). Table 4.3 shows the status of individuals with respect to training and whether they still work at Philips or not.

Of those fired (involuntary) the smallest percentages are found among those who completed the training, completed the training via APL or are still in training. As a result these categories of workers feature the highest percentages to still work at firm. Those who received their vocational qualification (diploma) as the result of a 100 percent score in the APL procedure are apparently highly valued by the firm as only $8 \%$ were fired and the remaining $92 \%$ are still at work in the firm. Dropouts and those who do not want to train show the highest percentages of having been fired. 
Table 4.3: External mobility: Training status and separation reason.

\begin{tabular}{|c|c|c|c|c|c|c|c|}
\hline & Completed & $\begin{array}{r}\text { Direct dipl. } \\
\text { via APL }\end{array}$ & $\begin{array}{r}\text { Still in } \\
\text { Training }\end{array}$ & $\begin{array}{r}\text { Does not } \\
\text { want to }\end{array}$ & $\begin{array}{r}\text { No qualifi- } \\
\text { cation }\end{array}$ & Dropout & Total \\
\hline \multirow[t]{2}{*}{ Fired } & 42 & 4 & 29 & 18 & 17 & 31 & 141 \\
\hline & $9 \%$ & $8 \%$ & $15 \%$ & $35 \%$ & $22 \%$ & $31 \%$ & $15 \%$ \\
\hline \multirow[t]{2}{*}{ Quit } & 2 & 0 & 0 & 2 & 0 & 0 & \\
\hline & $0 \%$ & $0 \%$ & $0 \%$ & $4 \%$ & $0 \%$ & $0 \%$ & $0 \%$ \\
\hline Still at & 438 & 48 & 159 & 32 & 62 & 70 & 809 \\
\hline Philips & $91 \%$ & $92 \%$ & $85 \%$ & $62 \%$ & $78 \%$ & $69 \%$ & $85 \%$ \\
\hline Total number & 428 & 52 & 188 & 52 & 79 & 101 & 954 \\
\hline Total column \% & $100 \%$ & $100 \%$ & $100 \%$ & $100 \%$ & $100 \%$ & $100 \%$ & $100 \%$ \\
\hline
\end{tabular}

These results give rise to the suggestion that workers who complete the training and therewith obtain a vocational qualification improve their (relative) employability. I test this formally in Section 4.6.4.

\subsection{Analysis methods}

\subsubsection{Wages}

To assess the effect of training on wages I use a Mincer type equation (Mincer, 1974) (equation 4.1) where $\mathrm{W}$ is the yearly wage, $\mathrm{T}$ is a dummy that records completion of the training (all those in categories 1 and 2 in Table 4.2 receive value ' 1 ' and those in the remaining categories value '0'), ET (Education/Tenure) includes the years of education, tenure and tenure squared; Vector PS (Part-time/Shift work) includes the percentage of part-time factor and a dummy for working in shifts; Vector GA (Gender/Age) includes gender, age and age squared; Y is a year dummy to correct for the possibility of trends and $\mu$ are standard errors clustered on the individual. This pooled model is first estimated using OLS and fixed effects.

$$
\ln W_{i, t}=\alpha+\beta T_{i, t}+\delta E T_{i, t}+\gamma P S_{i, t}+\psi G_{i} A_{i, t}+\phi Y_{i, t}+\mu_{i, t}
$$

The targeted group is low skilled, hence the ability distribution is expected to be relatively narrow. However, as there likely are other unobserved variables influencing the selection (eg. differences in motivation), I have to assume that selection effects exist. Therefore, pooled OLS is not consistent and instead I use a fixed effects Instrumental Variables estimator to instrument training participation and account for unobserved variables. Using an estimator that only accounts for fixed effects would still leave room for correlation between time-varying omitted variables and the included 
regressors. I combine this IV estimator with fixed effects, to correct for the possibility that my instrument is not entirely exogenous and might be correlated to unobserved time-consistent variables.

The instrument is constructed based on variation in the availability (supply) of the VQP. The VQP was introduced in 2002 and did not exist before 2002. So the mere absence of the program before 2002 and its introduction from 2002 onwards, creates variation in the probability to go into training as in a natural experiment. Thus by definition there was no possibility to train in the VQP before 2002. Starting with 2002, the VQP exists and each year there is the opportunity to start training. This yearly opportunity at training is modeled with year-dummies. For instance, dummy ' $\mathrm{i} 2$ ' is 1 if the year is 2002 and 0 otherwise, dummy ' $\mathrm{i} 3$ ' is 1 if the year is 2003 and zero otherwise, etc. Dummies i2 through 110 are used to instrument training participation. These dummies have no relation to the dependent variable (wage) but do affect the chance to train. Thus I assume this is a valid instrument. ${ }^{5,6}$ I test for weak instruments using the approach of Stock and Yogo (2005) who compare the Cragg-Donald statistic (Cragg and Donald, 1993) to the critical values the former have specified. In all cases the test statistic exceeds the critical value at 5 percent significance and we can reject the null hypothesis of weak instruments.

In one of the estimations of training on wage I include an interaction term that interacts the VQP completion dummy (1 if completed) with the number of years that have passed since an individual has completed the VQP. For example, if an individual has completed the VQP in 2005, this interaction term will be 0 in 2005, 1 in 2006, 2 in 2007 etc. The purpose of including this interaction term in the wage estimation, is to uncover whether completion of the VQP puts the trained workers on a higher growth path compared to those who did not complete the training.

\subsubsection{Job-level and internal promotions}

To estimate the effects of training completion on job-level I use two approaches. First, although job-level is a cardinal variable I assume for a moment that it can be interpreted as ordinal and can be estimated with linear methods. I base this assumption on the observation that between the job-levels 15 and 45 that I observe in the data, wages increase almost linearly with job-level. Moreover, predicted values of the regressions presented later in Table 4.5 are all between 15 and 45 . I apply the same IV method as for the estimation on wages, substituting log wages in the equation

\footnotetext{
${ }^{5}$ Data on other training that may have occurred before 2002 is not available, but as the VQP was designed for the low skilled target population identified in 2000, any training that may have occurred was not comprehensive enough to upgrade their skill level above low skilled.

${ }^{6} \mathrm{~A}$ more obvious but less precise instrument to use may be a dummy variable that is 0 prior to 2002 and 1 in 2002 and onwards. The dummy then represents the start of the VQP and with that the opportunity to train, whereas there is no relation to wages. I tested the model using this dummy as well and this lead to coefficients with the same signs and significance levels but of larger size than the ones reported in the chapter. I attribute this to the relatively lower precision of using only one dummy to instrument training.
} 
for the job-level. However, as this method relies on the assumptions of ordinality and linearity, its results have to be interpreted with caution.

To provide an alternative way to estimate the effect of training on job-level I construct a dummy that is 1 in each year where the job-level is higher than the previous year and 0 in years when there is no difference with the preceding year. This represent a 'promotion dummy' which I estimate again with a similar type IV regression, changing only the dependent variable. Using this dummy, interpretation of the results is not restricted anymore by the assumptions made above. As I need to instrument for training completion I choose to stick to pooled OLS and fixed effects models as the benchmarks, instead of switching to probit or logit, as these latter two cannot easily be combined with IV panel techniques.

\subsubsection{Performance ratings}

Instrumenting for training completion in the same manner as in previous estimations, I investigate if training completion also has an effect on the performance ratings.

\subsubsection{Involuntary separations: i.e. fired}

To formally test if workers who complete the training and therewith obtain a vocational qualification reduce their chances of being laid off, I construct a dummy variable that is ' 1 ' for every person that is involuntarily fired and 0 for those who have never been fired. As the number of voluntary separations (quits) is very low ( $\mathrm{n}=4$, see Table 4.3) we only analyze involuntary separations (lay-offs). Thus this ' 1 if fired' dummy is constant for each worker/year combination and does not track the separation status over time. Therefore I do not use panel estimation techniques but multiple cross section techniques. I estimate the effect of completing the VQP training on the ' 1 if fired' dummy using pooled OLS, probit, logit and IV estimators, with standard errors clustered on the individual in all cases.

\subsection{Results}

\subsubsection{The effect of training completion on wages and wage development}

Table 4.4 shows the results of the estimations of training completion on wages. The pooled OLS estimation serves as the standard benchmark, the fixed effects estimation offers a more advanced benchmark and finally the IV FE estimations are the most important ones, enabling inference about causal relations.

Column 3 shows that participants who complete the training and obtain a qualification earn almost 4 percent more than those who do not train and hence do not get a qualification. While a general positive relation between training and wages has been shown in several papers (see Section 4.2) it is unique that I find this relation exists for low skilled workers as well. The pooled OLS coefficient for VQP completion 
Table 4.4: The effect of training completion on wages

\begin{tabular}{|c|c|c|c|c|}
\hline & \multicolumn{4}{|c|}{ lnWage } \\
\hline & 1 & 2 & 3 & 4 \\
\hline & $\begin{array}{c}\text { Pooled } \\
\text { OLS }\end{array}$ & $\mathrm{FE}$ & IV FE & IV FE \\
\hline VQP training completion & $\begin{array}{c}0.008 \\
(0.005)\end{array}$ & $\begin{array}{l}0.010 * * * \\
(0.001)\end{array}$ & $\begin{array}{l}0.039 * * * \\
(0.003)\end{array}$ & $\begin{array}{l}0.043 * * * \\
(0.005)\end{array}$ \\
\hline Interaction term: Years since diploma & & & & $\begin{array}{c}-0.006 * * * \\
(0.001)\end{array}$ \\
\hline Year & $\begin{array}{l}0.003 * * * \\
(0.000)\end{array}$ & $\begin{array}{l}0.015 * * * \\
(0.000)\end{array}$ & $\begin{array}{l}0.014 * * * \\
(0.000)\end{array}$ & $\begin{array}{l}0.014 * * * \\
(0.000)\end{array}$ \\
\hline Tenure & $\begin{array}{l}0.006 * * * \\
(0.001)\end{array}$ & $\begin{array}{c}0.000 \\
(0.000)\end{array}$ & dropped & dropped \\
\hline Tenure $^{2}$ & $\begin{array}{c}-0.000 * * \\
(0.000)\end{array}$ & $\begin{array}{c}-0.000 * * * \\
(0.000)\end{array}$ & $\begin{array}{c}-0.000 * * * \\
(0.000)\end{array}$ & $\begin{array}{c}-0.000 * * * \\
(0.000)\end{array}$ \\
\hline Part-time factor & $\begin{array}{c}0.000 \\
(0.000)\end{array}$ & & & \\
\hline Age & $\begin{array}{l}0.017 * * * \\
(0.002)\end{array}$ & & & \\
\hline $\mathrm{Age}^{2}$ & $\begin{array}{c}-0.000 * * * \\
(0.000)\end{array}$ & & & \\
\hline Years of education & $\begin{array}{l}0.021 * * * \\
(0.003)\end{array}$ & & & \\
\hline 1 if female & $\begin{array}{c}-0.068 * * * \\
(0.006)\end{array}$ & & & \\
\hline 1 if shift-work & $\begin{array}{c}-0.031 * * * \\
(0.006)\end{array}$ & & & \\
\hline Constant & $\begin{array}{l}3.770 * * * \\
(0.869)\end{array}$ & $\begin{array}{c}-19.956 * * * \\
(0.370)\end{array}$ & & \\
\hline R-squared & 0.36 & & & \\
\hline $\mathrm{R}^{2}$ within & & 0.52 & & \\
\hline Centered $\mathrm{R}^{2}$ & & & 0.50 & 0.50 \\
\hline Cragg-Donald Wald F statistic & & & 307.6 & 161.4 \\
\hline 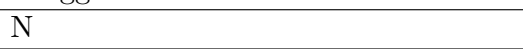 & 13, & 59 observati & ons / 971 grc & ups \\
\hline
\end{tabular}

The same regressions using annual wage-growth instead of log wages lead to results that are equal in terms of coefficients' significance and signs. Magnitudes obviously differ. Tenure is dropped due to collinearity with the variable year.

Cluster robust (OLS) and clustered standard errors (FE and IV) in parentheses. ${ }^{* * *} \mathrm{p}<0.01,{ }^{* *} \mathrm{p}<0.05,{ }^{*} \mathrm{p}<0.1$. See Appendix I for first stage estimation results.

can be interpreted as a 0.8 percent wage increase on average for the total population due to training completion. This turns out lower than the IV estimate which indicates that there is negative selection into training. Those workers with a priori the lowest wages select into training. Table 4.2 shows this as those that completed training, started but dropped out or are still in training, had lower wages in 2002 when the VQP started than average. Conversely, those workers that do not want to train or 
have no qualification earned higher than average wages in 2002.

Finally, column 4 presents the same model as column 3, with the addition of the interaction term 'years since diploma'. The coefficient for VQP completion now shows a wage increase of 4.3 percent but the negative sign of the interaction term shows that as the years after training completion pass, the wage growth of trained workers is relatively smaller than the wage growth of those who did not complete training. When using an interaction term in timeseries analysis such as this, the coefficient of training completion can be interpreted as a one-time wage increase in year zero after training. Subsequently the negative coefficient of the interaction term itself means the effect of training on wage diminishes over time. Figure 4.2 helps to illustrate this.

Figure 4.2: Wage growth profile of successfully trained vs untrained worker

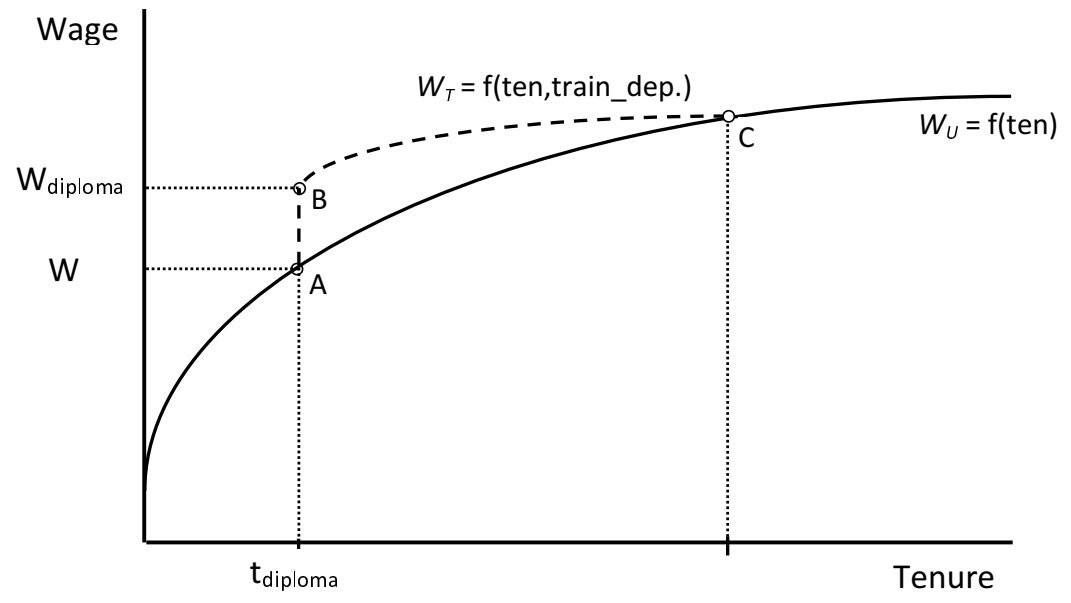

It graphs two wage functions, $W_{U}$ for an untrained worker and $W_{T}$ for a successfully trained worker. Now consider two workers, worker 1 and 2. Worker 1 does not train and his wage will always track along $W_{U}$, increasing with tenure. Suppose worker 2 completes training at point $t_{\text {diploma }}$. His wage jumps to $W_{\text {diploma }}$ (point B) as predicted by the coefficient of VQP completion. However, the negative coefficient for the interaction term means that the effect of training depreciates over time. Thus wage is now a function of tenure and training depreciation. The net result of this is that worker 2 enjoys a higher wage for 7.2 years $^{7}$, after which the wage has converged with that of worker 1 at point $\mathrm{C}$. This adds to existing literature as many studies report positive effects of training on wages immediately after training but do not study what happens in the long run. It is important to take into account that also in these studies the effect of training may diminish over time.

\footnotetext{
${ }^{7}$ Coefficient of VQP completion divided by the interaction term.
} 


\subsubsection{Internal mobility: The effect of training completion on job-level}

Table 4.5 shows the results of linear OLS and IV FE estimations of training completion on job-level. The effect of training completion in column 3 is significant and positive. Analogue to the wage estimations, column 4 adds the interaction term measuring how many years have passed since completing the training. The interaction term is

Table 4.5: The effect of training completion on job-level

\begin{tabular}{|c|c|c|c|c|}
\hline & \multicolumn{4}{|c|}{ job-level } \\
\hline & 1 & 2 & 3 & 4 \\
\hline & Pooled OLS & FE & IV FE & IV FE \\
\hline VQP training completed & $\begin{array}{l}0.504 * * \\
(0.250)\end{array}$ & $\begin{array}{l}0.477 * * * \\
(0.053)\end{array}$ & $\begin{array}{l}0.277 * * \\
(0.126)\end{array}$ & $\begin{array}{c}-0.489 * * \\
(0.205)\end{array}$ \\
\hline Interaction term: Years since diploma & & & & $\begin{array}{l}0.344 * * * \\
(0.053)\end{array}$ \\
\hline Year & $\begin{array}{l}0.071 * * * \\
(0.023)\end{array}$ & $\begin{array}{c}0.000 \\
(0.000)\end{array}$ & $\begin{array}{l}0.575 * * * \\
(0.009)\end{array}$ & $\begin{array}{l}0.582 * * * \\
(0.009)\end{array}$ \\
\hline Tenure & $\begin{array}{l}0.305 * * * \\
(0.049)\end{array}$ & $\begin{array}{l}0.568 * * * \\
(0.008)\end{array}$ & dropped & dropped \\
\hline Tenure $^{2}$ & $\begin{array}{c}-0.003 * * \\
(0.002)\end{array}$ & $\begin{array}{c}-0.009 * * * \\
(0.000)\end{array}$ & $\begin{array}{c}-0.009 * * * \\
(0.000)\end{array}$ & $\begin{array}{c}-0.009 * * * \\
(0.000)\end{array}$ \\
\hline Part-time factor & $\begin{array}{c}0.015 \\
(0.013)\end{array}$ & & & \\
\hline Age & $\begin{array}{l}0.520 * * * \\
(0.115)\end{array}$ & & & \\
\hline $\mathrm{Age}^{2}$ & $\begin{array}{c}-0.006 * * * \\
(0.002)\end{array}$ & & & \\
\hline Years of education & $\begin{array}{l}1.122 * * * \\
(0.155)\end{array}$ & & & \\
\hline 1 if female & $\begin{array}{c}-4.388 * * * \\
(0.372)\end{array}$ & & & \\
\hline 1 if shift-work & $\begin{array}{c}-1.511 * * * \\
(0.308)\end{array}$ & & & \\
\hline Constant & $\begin{array}{c}-140.181 * * * \\
(46.484)\end{array}$ & $\begin{array}{l}21.474 * * * \\
(0.065)\end{array}$ & & \\
\hline $\begin{array}{l}\mathrm{R}^{2} \\
\mathrm{R}^{2} \text { within }\end{array}$ & 0.33 & 0.45 & & \\
\hline Centered $\mathrm{R}^{2}$ & & & 0.45 & 0.45 \\
\hline Cragg-Donald Wald F statistic & & & 307.7 & 161.4 \\
\hline $\mathrm{N}$ & 13,65 & observation & s / 971 grou & \\
\hline
\end{tabular}

Cluster robust (OLS) and clustered standard errors (FE and IV) in parentheses. *** $\mathrm{p}<0.01,{ }^{* *} \mathrm{p}<0.05,{ }^{*} \mathrm{p}<0.1$ See Appendix I for first stage estimation results.

positive and significant, indicating that the returns to training in terms of a higher job-level do not emerge immediately at completion of the training but in the year after and onwards. So where wage responded immediately (in the same year) after obtaining a qualification, a promotion happens earliest in the first year after obtaining 
a qualification. Table 4.6 presents the results when I use the 'promotion dummy' as dependent variable instead of the job-level. These results underscore that training completion increases the relative chance to be promoted to a higher job-level.

Table 4.6: The effect of training completion on promotions

\begin{tabular}{|c|c|c|c|}
\hline & \multicolumn{3}{|c|}{ Promotion dummy: 1 if promoted } \\
\hline & 1 & 2 & 3 \\
\hline & Pooled OLS & FE & IV FE \\
\hline VQP training completed & $\begin{array}{l}0.032 * * * \\
(0.008)\end{array}$ & $\begin{array}{l}0.026 * * * \\
(0.009)\end{array}$ & $\begin{array}{l}0.089 * * * \\
(0.022)\end{array}$ \\
\hline Year & $\begin{array}{l}0.002 * * * \\
(0.001)\end{array}$ & $\begin{array}{c}-0.005 * * * \\
(0.001)\end{array}$ & $\begin{array}{c}-0.008 * * * \\
(0.002)\end{array}$ \\
\hline Tenure & $\begin{array}{c}-0.005 * * * \\
(0.001)\end{array}$ & $\begin{array}{c}0.000 \\
(0.000)\end{array}$ & dropped \\
\hline Tenure $^{2}$ & $\begin{array}{l}0.000 * * * \\
(0.000)\end{array}$ & $\begin{array}{c}0.000 * \\
(0.000)\end{array}$ & $\begin{array}{c}0.000 * \\
(0.000)\end{array}$ \\
\hline Part-time factor & $\begin{array}{l}0.001 * * * \\
(0.000)\end{array}$ & & \\
\hline Age & $\begin{array}{r}-0.005 * \\
(0.003)\end{array}$ & & \\
\hline $\mathrm{Age}^{2}$ & $\begin{array}{c}0.000 \\
(0.000)\end{array}$ & & \\
\hline Years of education & $\begin{array}{l}0.010 * * * \\
(0.002)\end{array}$ & & \\
\hline 1 if female & $\begin{array}{c}-0.003 \\
(0.007)\end{array}$ & & \\
\hline 1 if shift-work & $\begin{array}{c}-0.004 \\
(0.005)\end{array}$ & & \\
\hline Constant & $\begin{array}{c}-4.700 * * * \\
(1.217)\end{array}$ & $\begin{array}{l}10.858 * * * \\
(2.661)\end{array}$ & \\
\hline $\mathrm{R}^{2}$ & 0.03 & & \\
\hline $\mathrm{R}^{2}$ within & & 0.00 & \\
\hline Centered $\mathrm{R}^{2}$ & & & -0.00 \\
\hline Cragg-Donald Wald F statistic & & & 307.7 \\
\hline $\mathrm{N}$ & 13,66 & observation & 1 groups \\
\hline
\end{tabular}

\subsubsection{The effect of training completion on performance ratings}

The results of the estimations of training completion on performance ratings are presented in Table 4.7. The results provide no conclusive evidence that training completion has an effect on performance ratings. I also tested several transformations of the variable, including a number of dummies grouping performance ratings into a 
value of 1 or $0 .{ }^{8}$ No significant results of training on performance ratings were found. Therefore I conclude that training completion does not affect performance ratings. In

Table 4.7: The effect of training completion on performance ratings.

\begin{tabular}{|c|c|c|c|}
\hline & \multicolumn{3}{|c|}{ Performance rating } \\
\hline & 1 & 2 & 3 \\
\hline & Pooled OLS & $\mathrm{FE}$ & IV FE \\
\hline VQP training completed & $\begin{array}{l}0.099 * * * \\
(0.033)\end{array}$ & $\begin{array}{c}0.028 \\
(0.022)\end{array}$ & $\begin{array}{c}0.065 \\
(0.066)\end{array}$ \\
\hline Year & $\begin{array}{l}0.009 * * \\
(0.004)\end{array}$ & $\begin{array}{l}0.020 * * * \\
(0.005)\end{array}$ & $\begin{array}{l}0.017 * * * \\
(0.006)\end{array}$ \\
\hline Tenure & $\begin{array}{c}0.003 \\
(0.006)\end{array}$ & $\begin{array}{c}0.000 \\
(0.000)\end{array}$ & dropped \\
\hline Tenure $^{2}$ & $\begin{array}{c}-0.000 \\
(0.000)\end{array}$ & $\begin{array}{c}-0.000 * * * \\
(0.000)\end{array}$ & $\begin{array}{c}-0.000 * * * \\
(0.000)\end{array}$ \\
\hline Part-time factor & $\begin{array}{l}0.004 * * * \\
(0.001)\end{array}$ & & \\
\hline Age & $\begin{array}{c}0.021 \\
(0.018)\end{array}$ & & \\
\hline $\mathrm{Age}^{2}$ & $\begin{array}{c}-0.000 \\
(0.000)\end{array}$ & & \\
\hline Years of education & $\begin{array}{l}0.056 * * * \\
(0.015)\end{array}$ & & \\
\hline 1 if female & $\begin{array}{l}0.083 * * \\
(0.041)\end{array}$ & & \\
\hline 1 if shift-work & $\begin{array}{l}0.011 \\
(0.031)\end{array}$ & & \\
\hline Constant & $\begin{array}{r}-16.122 * \\
(8.790)\end{array}$ & $\begin{array}{c}-35.907 * * * * \\
(9.257)\end{array}$ & $\begin{array}{c}-31.213 * * \\
(12.245)\end{array}$ \\
\hline $\begin{array}{l}\mathrm{R}^{2} \\
\mathrm{R}^{2} \text { within }\end{array}$ & 0.03 & 0.00 & \\
\hline Centered $\mathrm{R}^{2}$ & & & 0.00 \\
\hline Cragg-Donald Wald F statistic & & & 106.1 \\
\hline $\mathrm{N}$ & & 344 observatic & 3 groups \\
\hline
\end{tabular}

Cluster robust standard errors (OLS) and default standard errors (IV) in parentheses. *** $\mathrm{p}<0.01,{ }^{* *} \mathrm{p}<0.05,{ }^{*} \mathrm{p}<0.1$ See Appendix I for first stage estimation results.

essence this is not surprising, as I already found positive effects of training on both wages and job-level. Given that workers that complete training have a higher chance to get a promotion to a higher job-level, it is logical to observe that in their new job they receive a similar performance rating as before. The reward to training is already expressed in the higher job-level and wage. This last notion might trigger the thought that those workers who complete training but do not move to a higher job-level, might

\footnotetext{
${ }^{8}$ eg. a dummy valued 1 for top performance (5) and 0 for performance categories $1-4$, a dummy valued 1 for above average performance ( 4 or 5 ) and 0 for below average and average performance (1-3), etc.
} 
benefit from training in terms of better performance on their current and unchanged job-level. However, several estimations that distinguish between promoted and not promoted workers do not provide support for this thought.

The results presented so far show that workers who complete the VQP -and therewith obtain a vocational qualification- earn more and more often get promoted to a higher job-level compared to workers who do not complete the VQP and do not obtain a vocational qualification. Assuming that these increases in wage and job-level somehow express the worker's value added to the firm it is clear that the VQP training increases this worker's value to the firm.

\subsubsection{The relation between training and external mobility}

Table 4.8 presents the result of several estimations on the dummy variable that represents if a worker is ever fired or not. I find that completing the training and hence obtaining a qualification, reduces the likelihood of being involuntarily fired. This confirms my expectation based on related studies discussed in Section 4.2. A number of other control variables are also significant and point out that women face a lower probability of being fired and that workers with relatively higher levels of education also face a lower probability of being fired. Furthermore workers that work in shifts seem to have a relatively high probability to be fired. 
Table 4.8: Training completion and involuntary separations 2002-2011.

\begin{tabular}{l|cccc}
\hline \hline & \multicolumn{4}{|c}{1 if fired } \\
\hline & 1 & 2 & 3 & 4 \\
\hline \multirow{3}{*}{ VQP training completed } & Pooled OLS & Probit & Logit & IV 2SLS \\
\cline { 2 - 5 } Years of education & $-0.094 * * *$ & $-0.597 * * *$ & $-1.180 * * *$ & $-0.101 * * *$ \\
& $(0.013)$ & $(0.086)$ & $(0.176)$ & $(0.022)$ \\
Part-time factor & $-0.018 * *$ & $-0.096 *$ & $-0.178 *$ & $-0.018 * *$ \\
& $(0.009)$ & $(0.051)$ & $(0.097)$ & $(0.009)$ \\
1 if shift-duty & 0.000 & 0.004 & 0.010 & 0.000 \\
& $(0.001)$ & $(0.007)$ & $(0.016)$ & $(0.001)$ \\
Age & $0.078 * * *$ & $0.438 * * *$ & $0.880 * * *$ & $0.078 * * *$ \\
& $(0.020)$ & $(0.132)$ & $(0.281)$ & $(0.020)$ \\
Age & 0.001 & 0.027 & 0.059 & 0.001 \\
1 if female & $(0.010)$ & $(0.054)$ & $(0.107)$ & $(0.010)$ \\
Tenure & 0.000 & 0.000 & 0.000 & 0.000 \\
Tenure & $(0.000)$ & $(0.001)$ & $(0.001)$ & $(0.000)$ \\
& $-0.059 * *$ & $-0.340 * *$ & $-0.685 * *$ & $-0.059 * *$ \\
Constant & $(0.023)$ & $(0.159)$ & $(0.304)$ & $(0.023)$ \\
& 0.003 & 0.014 & 0.027 & 0.003 \\
$\mathrm{R}^{2}$ & $(0.004)$ & $(0.020)$ & $(0.040)$ & $(0.004)$ \\
Pseudo R $^{2}$ & $-0.000 *$ & -0.001 & -0.002 & $-0.000 *$ \\
F statistic & $(0.000)$ & $(0.001)$ & $(0.001)$ & $(0.000)$ \\
\hline $\mathrm{N}$ & 0.101 & -1.897 & -3.867 & 0.102 \\
\hline \hline & $(0.230)$ & $(1.439)$ & $(3.116)$ & $(0.230)$ \\
\hline
\end{tabular}

Clustered standard errors in parentheses

${ }^{* * *} \mathrm{p}<0.01,{ }^{* *} \mathrm{p}<0.05,{ }^{*} \mathrm{p}<0.1$ See Appendix I for first stage estimation results.

\subsection{Conclusions}

While there are many papers that study the (wage) effects of training or that explain why firms invest in general training, there are very few papers that focus on the effects of training for low skilled workers. This chapter enters this void and analyzes the effects of the Vocational Qualification Program, a firm sponsored general training for low skilled workers, of which the data stem from a companies' personnel records. Using a fixed effect instrumental variables approach I showed that completing the training which means the workers obtains a vocational qualification- leads to 4.3 percent higher wages compared to not training. I also find that the wage effect of training diminishes over time, canceling out after 7 years. This means that for this category of workers, which are medium-skilled after they successfully obtained their certificate, lifelong learning is required to stay 'ahead of the curve'. In addition, I found two effects 
that signal an improved employability as a result of training. Firstly, workers that participated or completed the training have a higher chance to be internally promoted than those who do not complete the training and secondly, completing the training leads to a lower chance of getting fired. Assuming that a wage increase after training indicates an even greater increase in productivity (Acemoglu and Pischke, 1999b), the positive effect of training on wages, together with the increased internal employability, are indicative of the positive effects these newly qualified workers have for the firm. En passant, these results show that the existence of firm sponsored general training also extends to low skilled workers. This strengthens the evidence from existing literature on why firms invest in general training. It can benefit both the worker and the firm. 


\section{Appendix I: First stage estimation results}

Table 4.9: First stage estimation results of IV regressions on wages

\begin{tabular}{|c|c|c|}
\hline & 1 & 2 \\
\hline & Table 4.4, Column 3 & Table 4.4 , Column 4 \\
\hline Years since diploma & & $\begin{array}{l}0.219 * * * \\
(0.003)\end{array}$ \\
\hline Year & $\begin{array}{l}0.040 * * * \\
(0.001)\end{array}$ & $\begin{array}{l}0.017 * * * \\
(0.001)\end{array}$ \\
\hline Tenure & dropped & dropped \\
\hline Tenure $^{2}$ & $\begin{array}{c}-0.000 \\
(0.000)\end{array}$ & $\begin{array}{c}-0.000 * * \\
(0.000)\end{array}$ \\
\hline $\mathrm{i} 2$ & $\begin{array}{c}-0.166 * * * \\
(0.010)\end{array}$ & $\begin{array}{c}-0.063 * * * \\
(0.010)\end{array}$ \\
\hline i3 & $\begin{array}{c}-0.205 * * * \\
(0.010)\end{array}$ & $\begin{array}{c}-0.078 * * * \\
(0.010)\end{array}$ \\
\hline $\mathrm{i} 4$ & $\begin{array}{c}-0.244 * * * \\
(0.010)\end{array}$ & $\begin{array}{c}-0.093 * * * \\
(0.010)\end{array}$ \\
\hline i5 & $\begin{array}{c}-0.262 * * * \\
(0.010)\end{array}$ & $\begin{array}{c}-0.085 * * * \\
(0.010)\end{array}$ \\
\hline i6 & $\begin{array}{c}-0.227 * * * \\
(0.010)\end{array}$ & $\begin{array}{c}-0.031 * * * \\
(0.010)\end{array}$ \\
\hline i7 & $\begin{array}{c}-0.199 * * * \\
(0.010)\end{array}$ & $\begin{array}{c}-0.001 \\
(0.010)\end{array}$ \\
\hline i8 & $\begin{array}{c}-0.117 * * * \\
(0.010)\end{array}$ & $\begin{array}{l}0.070 * * * \\
(0.010)\end{array}$ \\
\hline i9 & $\begin{array}{l}0.034 * * * \\
(0.011)\end{array}$ & $\begin{array}{l}0.185 * * * \\
(0.010)\end{array}$ \\
\hline i10 & $\begin{array}{l}0.091 * * * \\
(0.011)\end{array}$ & $\begin{array}{l}0.161 * * * \\
(0.010)\end{array}$ \\
\hline Cragg-Donald Wald F statistic & 307.6 & 161.4 \\
\hline $\mathrm{N}$ & \multicolumn{2}{|c|}{ 13,663 observations / 971 groups } \\
\hline
\end{tabular}

Clustered standard errors in parentheses *** $\mathrm{p}<0.01,{ }^{* *} \mathrm{p}<0.05,{ }^{*} \mathrm{p}<0.1$ 
Table 4.10: First stage estimation results of IV regressions on Function-level, Jobpromotion and Performance rating

\begin{tabular}{|c|c|c|c|c|}
\hline & 1 & 2 & 3 & 4 \\
\hline & Table 4.5, Col. 1 & Table 4.5 , Col. 2 & Table 4.6 , Col. 3 & Table 4.7 , Col. 3 \\
\hline $\begin{array}{l}\text { Years since } \\
\text { diploma }\end{array}$ & & $\begin{array}{l}0.219 * * * \\
(0.003)\end{array}$ & & \\
\hline Year & $\begin{array}{l}0.040 * * * \\
(0.001)\end{array}$ & $\begin{array}{l}0.017 * * * \\
(0.001)\end{array}$ & $\begin{array}{l}0.040 * * * \\
(0.001)\end{array}$ & $\begin{array}{l}0.047 * * \\
(0.020)\end{array}$ \\
\hline Tenure & dropped & dropped & dropped & dropped \\
\hline Tenure $^{2}$ & $\begin{array}{c}-0.000 \\
(0.000)\end{array}$ & $\begin{array}{c}-0.000 * * \\
(0.000)\end{array}$ & $\begin{array}{c}-0.000 \\
(0.000)\end{array}$ & $\begin{array}{c}-0.000 * \\
(0.000)\end{array}$ \\
\hline i2 & $\begin{array}{c}-0.166 * * * \\
(0.010)\end{array}$ & $\begin{array}{c}-0.063 * * * \\
(0.010)\end{array}$ & $\begin{array}{c}-0.166 * * * \\
(0.010)\end{array}$ & $\begin{array}{r}-0.043 * \\
(0.024)\end{array}$ \\
\hline i3 & $\begin{array}{l}-0.205 * * * \\
(0.010)\end{array}$ & $\begin{array}{l}-0.078 * * * \\
(0.010)\end{array}$ & $\begin{array}{l}-0.205 * * * \\
(0.010)\end{array}$ & $\begin{array}{c}-0.086 * * \\
(0.041)\end{array}$ \\
\hline i4 & $\begin{array}{l}-0.244 * * * \\
(0.010)\end{array}$ & $\begin{array}{l}-0.093 * * * \\
(0.010)\end{array}$ & $\begin{array}{l}-0.244 * * * \\
(0.010)\end{array}$ & $\begin{array}{c}-0.128 * * \\
(0.061)\end{array}$ \\
\hline i5 & $\begin{array}{l}-0.262 * * * \\
(0.010)\end{array}$ & $\begin{array}{l}-0.086 * * * \\
(0.010)\end{array}$ & $\begin{array}{l}-0.262 * * * \\
(0.010)\end{array}$ & $\begin{array}{r}-0.150 * \\
(0.080)\end{array}$ \\
\hline i6 & $\begin{array}{l}-0.227 * * * \\
(0.010)\end{array}$ & $\begin{array}{l}-0.032 * * * \\
(0.010)\end{array}$ & $\begin{array}{l}-0.227 * * * \\
(0.010)\end{array}$ & $\begin{array}{c}-0.117 \\
(0.100)\end{array}$ \\
\hline i7 & $\begin{array}{l}-0.199 * * * \\
(0.010)\end{array}$ & $\begin{array}{c}-0.002 \\
(0.010)\end{array}$ & $\begin{array}{l}-0.199 * * * \\
(0.010)\end{array}$ & $\begin{array}{r}-0.094 \\
(0.119)\end{array}$ \\
\hline i8 & $\begin{array}{l}-0.117 * * * \\
(0.010)\end{array}$ & $\begin{array}{l}0.069 * * * \\
(0.010)\end{array}$ & $\begin{array}{l}-0.117 * * * \\
(0.010)\end{array}$ & $\begin{array}{c}-0.012 \\
(0.139)\end{array}$ \\
\hline i9 & $\begin{array}{l}0.034 * * * \\
(0.010)\end{array}$ & $\begin{array}{l}0.185 * * * \\
(0.010)\end{array}$ & $\begin{array}{l}0.034 * * * \\
(0.010)\end{array}$ & $\begin{array}{c}0.134 \\
(0.159)\end{array}$ \\
\hline i10 & $\begin{array}{l}0.091 * * * \\
(0.010)\end{array}$ & $\begin{array}{l}0.161 * * * \\
(0.010)\end{array}$ & $\begin{array}{l}0.091 * * * \\
(0.010)\end{array}$ & $\begin{array}{c}0.188 \\
(0.179)\end{array}$ \\
\hline $\begin{array}{l}\text { Cragg-Donald } \\
\text { Wald F- statistic }\end{array}$ & 307.7 & 161.4 & 307.6 & 106.1 \\
\hline$\overline{\mathrm{N}}$ & \multicolumn{2}{|c|}{$\begin{array}{l}13,659 \text { obs. } \\
971 \text { groups }\end{array}$} & $\begin{array}{l}13,663 \text { obs. } \\
971 \text { groups }\end{array}$ & $\begin{array}{l}8,844 \text { obs. } \\
953 \text { groups }\end{array}$ \\
\hline
\end{tabular}

Clustered standard errors in parentheses

*** $\mathrm{p}<0.01,{ }^{* *} \mathrm{p}<0.05,{ }^{*} \mathrm{p}<0.1$ 
Table 4.11: First stage estimation results of IV regression on 'Fired dummy'

\begin{tabular}{|c|c|}
\hline & 1 \\
\hline & Table 4.8, Column 4 \\
\hline Years of education & $\begin{array}{r}-0.001 \\
(0.007)\end{array}$ \\
\hline Part-time factor & $\begin{array}{l}0.002 * * * \\
(0.001)\end{array}$ \\
\hline 1 if shift-duty & $\begin{array}{r}-0.029 * \\
(0.016)\end{array}$ \\
\hline Age & $\begin{array}{r}-0.009 \\
(0.009)\end{array}$ \\
\hline $\mathrm{Age}^{2}$ & $\begin{array}{c}0.000 \\
(0.000)\end{array}$ \\
\hline 1 if female & $\begin{array}{c}0.006 \\
(0.021)\end{array}$ \\
\hline Tenure & $\begin{array}{l}0.009 * * * \\
(0.003)\end{array}$ \\
\hline Tenure $^{2}$ & $\begin{array}{l}-0.000 * * * \\
(0.000)\end{array}$ \\
\hline i2 & $\begin{array}{l}-0.589 * * * \\
(0.020)\end{array}$ \\
\hline i3 & $\begin{array}{l}-0.590 * * * \\
(0.020)\end{array}$ \\
\hline i4 & $\begin{array}{l}-0.591 * * * \\
(0.019)\end{array}$ \\
\hline $\mathrm{i} 5$ & $\begin{array}{l}-0.569 * * * \\
(0.019)\end{array}$ \\
\hline $\mathrm{i} 6$ & $\begin{array}{l}-0.494 * * * \\
(0.018)\end{array}$ \\
\hline i7 & $\begin{array}{l}-0.429 * * * \\
(0.018)\end{array}$ \\
\hline i8 & $\begin{array}{l}-0.310 * * * \\
(0.016)\end{array}$ \\
\hline i9 & $\begin{array}{l}0.125 * * * \\
(0.012)\end{array}$ \\
\hline i10 & $\begin{array}{l}0.029 * * * \\
(0.007)\end{array}$ \\
\hline Constant & $\begin{array}{l}0.547 * * * \\
(0.186)\end{array}$ \\
\hline $\begin{array}{l}\text { F-statistic } \\
\mathrm{N}\end{array}$ & $\begin{array}{c}128.4 \\
8,757 \text { observations / } 948 \text { groups }\end{array}$ \\
\hline
\end{tabular}

Clustered standard errors in parentheses

*** $\mathrm{p}<0.01,{ }^{*} * \mathrm{p}<0.05,{ }^{*} \mathrm{p}<0.1$ 


\section{Appendix II: Philips wage structure}

Figure 4.3: Wages according to job-level (x-axis) and step within job-level.

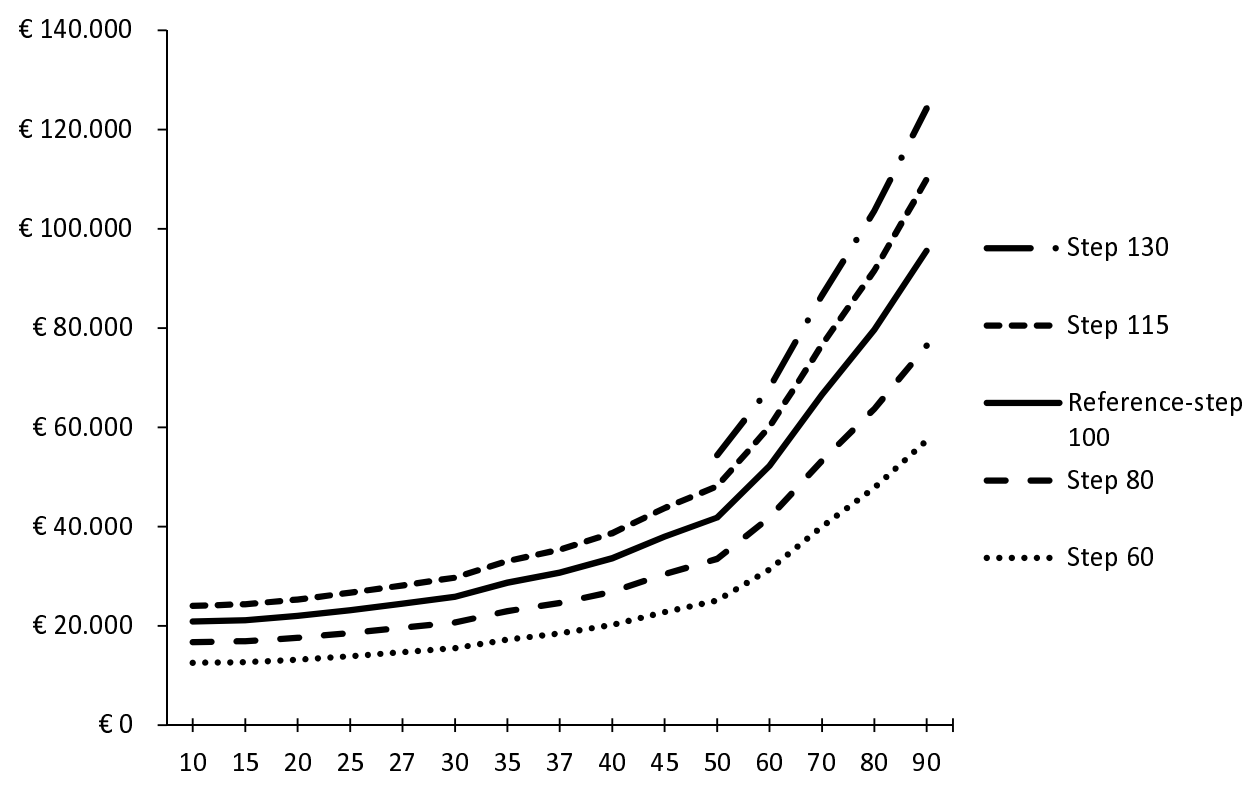

Source: Data come from Philips Collective Bargaining agreement 2010-2011. 


\section{Training vouchers and employability awareness}

\subsection{Introduction ${ }^{1}$}

The economic literature shows that worker employability is threatened by both globalization of product and service markets and skills-biased technological change (e.g., Feenstra and Hanson (1996), Strauss-Kahn (2003) and Geishecker (2006)). Conversely, training has been shown to increase worker employability (e.g., Groot and Maassen van den Brink (2000) and Sanders and de Grip (2004)). For this reason firms may consider encouraging their workforces to participate in training. Voucher schemes are one instrument designed to stimulate worker participation in training.

This chapter examines one firm's training voucher scheme. The scheme aims to stimulate firm employees to develop a more active attitude toward their own employability, i.e., to increase their 'employability awareness'. In this chapter, we analyze which workers use the vouchers and whether voucher use increases worker employability awareness and their willingness to participate in further training.

Using data from two surveys of the firm's workforce, we find that voucher use is related to personality traits as well as to other personal characteristics. In particular, worker ambition, goal setting, and education level are positively related to voucher use. Also, women and those with longer tenure more often spend their vouchers. Conversely, workers with higher self-image and negative reciprocity spend their vouchers less often. The negative relation between voucher use and negative reciprocity is alarming, as it suggests that workers with greater negative reciprocity perceive the voucher as a threat to their job security rather than an encouragement to improve their employability. Further, we find that voucher use positively affects worker employability awareness and worker willingness to train. Remarkably, participation in non-voucher training is only minimally related to personality traits. From a Human Resources (HR)

\footnotetext{
${ }^{1}$ This chapter is joint work with Andries de Grip and Maaike Witlox.
} 
perspective, this suggests that by employing a voucher scheme, the firm makes training participation dependent mainly on employee personality and individual characteristics.

The voucher scheme we analyze is run by Philips Electronics Netherlands and is called 'E-miles' (Employability miles). On 1 January 2009, all employees received a voucher with a face value of 1,000 'E-miles' regardless of their job or contract. These vouchers could be used for participation in a restricted number of training courses that attempt to contribute to worker employability awareness. The vouchers could not be used for any other training courses. In the remainder of this chapter 'voucher use' is therefore synonymous with 'participation in employability awareness training'. Workers could only redeem their voucher in the 2009 calendar year. The voucher expired on 31 December 2009.

We first examine which workers use their vouchers. Building on the existing literature, we focus on the role of personality traits (e.g., Leuven, Oosterbeek, Sloof and van Klaveren (2005)) and personal characteristics (e.g., Booth (1991), Barron, Black and Loewenstein (1993) and Arulampalam, Booth and Bryan (2004)). Our data include information not only on voucher use, but also on participation in other (regular) training courses not included in the voucher scheme ('non-voucher training'). Therefore, we also analyze which workers participate in non-voucher training and use this as a benchmark for our results with regard to the use of the training vouchers.

Next, we analyze whether workers who use their vouchers show increased employability awareness compared to workers who did not use their vouchers. Employability awareness is measured via five survey questions for which we compare outcomes between the two survey moments. Finally, we analyze whether willingness to train is affected by voucher use.

As the term employability can be interpreted in many ways (see De Grip, Van Loo and Sanders (2004) for a history of the term employability), we present a clear definition of our interpretation. We interpret employability to be defined as follows De Grip et al. (2004):

'Employability refers to the capacity and willingness of workers to remain attractive for the labor market (supply factors), by reacting to and anticipating changes in tasks and work environment (demand factors), facilitated by the human resource development instruments available to them (institutions).' (p. 216)

The remainder of this chapter is structured as follows. Section 5.2 discusses three relevant strands of the literature: the effects of voucher schemes; the relation between personality traits and training; and the incidence of training. Building on this literature, we formulate several hypotheses that guide our empirical analysis. Section 5.3 presents our data and details of the particular voucher scheme we analyze. This includes information on the questions we use to measure worker employability awareness and willingness to train. In Section 5.4, we present the results of our 
empirical analyses and relate the results to our hypotheses. Section 5.5 sets forth our conclusions.

\section{$5.2 \quad$ Literature}

\subsubsection{Voucher schemes}

Messer and Wolter (2009) conducted an experiment in which 2,437 randomly selected Swiss citizens received an adult education voucher. Recipients were free to select any adult education choice. The vouchers had three different face values (200, 750, and 1,500 Swiss francs). Messer and Wolter (2009) find a redemption rate of $18.4 \%$. However, redemption rates significantly differ by face value category. A breakdown by voucher value reveals that the voucher with the highest value has double the impact on training participation compared to intermediate-value vouchers, whereas vouchers with a lower face value only create a deadweight loss. Further, these authors find a deadweight loss of roughly $60 \%$ of all redeemed vouchers. This means that many vouchers were used to participate in training that the participants would have taken anyway in the absence of the voucher. This deadweight loss is highest for the more highly educated, for whom it amounts to $91.4 \%$. Additionally, Messer and Wolter find that voucher redemption mainly occurs among more highly educated females. Based on the same data used by Messer and Wolter (2009), Schwerdt, Messer, Woessmann and Wolter (2011) analyze the effect of voucher use on earnings and employment. However, these authors find no significant effects.

Van der Steeg, Elk and Webbink (2010) examine a training voucher scheme for teachers in The Netherlands. Unique to this voucher scheme are that teachers must apply for a voucher and that vouchers are assigned on a first-come, first-serve basis. Because getting the voucher is competitive and an active effort is required, these authors' results cannot be generalized to a voucher scheme in which individuals obtain a voucher without first applying for it. Nevertheless, some of the their results are in line with Messer and Wolter (2009). Van der Steeg et al. (2010) also find that introduction of a voucher scheme has a limited impact on training participation. Out of every 10 vouchers, only one is used for a training course that would not have been followed without the voucher. Eight out of every 10 vouchers is spent on training courses that voucher recipients would have followed anyway, which concurs with the finding of Messer and Wolter (2009) that vouchers schemes can lead to large deadweight losses.

Analysis of the voucher scheme described in this chapter differs slightly from these studies. In this chapter, the main focus is on two questions: (1) which personality traits and personal characteristics of workers are related to voucher use, and (2) do workers who redeem their vouchers actually perform differently with regard to the desired outcomes for the variables of the voucher scheme (i.e., worker employability awareness and worker willingness to train)? Since the training courses offered under the voucher scheme are designed to increase workers' employability awareness, we 
expect that voucher users improve their employability awareness compared to those who did not use their vouchers (hypothesis 1). Similarly, we expect a positive relation between voucher use and worker willingness to train (hypothesis 2).

\subsubsection{Personality traits and training participation}

There is a large body of theoretical and empirical literature on the incidence of training and whether workers or firms bear its costs. Standard human capital theory predicts that firms will not invest in general training, because workers might leave the firm after receiving training (Becker, 1962). However, more recent literature provides various theoretical explanations for firm investment in general training (e.g., Katz and Ziderman (1990), Stevens (1994), Acemoglu and Pischke (1998, 1999a and 1999b), Lazear (2009) and Booth and Katic (2010)). One departure from standard theory focuses on the role of personality traits in training participation. Building on the literature in this field, we include in our analysis various personality traits, ranging from reciprocal feelings to career ambition. ${ }^{23}$

Leuven et al. (2005) are among the first investigators to introduce reciprocity in the empirical training literature. They base their definition of reciprocity on Fehr and Gächter (2000) who define this term as an individual's response to a friendly action as 'frequently much nicer and much more cooperative than predicted by the self-interested model' (p.159). The same holds for unfriendly actions to which reciprocal individuals respond in a way much more 'nasty and even brutal' than standard theory would predict. Positive reciprocity refers to cooperative responses while negative reciprocity refers to retaliatory responses (Fehr and Gächter, 2000). The model that Leuven et al. (2005) use represents an adjustment to an earlier reciprocity theory by Dufwenberg and Kirchsteiger (2000). This model shows that a firm's investment in general training may be affected by a worker's sensitivity with respect to reciprocity. A firm's investment in general training might be perceived as a 'kind' action. The worker, in return, can reward this kind action by not leaving the firm after having taken the training. The firm can anticipate this positive reciprocity by investing more in general training. The main finding of Leuven et al. (2005) is that workers who are driven by positive reciprocal motives are more likely to participate in training. Building on these findings, we expect that positive reciprocity is positively related to the use of vouchers. In addition, we expect that negative reciprocity is negatively related to voucher use. Since the voucher scheme was introduced in the midst of the global financial crisis and since Philips Netherlands has undergone a number of large-scale reorganizations, workers may perceive the employability voucher as a threat. Workers who are more driven by negative reciprocal behavior might respond to this perceived threat by refusing to use their vouchers.

\footnotetext{
${ }^{2}$ Our selection of personality traits builds on the results of a meta-analysis by Colquitt, LePine and Noe (2000).

${ }^{3}$ The survey questions we use to measure workers' personality traits are listed in Appendix I.
} 
Whether workers believe that the (positive or negative) results from their actions are due to their own efforts depends on their locus of control. Individuals with an internal locus of control share the opinion that their own successes and failures are attributable to their own actions and decisions. Noe (1986) argues that people with an internal locus of control feel that they can control their environment. This is the reason that such individuals take opportunities that may increase their probability of receiving rewards such as promotions, pay increases, or recognition (p.739). Conversely, individuals who have an external locus of control believe that work outcomes can be attributed to luck, fate, specific circumstances, or the actions of people around them. Noe (1986) finds that workers with an internal locus of control more often participate in training. Colquitt, LePine and Noe (2000) confirm this finding. Therefore, our expectation is that workers with a more internal locus of control are more likely to use their vouchers.

Anxiety is a measure of whether individuals fear situations they are not familiar with. Fear of exams is a typical factor for which individuals with anxiety score high (Fouarge, Schils and De Grip, 2010). Anxiety is found to be negatively related to worker motivation to learn (Colquitt et al. (2000) and Webster and Martocchio (1993)), training participation, and the level of regret individuals show in the choices they make (Borghans, Golsteyn and De Grip, 2006). Based on these results, we expect that anxiety is negatively related to voucher use.

Self-confidence is the extent to which individuals believe in themselves. Bénabou and Tirole (2002) conclude that 'an individual's confidence in his abilities can help him to undertake more ambitious goals' (p.872). Borghans et al. (2006) find that more highly educated individuals show a greater level of self-confidence. This effect may be self-reinforcing since another finding in Borghans (2006) is that self-confident individuals are more willing to participate in training and consequently do participate more. Hence, we expect that self-confidence is positively related to voucher use.

Self-image is the extent to which individuals are able to reflect on who they are. Borghans et al. (2006) argue that individuals who have positive self-image are better able to determine whether training is useful to them. However, this could affect workers' willingness to train either positively (if they think a particular course of training is useful to them) or negatively (if they think they do not need training).

We measure workers' imagination by asking to what extent they imagine what their life will look like in 15 years. Individuals with higher levels of imagination may also have a better picture of how training can contribute to this envisioned future. We therefore expect that imagination is positively related to voucher use.

Facteau, Dobbins, Russell, Ladd and Kudisch (1995) find a relationship between planning behavior and training motivation. Individuals with a high level of goal setting indicate that they set achievement goals. To set goals, individuals first must assess their current situation and compare it to their future desired situation. They must be aware of their strengths and weaknesses before they can set relevant goals. Individuals 
may be more eager to participate in training because they know it can improve their weaknesses, leading to a greater willingness to participate (Colquitt et al., 2000). Hence, we expect that goal setting is positively related to voucher use.

Career ambition can also be a driver of training participation (Colquitt et al., 2000). We measure workers' career ambition by the extent to which they indicate that they picture themselves switching to a different firm within five years. An ambitious attitude with respect to career means that the individual wishes to develop and probably has a clear view of the role that training can have in this respect (e.g., Mathieu, Martineau and Tannenbaum (1993) and Facteau et al. (1995)). Therefore, we expect that career ambition is positively related to voucher use.

In the above overview of the literature, we expressed the direction in which we expect each of several personality traits to affect voucher use. We thus set forth the hypothesis that each personality trait affects voucher use in the expected direction (hypothesis 3)

\subsubsection{Personal characteristics and training participation}

The literature on the incidence and duration of training generally finds that younger and more highly educated workers are more likely to participate in training (Bassanini, Booth, Brunello, De Paola and Leuven, 2005). Therefore, we expect that worker age is negatively and education is positively related to voucher use.

With respect to gender, the results from the literature are mixed. Studies in the 1980s and 1990s often found that women report more training incidence than men, but these courses were short in duration, leading to the conclusion that women receive less training (e.g., Altonji and Spletzer (1991)). However, more recently Bassanini et al. (2005) find that women are more likely to participate in training and that this includes training of longer duration. However, the gender difference that Bassanini et al. (2005) find is small and disappears when these authors focus their analysis on employer-sponsored training only (rather than all training courses), suggesting that the higher training participation of female workers is related to training courses that they pay for themselves. O'Halloran (2008), however, shows results that are in line with the literature of the 1980s and 1990s; that is, women have a higher incidence of training but the duration of such training is less. Finally, Dieckhoff and Steiber (2010) find that women receive less training than men. Messer and Wolter (2009) find that women are more likely to use their vouchers than men. Moreover, the courses offered through the E-miles voucher scheme that we analyze are very short in duration (maximum of one day) and are much shorter than the average for non-voucher training. Therefore, we expect that women are more likely to use their vouchers than men.

With respect to the relation between worker tenure and training participation, the findings from the literature are also mixed. Loewenstein and Spletzer (1997) and Croce and Tancioni (2007) find that training increases with tenure, because just after hiring, initial uncertainty about the job match reduces training incentives. However, Frazis, 
Gittleman and Joyce (2000) find no significant effect of tenure on the probability of training, whereas Bassanini et al. (2005) find a U-shaped relation between tenure and training. The latter argue that, initially, new employees need to be trained to adapt to the requirements of the new job, after which further training is delayed, in line with the findings of Loewenstein and Spletzer (1997). However, these studies evaluate the relation between training and tenure as a decision concerning to whom the firm wants to offer training opportunities. However, in our study, the firm supplied a voucher to all employees, guaranteeing training supply. As a result, the relation between voucher use and tenure can be explained only from the perspective of the workers themselves. We expect that tenure is positively related to voucher use, because workers with short tenure have been hired more recently and have therefore recently been active in the job-search process. This gives them 'confirmation' of their employability, whereas those with longer tenure might be more uncertain about their employability and might therefore be more eager to use the E-miles voucher.

In the overview of the literature above, we expressed the direction in which we expect each personal characteristic to affect voucher use. We hypothesize that each personal characteristic affects the use of vouchers in the expected direction (hypothesis 4)

\subsubsection{Schematic overview}

Figure 5.1 summarizes the structure of our analysis and hypotheses. All dependent variables are shown in italics. All dependent variables are either ranked order outcomes or $0 / 1$ dummies. We use ordered logit or logit estimators, which enables us to report odds ratios, providing enhanced interpretation of results ${ }^{4}$. In addition, we estimate a treatment effects model to correct for possible endogeneity of voucher use.

Figure 5.1: Structure of the empirical analysis and hypotheses.

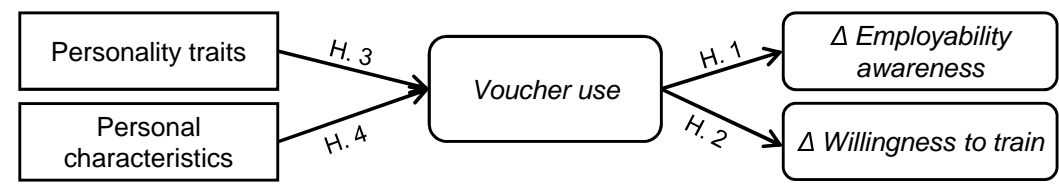

\subsection{Data}

Our data come from two surveys that we conducted in cooperation with Philips Netherlands. The first survey took place in December 2008, before the introduction of the voucher scheme. At that time, employees were not yet informed about the

\footnotetext{
${ }^{4}$ Using ordered probit or probit leads to very similar results that do not change any interpretation or conclusion.
} 
introduction of the voucher scheme. Therefore, this first survey establishes a baseline. The second survey took place in February 2010, i.e., just after the expiration date of the 2009 voucher. Both surveys addressed various aspects of the training, personality traits, the workplace, and voucher use. Most survey questions were yes/no or 5point Likert scale, allowing workers to indicate to what extent they (dis-)agree with a given statement. Both surveys were conducted among a randomly drawn sample of 2,500 regular employees. The response rate in both surveys was $38 \%$. Personal characteristics were collected in the first survey. To be able to use these personal characteristics in our analysis, only those individuals who responded to both surveys are retained in our sample. This leads to a sample of 648 individuals who responded to both surveys. ${ }^{5}$ With respect to several observable characteristics, these respondents are representative of the workforce of Philips Netherlands. ${ }^{6}$

\subsubsection{Descriptives}

Table 5.1 provides an overview of the training courses offered through the voucher scheme and the amount of E-miles needed per course. Before the start of the voucher scheme, all employees received information on the voucher via e-mail. This e-mail also included information about the various training courses offered. Enrolment for training took place via online registration. The 'E-check' course requires all the Emiles a worker has received; the 'self-insight' training is also relatively expensive. 'Employability advice', 'career stop', and 'route planner' require fewer E-miles. Workers are allowed to spend their voucher on more than one training course.

From the sample of 648 employees, 123 (19\%) used their vouchers. This is rather low but in line with results from the studies discussed in Section 5.2. For respondents who did not use their vouchers, the most important single reason given was 'a lack of time' $(22 \%)$. Other reasons included 'no interesting products in E-miles offer' (16\%) and 'never heard of E-miles' (11\%). ${ }^{7}$ Figure 5.2 depicts the share of vouchers spent on the various training courses in 2009. More than half of the vouchers were spent on the most 'expensive' training course, the 'E-check', requiring the entire amount

\footnotetext{
${ }^{5}$ There could be bias in our results, based on our sample of 648 individuals who responded to both surveys, because the sample only considers those who 'stayed' with Philips. However, by analyzing e-mail server bounces we identify only 32 persons as possible 'leavers' as their e-mail address returned a server bounce at the second survey. A number of T-tests on key personal characteristics and survey questions shows that these 32 individuals have similar characteristics and give similar answers to key questions as those who 'stayed' at Philips.

${ }^{6}$ The average age of respondents is 44 , and the average age of Philips' total workforce is 43 . In both cases, more than $60 \%$ of the population is male. Further, respondents have 12 years of education on average and Philips' total workforce has 13 years of education. Finally, respondents have on average 17 years of tenure; whereas this figure is 13 years for the total Philips population. However, the standard deviation of our sample's tenure is 11 . So the sample mean may not be statistically different from the population mean. As we do not have data on the population standard deviation, we cannot test this.

${ }^{7} 38 \%$ answered 'other reason', $7 \%$ answered 'not enough support from manager' and 3\% answered 'registration for courses was too complicated'. The remaining $3 \%$ were split among several other answers.
} 
Table 5.1: Voucher training courses

\begin{tabular}{|c|c|c|}
\hline Training & Content & E-miles required \\
\hline $\mathrm{E}($ mployability)- check & $\begin{array}{l}2 \text { hour computer test, } 1 \text { hour individual } \\
\text { evaluation with career counselor }\end{array}$ & 1,000 \\
\hline Self-insight & $\begin{array}{l}30 \text { minutes computer test, } 1 \text { hour individual } \\
\text { evaluation with career counselor }\end{array}$ & 700 \\
\hline Employability advice & $\begin{array}{l}\text { One hour individual consultation with } \\
\text { career counselor }\end{array}$ & 350 \\
\hline Career pit-stop & Workshop on career development, 4 hours & 300 \\
\hline Route planner & Competence game, 4 hours & 300 \\
\hline
\end{tabular}

of E-miles. Around $30 \%$ of workers spent their voucher on 'self-insight' (the second most expensive training course), and almost one-quarter of voucher users spent their vouchers on 'employability advice'. 'Career pit stop' was used by only $6 \%$. One-third of the workers who used their vouchers purchased only one of the low-priced training courses, thus not spending all their E-miles. ${ }^{8}$

Figure 5.2: Which voucher training did you take?

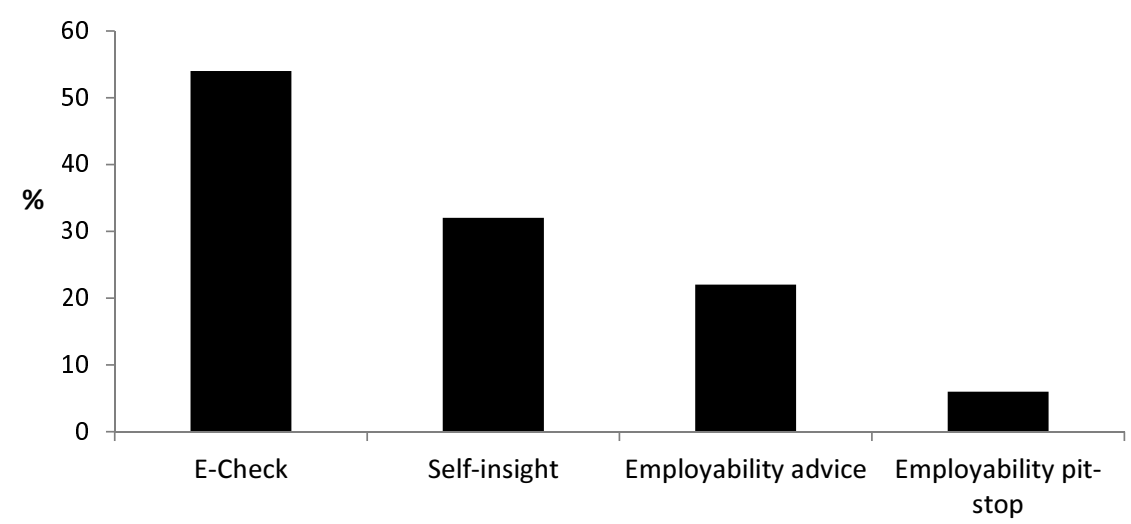

Figure 5.3, panels $\mathrm{A}$ and $\mathrm{B}$, show voucher use by age and tenure, respectively. Younger workers and workers with shorter tenure have a relatively high voucher redemption rate. Further, voucher use appears to be far more popular among female workers. Whereas only $15.5 \%$ of male workers used their vouchers, almost $26 \%$ of female workers spent their E-miles.

\footnotetext{
${ }^{8}$ Since the 'route planner' was used by none of the respondents, it is omitted in this figure.
} 
Figure 5.3: Voucher use by age (Panel A) and tenure (Panel B)
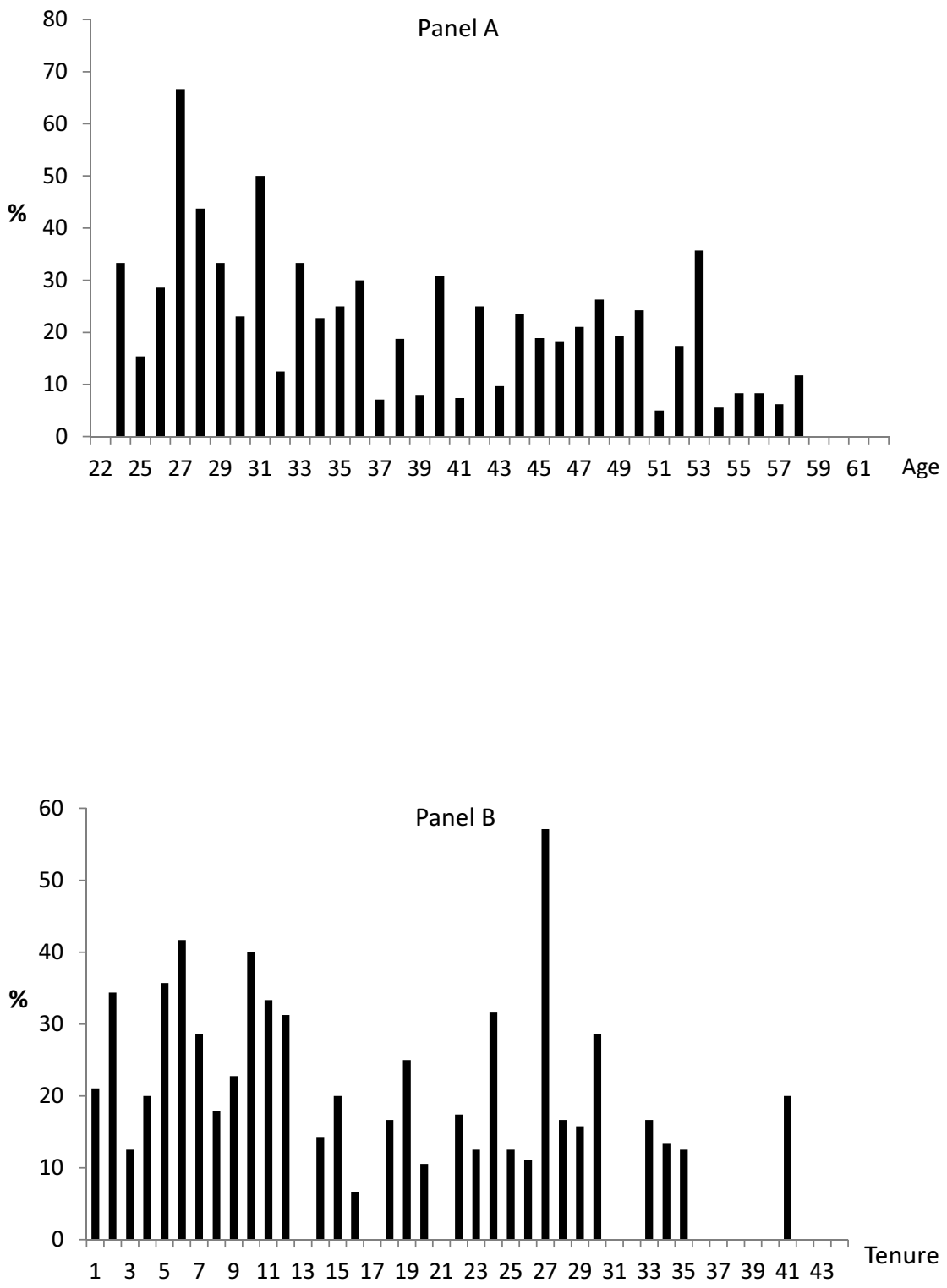
Table 5.2 shows the means and standard deviations of the variables included in the empirical analyses. The remainder of this section discusses the descriptive statistics for the variables we used in our analysis.

\subsubsection{Dependent variables}

Voucher use and participation in non-voucher training have been measured by straightforward yes/no questions. Employability awareness is assessed by asking the workers to reply to a number of statements on a 5-point Likert scale. These statements are:

1. I am responsible for my future development myself.

2. I have a clear view of how I want to develop myself in the years to come.

3. I know what I need to do to achieve my goals at work.

4. Would you like to have a new job within Philips in the next 5 years?

5. Would you like to have a new job outside Philips in the next 5 years?

The definition of employability we use (see Section 4.1) includes two dimensions: worker willingness and worker capacity. From De Grip et al. (2004):

'The first - willingness - measures peoples' desire to engage in activities that keep them attractive on the labor market. The second - capacity - is concerned with the power to develop one's position on the labor market.'

(p. 217)

These two dimensions can be further broken down into a number of indicators of employability (see Bolweg and Maenhout (1995) and De Grip et al. (2004)). All five statements we use to measure employability awareness relate to one of the indicators of employability. Statements 1 and 2 refer to the 'capacity to participate in training', statement 3 to the 'capacity to be mobile', and statements 4 and 5 to the 'willingness to be mobile'. The more positive workers respond to each of these statements, the more active their attitude is and the higher we assess their employability awareness. We measure workers' willingness to train (which is also one of the indicators of employability) via a question that attempts to indicate whether workers want to spend leisure time on training participation:

- If there would be the possibility to take a one-year training course for which you have to study 8 hours per week (in your leisure time) and in return you might get a $5 \%$ salary increase, would you take the training?

\footnotetext{
${ }^{9}$ Personality traits are assumed to remain constant over time. Even though this is not necessarily the case, many economists and psychologists use this assumption. See for example Borghans, Duckworth, Heckman and Ter Weel (2008).
} 
Table 5.2: Descriptive statistics of the sample

\begin{tabular}{|c|c|c|c|c|c|c|c|c|}
\hline & \multicolumn{3}{|c|}{ Survey 1} & \multicolumn{3}{|c|}{ Survey 2} & \multirow[b]{2}{*}{ Min } & \multirow[b]{2}{*}{$\operatorname{Max}$} \\
\hline & Obs. & Mean & s.d. & Obs. & Mean & s.d. & & \\
\hline Training participation & & & & & & & & \\
\hline 1 if used voucher & 0 & - & - & 646 & 0.19 & 0.39 & 0 & 1 \\
\hline 1 if took non-voucher trn. & 636 & 0.61 & 0.49 & 633 & 0.43 & 0.50 & 0 & 1 \\
\hline \multicolumn{9}{|l|}{ Personality traits ${ }^{9}$} \\
\hline Locus of control & 585 & 2.88 & 0.99 & - & - & - & 1 & 5 \\
\hline Self-confidence & 583 & 2.63 & 1.14 & - & - & - & 1 & 5 \\
\hline Anxiety & 577 & 2.24 & 1.13 & - & - & - & 1 & 5 \\
\hline Self-image & 576 & 3.97 & 0.83 & - & - & - & 1 & 5 \\
\hline Imagination & 586 & 3.36 & 1.20 & - & - & - & 1 & 5 \\
\hline Positive reciprocity & 594 & 4.06 & 0.78 & - & - & - & 1 & 5 \\
\hline Negative reciprocity & 596 & 2.43 & 0.87 & - & - & - & 1 & 5 \\
\hline Goal setting & 603 & 3.62 & 1.02 & - & - & - & 1 & 5 \\
\hline Career ambition & 599 & 2.28 & 0.93 & - & - & - & 0.75 & 4 \\
\hline \multicolumn{9}{|l|}{ Personal characteristics } \\
\hline Age & 639 & 43.62 & 9.30 & - & - & - & 22 & 62 \\
\hline 1 if female & 635 & 0.36 & 0.48 & - & - & - & 0 & 1 \\
\hline Years of education & 636 & 12.20 & 2.66 & - & - & - & 6 & 16 \\
\hline Tenure & 639 & 17.04 & 11.18 & - & - & - & 1 & 44 \\
\hline \multicolumn{9}{|l|}{ HR instruments ( 1 if yes) ${ }^{a}$} \\
\hline Assessment interviews & 627 & $95 \%$ & & 616 & $95 \%$ & & & \\
\hline Personal development plan & 611 & $47 \%$ & & 609 & $47 \%$ & & & \\
\hline Feedback on a regular basis & 614 & $56 \%$ & & 607 & $60 \%$ & & & \\
\hline Task/job rotation & 610 & $44 \%$ & & 605 & $40 \%$ & & & \\
\hline Mid-year review & 610 & $53 \%$ & & 609 & $55 \%$ & & & \\
\hline \multicolumn{9}{|l|}{ Sector $^{b}$} \\
\hline Consumer Lifestyle & 648 & $16 \%$ & & - & - & - & & \\
\hline Healthcare & 648 & $22 \%$ & & - & - & - & & \\
\hline Lighting & 648 & $34 \%$ & & - & - & - & & \\
\hline Other & 648 & $27 \%$ & & - & - & - & & \\
\hline
\end{tabular}

${ }^{a}$ Percentage of workers that report this instrument is used/offered by their manager/outlet.

${ }^{b}$ Percentage of workers that work in this sector. 


\subsubsection{Independent variables}

The personality traits listed in Table 5.2 are measured on a five-point Likert scale. A higher score means that the respondent exhibits the corresponding personality trait to a greater extent. All personality traits are measured using three questions. In our analysis, we use standard factors of these variables when Cronbach's Alpha was sufficiently high (over 0.7, based on Peterson (1994)). Appendix I lists all questions per construct and, where applicable, Cronbach's Alpha. For constructs for which Cronbach's Alpha was too low, only one of the questions was used to represent that particular personality trait. In these cases, we used the question with the most prominent results. The table shows that respondents have, on average, a relatively high score (a mean around three out of five or higher) for being able to create a self-image, being able to imagine the future, positive reciprocity, and goal setting. Conversely, respondents have, on average, relatively low levels of anxiety, negative reciprocity, and career ambition. The relatively low level of career ambition may be related to the fact that Philips is commonly viewed as one of the most popular employers in the Netherlands, combined with the fact that our measure of career ambition measures only external ambition (the ambition to continue one's career outside Philips). As our sample already works with Philips, they may already be very content with having achieved this, and this may relate to the lower (external) career ambition.

Several personal characteristics are included in the analyses. Respondents were asked to report their age, tenure, gender and education level. ${ }^{10}$ We measure respondents' level of education by converting Dutch educational attainment levels to the related nominal years of education. The average age of all respondents is 44 , and the sample contains more male than female respondents. Respondents have, on average, 12 years of education and an average tenure of 17 years. This set of averages on personal characteristics may provide a further clue about the relatively low career ambition overall. At middle age with substantial tenure and no higher education, workers may simply not have much ambition remaining. Employing many workers with these characteristics makes the relevance of the E-miles program and its attention to employability relatively higher than if the average age and tenure were much lower and level of education higher.

We control for several factors that may affect the dependent variable. These control variables are: HR instruments and the sector in which respondents work. With regard to the HR instruments, respondents were asked to indicate whether a particular instrument has been used by their manager or department ('yes' or 'no'). Table 5.2 includes the HR instruments used by the firm.

\footnotetext{
${ }^{10} \mathrm{Age}^{2}$ and tenure ${ }^{2}$ are included in our regression analyses
} 


\subsection{Results}

\subsubsection{Which workers use their voucher?}

Table 5.3 shows a series of binomial logit estimations on the use of E-miles vouchers. Column 1 shows the results of an estimation without the control variables, whereas column 2 includes the sector dummies and column 3 includes both the sector dummies and the various HR instruments. In the final column, we report the odds ratio for variables that have a significant coefficient. The odds ratio shows the factor with which the probability of voucher use increases, as the value of the respective independent variables increases by one unit.

The table shows that the personality traits locus of control, goal setting, and career ambition are positively related to the use of vouchers. These results confirm our expectations formulated in Section 5.2.2 with regard to these variables. The odds ratio for career ambition shows that if career ambition increases by one unit, the probability of voucher use increases by 1.44 times. All other odds ratios can be interpreted in the same way. It is not surprising that workers with higher career ambitions are more likely to use the opportunity that E-miles provides to assess their current and future employability. The negative relation between negative reciprocity and voucher use confirms our expectation. The weakly significant negative coefficient for self-image suggests that workers who have a better self-image less often think they need to improve their employability awareness.

Most personal characteristics included in the analyses do not significantly contribute to voucher use. Only education level shows a highly significant relation to voucher use, confirming our expectation. In column 1 we observe a weakly positive coefficient for female workers on voucher use. For tenure, we also find a weakly significant positive relation to voucher use. However, voucher use is not significantly related to worker age.

Of the included sets of HR control variables, only the 'mid-year review' is positively significant. Workers who had a mid-year review more often used their voucher in the second half of the year than those who did not have a mid-year review. This suggests that the mid-year review was possibly used to remind those who had not used their voucher yet to do so. ${ }^{11}$

Table 5.4 shows a series of estimations on worker participation in non-voucher training. To compare these outcomes with those on voucher use in Table 5.3, we used information from survey two only. Of the personality traits, only goal setting is significant, whereas negative reciprocity is only weakly significant when all control variables are included. From the set of personal characteristics, one highly significant result emerges: women are less likely to participate in non-voucher training than

\footnotetext{
${ }^{11}$ There were also some differences between sectors. Workers in sector 'lighting' were more prone to use their vouchers than workers in sector 'consumer lifestyle', reflecting differences in culture between these sectors.
} 
Table 5.3: Voucher redemption

\begin{tabular}{|c|c|c|c|c|}
\hline & \multicolumn{4}{|c|}{1 if used voucher } \\
\hline & 1 & 2 & 3 & Odds ratio $^{a}$ \\
\hline Locus of control & $\begin{array}{l}0.254 * * \\
(0.130)\end{array}$ & $\begin{array}{c}0.243 * \\
(0.132)\end{array}$ & $\begin{array}{c}0.254 * \\
(0.133)\end{array}$ & 1.28 \\
\hline Self confidence & $\begin{array}{c}0.151 \\
(0.110)\end{array}$ & $\begin{array}{c}0.137 \\
(0.110)\end{array}$ & $\begin{array}{c}0.133 \\
(0.111)\end{array}$ & \\
\hline Anxiety & $\begin{array}{c}-0.021 \\
(0.112)\end{array}$ & $\begin{array}{r}-0.017 \\
(0.113)\end{array}$ & $\begin{array}{r}-0.010 \\
(0.114)\end{array}$ & \\
\hline Self image & $\begin{array}{c}-0.257 * \\
(0.153)\end{array}$ & $\begin{array}{r}-0.267 * \\
(0.153)\end{array}$ & $\begin{array}{r}-0.271 * \\
(0.156)\end{array}$ & 0.76 \\
\hline Imagination & $\begin{array}{c}0.054 \\
(0.101)\end{array}$ & $\begin{array}{c}0.041 \\
(0.102)\end{array}$ & $\begin{array}{c}0.057 \\
(0.103)\end{array}$ & \\
\hline Pos reciprocity & $\begin{array}{c}0.037 \\
(0.136)\end{array}$ & $\begin{array}{c}0.043 \\
(0.136)\end{array}$ & $\begin{array}{c}0.039 \\
(0.137)\end{array}$ & \\
\hline Neg reciprocity & $\begin{array}{r}-0.252 * \\
(0.133)\end{array}$ & $\begin{array}{c}-0.276 * * \\
(0.135)\end{array}$ & $\begin{array}{l}-0.281 * * \\
(0.139)\end{array}$ & 0.76 \\
\hline Goal setting & $\begin{array}{l}0.295 * * \\
(0.129)\end{array}$ & $\begin{array}{l}0.300 * * \\
(0.129)\end{array}$ & $\begin{array}{l}0.294 * * \\
(0.132)\end{array}$ & 1.34 \\
\hline Career ambition & $\begin{array}{l}0.414 * * * \\
(0.119)\end{array}$ & $\begin{array}{l}0.378 * * * \\
(0.121)\end{array}$ & $\begin{array}{l}0.366 * * * \\
(0.125)\end{array}$ & 1.44 \\
\hline Age & $\begin{array}{c}-0.005 \\
(0.137)\end{array}$ & $\begin{array}{c}0.011 \\
(0.139)\end{array}$ & $\begin{array}{r}-0.014 \\
(0.139)\end{array}$ & \\
\hline $\mathrm{Age}^{2}$ & $\begin{array}{l}-0.000 \\
(0.002)\end{array}$ & $\begin{array}{r}-0.000 \\
(0.002)\end{array}$ & $\begin{array}{r}-0.000 \\
(0.002)\end{array}$ & \\
\hline 1 if female & $\begin{array}{r}0.411 * \\
(0.247)\end{array}$ & $\begin{array}{c}0.383 \\
(0.253)\end{array}$ & $\begin{array}{c}0.376 \\
(0.255)\end{array}$ & 1.51 \\
\hline Years of education & $\begin{array}{l}0.151 * * * \\
(0.053)\end{array}$ & $\begin{array}{l}0.159 * * * \\
(0.055)\end{array}$ & $\begin{array}{l}0.143 * * \\
(0.057)\end{array}$ & 1.15 \\
\hline Tenure & $\begin{array}{r}0.099 * \\
(0.053)\end{array}$ & $\begin{array}{r}0.091 * \\
(0.054)\end{array}$ & $\begin{array}{r}0.093 * \\
(0.054)\end{array}$ & 1.10 \\
\hline Tenure $^{2}$ & $\begin{array}{r}-0.002 * \\
(0.001)\end{array}$ & $\begin{array}{c}-0.002 \\
(0.001)\end{array}$ & $\begin{array}{c}-0.002 \\
(0.001)\end{array}$ & 1.00 \\
\hline Constant & $\begin{array}{r}-4.910 \\
(3.010) \\
\end{array}$ & $\begin{array}{r}-5.667 * \\
(3.058) \\
\end{array}$ & $\begin{array}{c}-5.118 \\
(3.146) \\
\end{array}$ & \\
\hline Controls included $^{b}$ : & & & & \\
\hline $\begin{array}{l}\text { Sector dummies } \\
\text { HR instruments }\end{array}$ & $\begin{array}{l}\text { No } \\
\text { No }\end{array}$ & $\begin{array}{l}\text { Yes } \\
\text { No }\end{array}$ & $\begin{array}{l}\text { Yes } \\
\text { Yes }\end{array}$ & \\
\hline Pseudo $\mathrm{R}^{2}$ & 0.11 & 0.12 & 0.13 & \\
\hline Observations & 510 & 510 & 510 & \\
\hline
\end{tabular}


Table 5.4: Participation in non-voucher training

\begin{tabular}{|c|c|c|c|}
\hline & \multicolumn{3}{|c|}{1 if participated in non-voucher training } \\
\hline & 1 & 2 & 3 \\
\hline Locus of control & $\begin{array}{c}-0.070 \\
(0.099)\end{array}$ & $\begin{array}{c}-0.070 \\
(0.100)\end{array}$ & $\begin{array}{c}-0.076 \\
(0.101)\end{array}$ \\
\hline Self confidence & $\begin{array}{c}-0.085 \\
(0.088)\end{array}$ & $\begin{array}{c}-0.086 \\
(0.088)\end{array}$ & $\begin{array}{c}-0.082 \\
(0.089)\end{array}$ \\
\hline Anxiety & $\begin{array}{l}0.095 \\
(0.088)\end{array}$ & $\begin{array}{c}0.094 \\
(0.088)\end{array}$ & $\begin{array}{l}0.081 \\
(0.090)\end{array}$ \\
\hline Self image & $\begin{array}{c}-0.141 \\
(0.125)\end{array}$ & $\begin{array}{r}-0.140 \\
(0.126)\end{array}$ & $\begin{array}{r}-0.139 \\
(0.128)\end{array}$ \\
\hline Imagination & $\begin{array}{c}-0.051 \\
(0.080)\end{array}$ & $\begin{array}{r}-0.064 \\
(0.081)\end{array}$ & $\begin{array}{r}-0.068 \\
(0.081)\end{array}$ \\
\hline Pos reciprocity & $\begin{array}{l}0.085 \\
(0.101)\end{array}$ & $\begin{array}{c}0.087 \\
(0.102)\end{array}$ & $\begin{array}{c}0.092 \\
(0.103)\end{array}$ \\
\hline Neg reciprocity & $\begin{array}{c}0.157 \\
(0.098)\end{array}$ & $\begin{array}{c}0.152 \\
(0.099)\end{array}$ & $\begin{array}{r}0.171 * \\
(0.100)\end{array}$ \\
\hline Goal setting & $\begin{array}{l}0.247 * * \\
(0.098)\end{array}$ & $\begin{array}{l}0.247 * * \\
(0.099)\end{array}$ & $\begin{array}{l}0.242 * * \\
(0.100)\end{array}$ \\
\hline Career ambition & $\begin{array}{r}0.169 * \\
(0.094)\end{array}$ & $\begin{array}{c}0.141 \\
(0.096)\end{array}$ & $\begin{array}{l}0.149 \\
(0.099)\end{array}$ \\
\hline Age & $\begin{array}{l}0.028 \\
(0.105)\end{array}$ & $\begin{array}{c}0.046 \\
(0.106)\end{array}$ & $\begin{array}{l}0.038 \\
(0.107)\end{array}$ \\
\hline $\mathrm{Age}^{2}$ & $\begin{array}{c}-0.001 \\
(0.001)\end{array}$ & $\begin{array}{r}-0.001 \\
(0.001)\end{array}$ & $\begin{array}{r}-0.001 \\
(0.001)\end{array}$ \\
\hline 1 if female & $\begin{array}{l}-0.667 * * * \\
(0.204)\end{array}$ & $\begin{array}{c}-0.719 * * * \\
(0.210)\end{array}$ & $\begin{array}{c}-0.704 * * * \\
(0.211)\end{array}$ \\
\hline Years of education & $\begin{array}{c}-0.024 \\
(0.041)\end{array}$ & $\begin{array}{c}-0.024 \\
(0.043)\end{array}$ & $\begin{array}{r}-0.032 \\
(0.044)\end{array}$ \\
\hline Tenure & $\begin{array}{c}-0.020 \\
(0.038)\end{array}$ & $\begin{array}{c}-0.027 \\
(0.038)\end{array}$ & $\begin{array}{c}-0.025 \\
(0.039)\end{array}$ \\
\hline Tenure $^{2}$ & $\begin{array}{l}0.000 \\
(0.001)\end{array}$ & $\begin{array}{c}0.000 \\
(0.001)\end{array}$ & $\begin{array}{c}0.000 \\
(0.001)\end{array}$ \\
\hline Constant & $\begin{array}{l}0.388 \\
(2.366)\end{array}$ & $\begin{array}{r}-0.108 \\
(2.396)\end{array}$ & $\begin{array}{c}0.153 \\
(2.455)\end{array}$ \\
\hline $\begin{array}{r}\text { Controls included }{ }^{a} \text { : } \\
\text { Sector dummies }\end{array}$ & No & Yes & Yes \\
\hline HR instruments & No & No & Yes \\
\hline Pseudo $\mathrm{R}^{2}$ & 0.06 & 0.06 & 0.07 \\
\hline Observations & 509 & 509 & 509 \\
\hline
\end{tabular}


men. None of the control variables have a significant impact on the probability of participation in non-voucher training.

Comparing the results from Tables 5.3 and 5.4, we observe that both personality traits and personal characteristics play a far more important role in voucher use than in participation in non-voucher training. Locus of control, self-image, negative reciprocity, goal setting, and career ambition all relate to voucher use across the three estimations, whereas only goal setting is consistently significant with regard to participation in non-voucher training. Further, the estimation results show that women are more likely to use their voucher (although this result is weakly significant), but less likely to participate in non-voucher training. Other personal characteristics such as education and tenure also relate to voucher use, whereas they do not relate to participation in non-voucher training. From an HR perspective, these differences suggest that by employing a voucher scheme, the firm makes training participation more dependent on employee personality and individual characteristics. We elaborate on this interpretation in Section 5.5.

Although not reported in a table, we also ran the estimations from Table 5.4 using observations from both surveys while clustering on the individual. Here we find that the HR instruments 'personal development plan' and 'mid-year review' relate positively and significantly to participation in non-voucher training. This suggests that participation in non-voucher training is more likely a decision made by the line manager or jointly made by the manager and worker and formalized in a personal development plan or mid-year review.

\subsubsection{Does voucher use increase employability awareness?}

Table 5.5 shows the estimation results of ordered logit regressions on the relation between voucher use and the change $\left(t_{2}-t_{1}\right)$ in five indicators of worker employability awareness and willingness to train. In all regressions, the dependent variable measures the difference in employability awareness or willingness to train between December 2008, before the introduction of the voucher system, and February 2010, immediately after the expiration date of the vouchers. For each dependent $t_{2}-t_{1}$ change variable, we ran an ordered logit regression including various sets of controls ${ }^{12}$. By analyzing the difference between $t_{2}$ and $t_{1}$, we correct for selection effects that might otherwise occur with regard to the initial level of the dependent variable.

Table 5.5 shows that workers who used their vouchers experienced a positive change in their employability awareness compared to workers who did not redeem their vouchers. This holds for four components of employability awareness: responsibility for one's future development, knowing what to do to achieve goals at work, having a clear view of how to develop in the next few years, and aspiring a new job with Philips in the next five years. The variable measuring workers' ambition to work outside Philips within the next 5 years is not significant. With four out of five variables

\footnotetext{
${ }^{12}$ Regressions with varying sets of controls provide robust results.
} 
significant, these results largely confirm hypothesis 1 . However, this table also shows that those who used their vouchers do not show a significantly different change in their willingness to train than those who did not use their vouchers. Thus, hypothesis 2 cannot be confirmed on the basis of this estimation. 


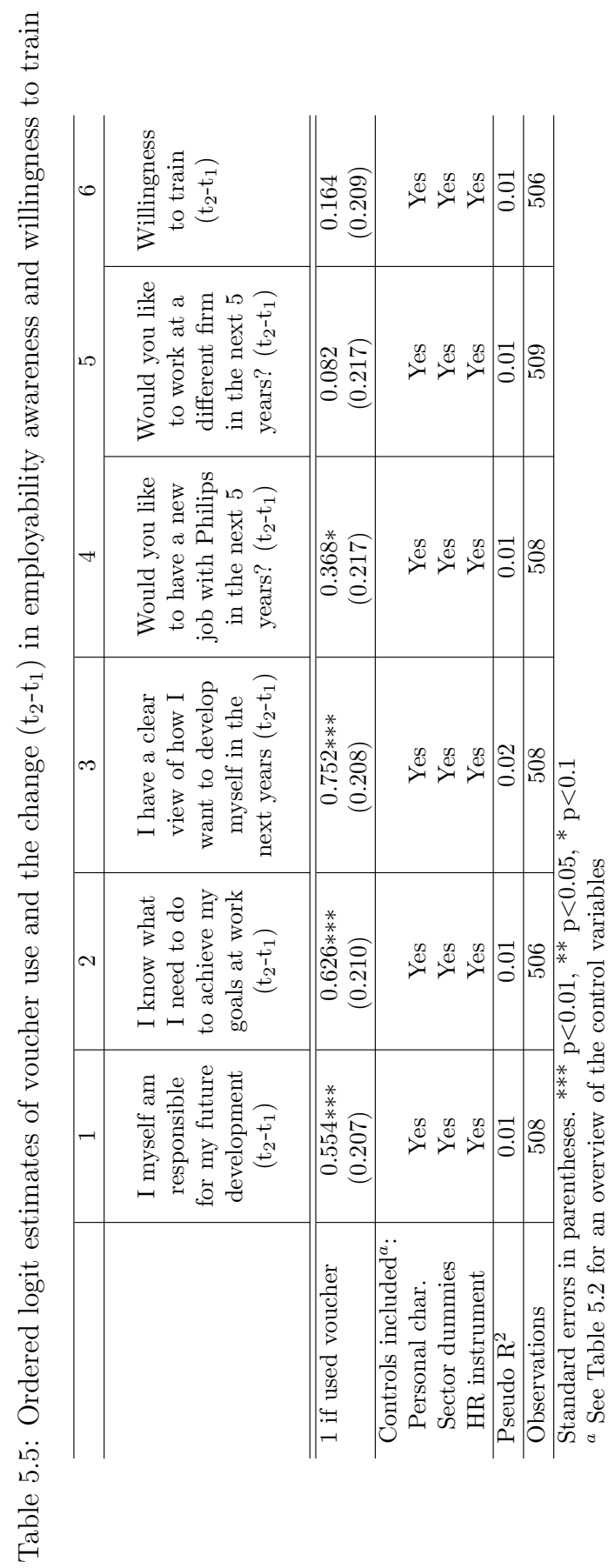


The estimations reported in Table 5.5 correct for selection effects that may occur with respect to the initial level of the dependent variable. To correct for the possibility of unobserved variables that are time-inconsistent and the possible effects of the unobserved variables on the change in the dependent variable, we estimate a treatment effects model that simultaneously estimates voucher use and its effect on the relevant $t_{2}-t_{1}$ change variable. In the first stage voucher use is estimated with the same variables as in Table 5.3; personality traits, personal characteristics, the sector and the HR instruments. The outcomes are the same as those in Table $5.3^{13}$. The second stage then estimates the effect of voucher use on the relevant dependent variable. Table 5.6 reports the results of these treatment effects estimations. The likelihood ratio test of independent equations rejects the null hypothesis of independence for all estimations, confirming the endogeneity problem and the need to use this treatment effects model. Therefore, this is our preferred estimator as it corrects for more forms of endogeneity than the ordered logit estimates we presented in Table 5.5.

The estimation results show that voucher use significantly affects all measures of employability awareness as well as the willingness to train. The significant positive coefficients for voucher use in columns 1, 2 and 3 confirm the results found in Table 5.5. The coefficient for aspiring a new job with Philips in the next five years turns out negative and significant using the treatment effects model, whereas it was positive and weakly significant in the ordered logit estimates. The coefficient for aspiring a new job in a different firm in the next five years is now significant and positive, whereas it was insignificant in Table 5.5. The negative significant coefficient for 'within Philips mobility ambition' and positive coefficient for 'outside Philips mobility ambition' shows that voucher use only increases firm external employability awareness. These outcomes further confirm hypothesis 1 . Finally, column 6 of Table 5.6 shows that voucher use is positively related to worker willingness to train, confirming hypothesis 2 .

\footnotetext{
${ }^{13}$ Only the size of the coefficient differs as the treatment effects model uses a probit instead of a logit estimator for the first stage.
} 


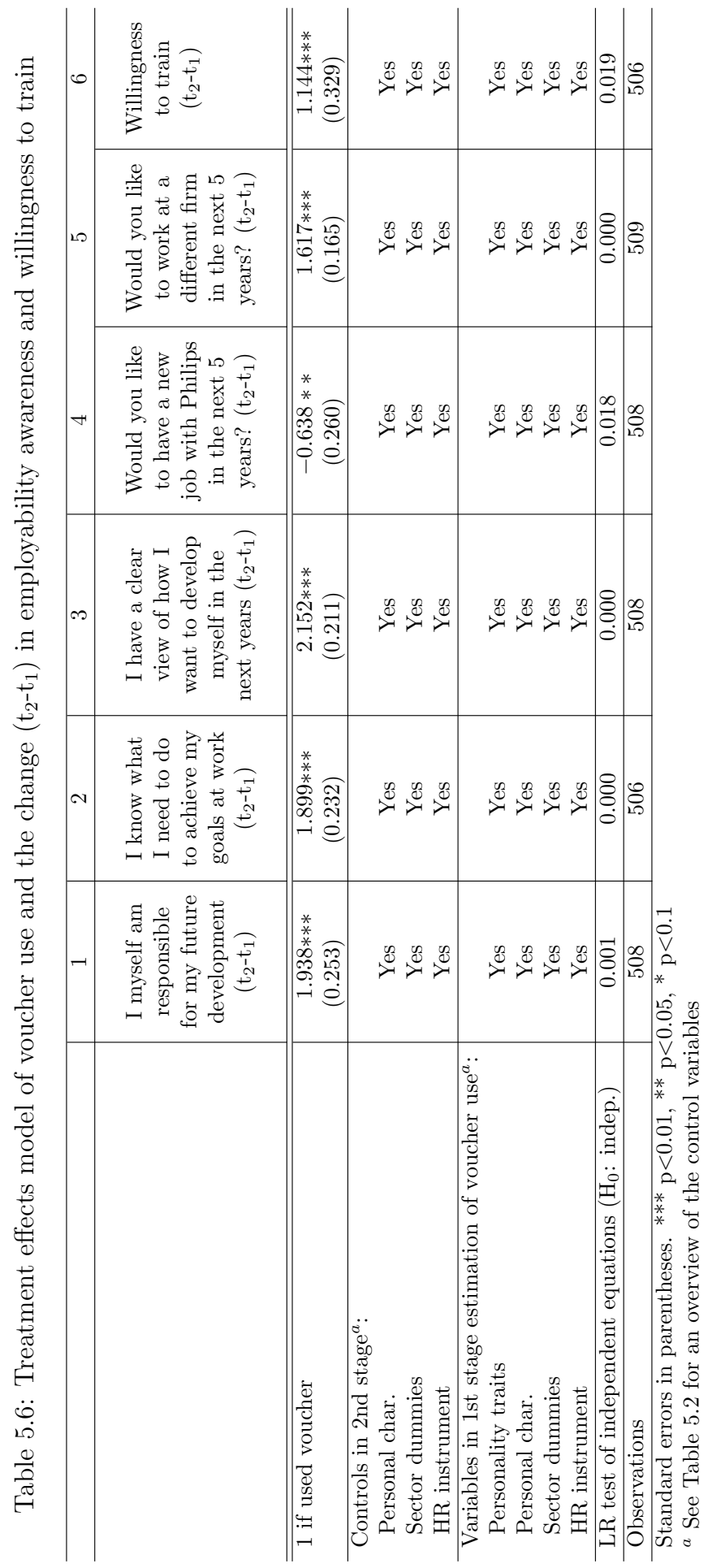




\subsection{Discussion and conclusions}

In this chapter, we analyze a firm's training voucher scheme to determine which workers use their vouchers and whether the vouchers increase the employability awareness of workers and their willingness to participate in further training. Overall, voucher redemption is low at $19 \%$, which is similar to findings from other studies on voucher schemes.

We find that voucher use is related to personality traits and personal characteristics. Voucher use is higher for workers with a more internal locus of control as well as higher levels of goal setting, career ambition, education, and tenure. In particular, goal setting and career ambition, which embody the ability to reflect on the future, have the highest odds ratios. Moreover, we find (weakly significant) that women redeem their vouchers more than men. Workers with higher levels of self-image and negative reciprocity use their vouchers less often. The negative relation between selfimage and voucher use shows that workers with a lower self-image are more likely to use their vouchers, which is positive, as the voucher training courses are designed to increase worker employability awareness, and as such, should aid the construction of worker self-image. However, the negative relation between voucher use and negative reciprocity is alarming, as this suggests that workers who behave with greater negative reciprocity perceive the voucher as a threat. Since the timing of the voucher scheme coincided with a global financial crisis, workers with greater negative reciprocity may perceive the employability vouchers as a signal that they are being prepared to be sacked.

We benchmarked the findings with regard to voucher use against an analysis of worker participation in non-voucher training. Contrary to voucher use, we find that participation in non-voucher training is not significantly related to personality traits and personal characteristics. We conclude that the more significant role of personality traits and personal characteristics in voucher use is a result of the design of the voucher system. All workers were given the vouchers and the firm thereby guaranteed the opportunity to train. The workers decided for themselves whether they would use their vouchers. As this is their own individual decision, their personalities and personal backgrounds affect their decisions. From an HR perspective, this suggests that by employing a voucher scheme, the firm makes training participation more dependent on employee personality and individual characteristics. Conversely, participation in non-voucher training is determined by management decision-making or a joint decision of the worker and a manager. This decision particularly depends on available time, budget, and return on investment. The latter factor is underscored by the positive relation between participation in non-voucher training and the use of HR practices such as 'personal development plans' and 'mid-year reviews'. These HR instruments are typically used to formalize agreements between workers and management about workers' work-related development and the role training has in this development. 
Finally, we find that the voucher scheme positively affects the employability awareness of workers who used their vouchers. We find these effects by analyzing various indicators of employability awareness and their development over time between the two surveys. All indicators show that employability awareness for workers who used their vouchers significantly improves compared to those workers who did not use their vouchers. The analysis also shows that workers who used their vouchers show a significantly positive change in their willingness to train than workers who did not use their vouchers.

Overall, the voucher scheme appears to achieve the goal it was designed for: It significantly increases employability awareness among those who spent their vouchers. However, our results also show that those workers who are more likely to use their vouchers are the ones who already have higher levels of ambition and education, an internal locus of control, and lower levels of negative reciprocity. We could argue that workers with these traits and characteristics are the ones who have relatively less to gain from employability training, because they are already better equipped to withstand future threats to employability than workers who have less education and ambition, an external locus of control, and higher levels of negative reciprocity. As we argue above, workers who are more driven by negative reciprocal behavior may perceive the voucher as a threat to their employability, whereas it is in fact intended as a stepping stone to improving their employability. This suggests that voucher redemption can be further optimized if the voucher system and the communications around it are designed to minimize the scope within which voucher recipients may view the system with suspicion. 


\section{Appendix I: Survey questions}

Table 5.7: Survey questions corresponding with variables*

\begin{tabular}{|c|c|c|}
\hline Variable & Question & $\begin{array}{l}\text { Cron. } \\
\text { Alpha }\end{array}$ \\
\hline \multicolumn{3}{|l|}{ Personality traits: } \\
\hline Locus of control & - Setbacks can usually be blamed on other people. & \\
\hline Self-confidence & - I have the tendency to think someone else is better than I am. & \\
\hline Anxiety & - I am scared of going to places where I have not been before. & \\
\hline Self-image & $\begin{array}{l}\text { - Generally, I have a clear picture of who I am and what I am capable } \\
\text { of. }\end{array}$ & \\
\hline Imagination & - Sometimes I imagine what my life will look like in 15 years. & \\
\hline Negative reciprocity & $\begin{array}{l}\text { - If someone treats me unfair, I will do anything I can to take revenge. } \\
\text { - If I feel offended by someone, I will do the same to him. } \\
\text { - If someone puts me in a unfavorable position, I will do the same to } \\
\text { him. }\end{array}$ & 0.81 \\
\hline Positive reciprocity & $\begin{array}{l}\text { - When someone pleases me, I am willing to give something in return. } \\
\text { - I always try to help someone who has helped out in the past. } \\
\text { - I am willing to provide effort in order to help someone who has helped } \\
\text { me out in the past. }\end{array}$ & 0.78 \\
\hline Career ambition & $\begin{array}{l}\text { - Would you like to work for a different company in five years from } \\
\text { now? } \\
\text { - Do you think you will work for a different firm in five years from now? }\end{array}$ & 0.75 \\
\hline Goal setting & - I set goals in what I want to achieve. & \\
\hline \multicolumn{3}{|l|}{ Employability awareness } \\
\hline $\begin{array}{l}\text { Responsibility for } \\
\text { future development }\end{array}$ & - I myself am responsible for my future development. & \\
\hline Clarity of approach & - I know what I need to do to achieve my goals at work. & \\
\hline $\begin{array}{l}\text { Image of future } \\
\text { self development }\end{array}$ & - I have a clear view of how I want to develop myself in the next years. & \\
\hline New job within 5 years & - Would you like to have a new job within Philips in the next 5 years? & \\
\hline Willingness to train & $\begin{array}{l}\text { - If there would be the possibility to take a one-year training course for } \\
\text { which you have to study } 8 \text { hours per week (in your leisure time) and in } \\
\text { return you might get a } 5 \% \text { salary increase, would you take the training? }\end{array}$ & \\
\hline \multicolumn{3}{|l|}{ Control variables } \\
\hline $\begin{array}{l}\text { HR instruments } \\
\text {-Assessment interviews } \\
\text {-Personal dev. plan } \\
\text {-Regular feedback } \\
\text {-Task/job rotation } \\
\text {-Mid-year review }\end{array}$ & $\begin{array}{l}\text { Does the Philips outlet you work in use the following HR instruments? } \\
\text { (yes/no) } \\
\text { - Assessment interviews } \\
\text { - Assistance in making a personal development plan } \\
\text { - I get regular feedback from my direct superior } \\
\text { - The option of task/job rotation exists } \\
\text { - Development-interviews (mid-year reviews) are being held }\end{array}$ & \\
\hline
\end{tabular}

All questions in this table (except HR instruments) are answered on a 5-point Likert scale. The remaining (straightforward) questions asked include personal characteristics: age, gender, tenure and education level as well as the sector in which employees work: consumer lifestyle, healthcare, lighting or other.

*For some personality traits we report only one question in this table. In these cases the Cronbach's Alpha turned out relatively low and we decided for our analyses, to use only the question reported in the table for that personality trait. 


\section{Bibliography}

Aakvik, A., J. Heckman, and E. Vytlacil (2005). Estimating treatment effects for discrete outcomes when responses to treatment vary: an application to Norwegian vocational rehabilitation programs. Journal of Econometrics 125(1), 15-52.

Aarts, L., P. R. de Jong, and R. van der Veen (2002). Met de beste bedoelingen: WAO 1975-1999, trends, onderzoek en beleid. APE ism Universiteit Twente; Elsevier Bedrijfsinformatie.

Abadie, A. and G. Imbens (2002). Simple and Bias-Corrected Matching Estimators for Average Treatment Effects. NBER Technical Working Papers (No. 283).

Abbring, J. H., G. J. Berg, and J. C. Ours (2005). The effect of unemployment insurance sanctions on the transition rate from unemployment to employment*. The Economic Journal 115(505), 602-630.

Acemoglu, D. and J. Pischke (1998). Why do Firms Train? Theory and Evidence. Quarterly Journal of Economics 113(1), 79-118.

Acemoglu, D. and J. Pischke (1999a). Beyond Becker: training in imperfect labour markets. The Economic Journal 109 (453), 112-142.

Acemoglu, D. and J. Pischke (1999b). The structure of wages and investment in general training. Journal of Political Economy 107(3), 539-572.

Altonji, J. and J. Spletzer (1991). Worker Characteristics, Job Characteristics, and the Receipt of On-the-Job Training. Industrial and Labor Relations Review 45(1), $58-79$.

Arulampalam, W., A. Booth, and M. Bryan (2004). Training in Europe. Journal of the European Economic Association 2(2-3), 346-360.

Asplund, R. (2005). The Provision and Effects of Company Training: A Brief Review of the Literature. Nordic Journal of Political Economy 31, 47-73.

Asplund, R. and W. Salverda (2004). Introduction: Company training and services with a focus on low skills. International Journal of Manpower 25(1), 8-16. 
Autor, D., F. Levy, and R. Murnane (2003). The Skill Content of Recent Technological Change: An empirical exploration*. Quarterly journal of economics 118(4), 12791333.

Baccaro, L. and D. Rei (2005). Institutional determinants of unemployment in OECD countries: A time series cross-section analysis (1960-98). International Institute for Labor Studies Discussion Paper.

Bachmann, R. and S. Braun (2011). The Impact of International Outsourcing on Labour Market Dynamics in Germany. Scottish Journal of Political Economy 58(1), $1-28$.

Baker, D., A. Glyn, D. Howell, and J. Schmitt (2004). Unemployment and labour market institutions: the failure of the empirical case for deregulation. ILO Working Paper 43.

Barron, J., D. Black, and M. Loewenstein (1993). Gender differences in training, capital, and wages. The journal of human resources 28(2), 343-364.

Bartel, A. (1995). Training, wage growth, and job performance: Evidence from a company database. Journal of Labor Economics 13(3), 401-425.

Bassanini, A., A. Booth, G. Brunello, M. De Paola, and E. Leuven (2005). Workplace Training in Europe. IZA Discussion Papers.

Bassanini, A. and R. Duval (2006). Employment patterns in OECD countries: reassessing the role of policies and institutions. Technical report, OECD Economics Department Working Paper.

Bauer, T. and S. Bender (2004). Technological change, organizational change, and job turnover. Labour Economics 11(3), 265-291.

Becker, G. (1962). Investment in human capital: a theoretical analysis. The Journal of Political Economy 70(5), 9-49.

Bénabou, R. and J. Tirole (2002). Self-Confidence and Personal Motivation. Quarterly Journal of Economics 117(3), 871-915.

Berman, E., J. Bound, and S. Machin (1998). Implications of Skill-Biased Technological Change: International Evidence. Quarterly Journal of Economics 113(4), 1245-1279.

Bolweg, J. and J. Maenhout (1995). Full-employability: Economisch noodzakelijk, sociologisch naief? In L.Faase, M. Ott and C.J. Voss (eds.): Nieuwe Breukvlakken in het Arbeidsbestel: Balans van 10 jaar veranderingen in Nederland en België. 10, 92-99.

Booth, A. (1991). Job-related formal training: who receives it and what is it worth? Oxford Bulletin of Economics and Statistics 53(3), 281-294.

Booth, A. and M. Bryan (2002). Who Pays for General Training? New Evidence for British Men and Women. IZA Discussion Papers.

Booth, A. and P. Katic (2010). Men at Work in a Land Down-Under: Testing Some Predictions of Human Capital Theory. British Journal of Industrial Relations. 
Borghans, L. and A. De Grip (2000). 1. The Debate in Economics about Skill Utilization. The overeducated worker?: the economics of skill utilization, 1.

Borghans, L., A. Duckworth, J. Heckman, and B. Ter Weel (2008). The Economics and Psychology of Cognitive and Non-Cognitive Traits. Journal of Human Resources 43(4), 972-1059.

Borghans, L., B. Golsteyn, and A. de Grip (2006). Meer werken is meer leren: determinanten van kennisontwikkeling. CINOP.

Bovenberg, A. L. (2000). Reforming Social Insurance in The Netherlands. International Tax and Public Finance 7(3), 345-368.

Brandt, N., J. Burniaux, and R. Duval (2005). Assessing the OECD Jobs Strategy: Past developments and reforms. OECD.

Card, D., J. Kluve, and A. Weber (2009). Active Labor Market Policy Evaluations: A Meta-Analysis (March 1, 2009). CESifo Working Paper Series No. 2570; Ruhr Economic Paper No. 86. Available at SSRN: http://ssrn.com/abstract=1356534.

Carling, K. and K. Richardson (2004). The relative efficiency of labor market programs: Swedish experience from the 1990s. Labour Economics 11(3), 335-354.

Caroli, E. and J. Van Reenen (2001). Skill-Biased Organizational Change? Evidence from a Panel of British and French Establishments. Quarterly Journal of Economics 116(4), 1449-1492.

Colquitt, J., J. LePine, and R. Noe (2000). Toward an integrative theory of training motivation: A meta-analytic path analysis of 20 years of research. Journal of Applied Psychology 85(5), 678.

CPB (2009). Macroeconomic Outlook 2009. CPB, The Hague.

CPB (2010). Macroeconomic Outlook 2011. CPB, The Hague.

Cragg, J. and S. Donald (1993). Testing identifiability and specification in instrumental variable models. Econometric Theory 9, 222-222.

Croce, G. and M. Tancioni (2007). Disentangling factors behind training participation in Italy. Univ. of Rome, Dept. of Economics Working Paper No. 101.

Cuesta, M. and W. Salverda (2009). Low-wage Employment and the Role of Education and On-the-job Training. Labour 23(s1), 5-35.

De Grip, A. (2006). Evaluating human capital obsolescence. Research Centre for Education and the Labour Market (ROA), working paper ROA-RM-2006/2E, Maastricht.

De Grip, A., J. Van Loo, and J. Sanders (2004). The industry employability index: Taking account of supply and demand characteristics. International Labour Review 143(3), 211-233.

De Grip, A. and van Breugel, G. and Dieter, D. (2011). Ontwikkelingscheque. Uitwerking Advies Denktank Leren en Werken.

De Koning, J., R. Layard, S. Nickell, and N. Westergaard-Nielsen (2003). Policies for full employment. Report within the project of The European Task Force on 
Employment (RL340b) 20.

De Vries, R., M. Wolbers, and R. van der Velden (2004). De arbeidsmarktpositie van schoolverlaters en werkenden zonder startkwalificatie. Raad voor Werk en Inkomen.

Dehejia, R. and S. Wahba (2002). Propensity score-matching methods for nonexperimental causal studies. Review of Economics and statistics 84(1), 151161.

Dieckhoff, M. and N. Steiber (2010). A Re-Assessment of Common Theoretical Approaches to Explain Gender Differences in Continuing Training Participation. British Journal of Industrial Relations.

DIW (1997). Das Niederlandische Beschäftigungsmodel. Deutsches Institut für Wirtschaftsforschung, Wochenbericht 1997/16.

Dostie, B. (2010). Estimating the returns to firm-sponsored on-the-job and classroom training. IZA Discussion Papers.

EC. European Commission Economic and Financial Affairs (2007). LABREF Labour Market Reforms Database.

Elmeskov, J., J. P. Martin, and S. Scarpetta (1998). Key Lessons for Labour Market Reforms: Evidence from OECD Countries Experiences. Swedish Economic Policy Review 5(2), 205-252.

Engle, R. F. and C. W. J. Granger (2001). Co-integration and error-correction: representation, estimation and testing. Essays in Econometrics: Collected Papers of Clive WJ Granger 55, 251-276.

Facteau, J., G. Dobbins, J. Russell, R. Ladd, and J. Kudisch (1995). The influence of general perceptions of the training environment on pretraining motivation and perceived training transfer. Journal of Management 21(1), 1.

Falk, M. and Y. Wolfmayr (2005). Employment effects of trade in intermediate inputs with the EU Member States and Asia. Aussenwirtschaft-Zurich 60(4), 441.

Falk, M. and Y. Wolfmayr (2008). Services and materials outsourcing to low-wage countries and employment: Empirical evidence from EU countries. Structural Change and Economic Dynamics 19(1), 38-52.

Feenstra, R. and G. Hanson (1996). Globalization, Outsourcing, and Wage Inequality. The American Economic Review 86(2), 240-245.

Fehr, E. and S. Gächter (2000). Fairness and retaliation: The economics of reciprocity. The Journal of Economic Perspectives 14(3), 159-181.

Fouarge, D., A. Gielen, R. Grim, M. Kerkhofs, A. Roman, J. Schippers, and T. Wilthagen (2006). Trendrapport Aanbod van Arbeid 2005. OSA A220.

Fouarge, D., T. Schils, and A. De Grip (2010). Why do low-educated workers invest less in further training? IZA Discussion Papers.

Frazis, H., M. Gittleman, and M. Joyce (2000). Correlates of training: an analysis using both employer and employee characteristics. Industrial and Labor Relations Review, 443-462. 
Furceri, D. and A. Mourougane (2009). How do Institutions Affect Structural Unemployment in Times of Crises? OECD Economics Department Working Papers.

Geishecker, I. (2006). Does outsourcing to Central and Eastern Europe really threaten manual workers' jobs in Germany? The World Economy 29(5), 559-583.

Gerards, R., J. Muysken, and R. Welters (2010). Active labour market policy by a profit maximizing firm. Meteor Research Memorandum $10(042)$.

Gerfin, M., M. Lechner, and H. Steiger (2005). Does subsidised temporary employment get the unemployed back to work? Aneconometric analysis of two different schemes. Labour Economics 12(6), 807-835.

Gesthuizen, M. and P. Scheepers (2010). Economic Vulnerability among Low-Educated Europeans. Acta Sociologica 53(3), 247.

Gesthuizen, M., H. Solga, and R. Kunster (2010). Context Matters: Economic Marginalization of Low-Educated Workers in Cross-National Perspective. European Sociological Review.

Gesthuizen, M. and M. Wolbers (2010). Employment transitions in the Netherlands, 1980-2004: Are low educated men subject to structural or cyclical crowding out? Research in Social Stratification and Mobility.

Gilbert, N. (2002). Transformation of the welfare state: the silent surrender of public responsibility. Oxford University Press, USA.

Gilbert, N. (2005). The "Enabling State?" from public to private responsibility for social protection: Pathways and pitfalls. OECD Social, Employment and Migration Working Papers.

Goux, D. and E. Maurin (2000). Returns to firm-provided training: evidence from French worker-firm matched data. Labour Economics 7(1), 1-19.

Graversen, B. (2004). Employment effects of active labour market programmes: do the programmes help welfare benefit recipients to find jobs? Aarhus Universitet, Institut for Økonomi, P.h.D. thesis.

Graversen, B. and P. Jensen (2010). A Reappraisal of the Virtues of Private Sector Employment Programmes. Scandinavian Journal of Economics 112(3), 546-569.

Groot, S. and H. De Groot (2011). Wage inequality in the Netherlands: Evidence, trends and explanations. CPB Discussion Paper (186).

Groot, W. and H. Maassen van den Brink (2000). Education, training and employability. Applied Economics 32, 573-581.

Hale, J. (2007). European Social Fund: 50 years investing in people. Luxembourg: Office for Official Publications of the European Communities.

Hartog, J. (1999). Wither Dutch Corporatism? Two Decades of Employment Policies and Welfare Reforms. Scottish Journal of Political Economy 46(4), 458-487.

Hummels, D., J. Ishii, and K. Yi (2001). The nature and growth of vertical specialization in world trade. Journal of International Economics 54 (1), 75-96.

Jacobs, B. (2004). The lost race between schooling and technology. De 
Economist 152(1), 47-78.

Jaenichen, U. and G. Stephan (2009). The effectiveness of targeted wage subsidies for hard-to-place workers. Applied Economics (0003-6846).

Jansen, H. (2001). De arbeidsmarktpositie van de ex-deelnemers aan de EAU, meting situatie tot en met 1999 .

Jones, M., R. Jones, P. Latreille, and P. Sloane (2009). Training, Job Satisfaction, and Workplace Performance in Britain: Evidence from WERS 2004. LABOUR 23(s1), 139-175.

Katz, E. and A. Ziderman (1990). Investment in general training: the role of information and labour mobility. The Economic Journal 100(403), 1147-1158.

Kluve, J. (2010). The effectiveness of European active labor market programs. Labour Economics (In Press, Corrected Proof).

Koning, P. and D. Van Vuuren (2007). Hidden Unemployment in Disability Insurance. Labour 21(4-5), 611-636.

Kranendonk, H., J. Bonenkamp, and J. Verbruggen (2004). A leading indicator for the dutch economy: methodological and empirical revision of the CPB system. $C P B$ Discussion Papers.

Krueger, A. and C. Rouse (1998). The effect of workplace education on earnings, turnover, and job performance. Journal of Labor Economics 16(1), 61-94.

Kuckulenz, A. and T. Zwick (2004). The impact of training on earnings: Differences between participant groups and training forms.

Lazear, E. (2009). Firm-Specific Human Capital: A Skill-Weights Approach. Journal of Political Economy 117(5), 914-940.

Lechner, M. and C. Wunsch (2009). Are training programs more effective when unemployment is high? Journal of Labor Economics 27(4).

Leuven, E. (2005). The economics of private sector training: A survey of the literature. Journal of economic surveys 19(1), 91-111.

Leuven, E. and H. Oosterbeek (2008). An alternative approach to estimate the wage returns to private-sector training. Journal of Applied Econometrics 23(4), 423-434.

Leuven, E., H. Oosterbeek, R. Sloof, and C. Van Klaveren (2005). Worker reciprocity and employer investment in training. Economica 72(285), 137-149.

Loewenstein, M. and J. Spletzer (1997). Delayed Formal On-the-Job Training. Industrial and Labor Relations Review, 82-99.

Machin, S. (2008). An appraisal of economic research on changes in wage inequality. Labour 22, 7-26.

Martin, C. and D. Swank (2004). Does the organization of capital matter? Employers and active labor market policy at the national and firm levels. American Political Science Review 98(04), 593-611.

Martin, J. and D. Grubb (2001). What Works and for Whom: A Review of OECD Countries' experiences with active labour market policies. Swedish Economic Policy 
Review 8(2), 9-56.

Mathieu, J., J. Martineau, and S. Tannenbaum (1993). Individual and situational influences on the development of self-efficacy: implications for training effectiveness. Personnel Psychology 46(1), 125-147.

Messer, D. and S. Wolter (2009). Money matters: Evidence from a large-scale randomized field experiment with vouchers for adult training. CESifo, Center for Economic Studies and Ifo Institute for economic research.

Mincer, J. (1974). Schooling, Experience, and Earnings. Human Behavior \& Social Institutions No. 2.

Mitchell, W. and J. Muysken (2008). Full employment abandoned: shifting sands and policy failures. Aldershot: Edward Elgar.

Mitchell, W. and J. Muysken (2010). Full employment abandoned: shifting sands and policy failures. International Journal of Public Policy 5(4), 295-313.

Munch, J. (2010). Whose job goes abroad? International outsourcing and individual job separations. Scandinavian Journal of Economics 112(2), 339-360.

Muysken, J. (2003). Job growth and social harmony: a Dutch miracle? Routledge Studies in International Business and the World Economy 30, 226-247.

Nelis, J., Y. van den Berg, P. van Mill, A. Swart, and F. Visser (2004). Annual Report Philips Employment Scheme 2003. Philips Human Resources Nederland.

Nickell, S. and R. Layard (1999). Labor market institutions and economic performance. Volume 3 of Handbook of Labor Economics, pp. 3029-3084. Elsevier.

Nickell, S., L. Nunziata, and W. Ochel (2005). Unemployment in the OECD Since the 1960s. What Do We Know? The Economic Journal 115(500), 1-27.

Nickell, S. and J. van Ours (2000). Falling Unemployment: The Dutch and British Cases. Economic Policy 30, 136-180.

Noe, R. (1986). Trainees' attributes and attitudes: Neglected influences on training effectiveness. The Academy of Management Review 11(4), 736-749.

OECD (1994). The OECD Jobs Study. Technical report, OECD, Paris.

OECD (2000). Economic Surveys: 1999-2000 Netherlands. Technical report, OECD, Paris.

Oesch, D. (2010). What explains high unemployment among low-skilled workers? Evidence from 21 OECD countries. European Journal of Industrial Relations 16(1), 39.

O'Halloran, P. L. (2008, December). Gender differences in formal on-the-job training: Incidence, duration, and intensity. LABOUR 22(4), 629-659.

Pavlopoulos, D., R. Muffels, and J. Vermunt (2009). Training and Low-pay Mobility: The Case of the UK and the Netherlands. Labour $23(\mathrm{~s} 1), 37-59$.

Peterson, R. (1994). A meta-analysis of Cronbach's coefficient alpha. Journal of consumer research, 381-391.

Pfeifer, C., S. Janssen, P. Yang, and U. Backes-Gellner (2011). Effects of Training on 
Employee Suggestions and Promotions in an Internal Labor Market. Working Paper Series in Economics.

Philips-Personeelszaken (1986-1990). Rapportage werkgelegendheidsplan. Philips Personeelszaken.

Picchio, M. and J. van Ours (2011). DP8320 Retaining through training; even for older workers.

Piva, M., E. Santarelli, and M. Vivarelli (2005). The skill bias effect of technological and organisational change: Evidence and policy implications. Research Policy 34 (2), 141-157.

Sanders, J. and A. de Grip (2004). Training, task flexibility and the employability of low-skilled workers. International Journal of Manpower 25(1), 73-89.

Scarpetta, S. (1996). Assessing the Role of Labour Market Policies and Institutional Settings on Unemployment: A Cross-Country Study. OECD Economics Studies, $43-98$.

Schwerdt, G., D. Messer, L. Woessmann, and S. Wolter (2011). Effects of Adult Education Vouchers on the Labor Market: Evidence from a Randomized Field Experiment. IZA Discussion Papers 5431.

Sen, A. (1997). Inequality, Unemployment and Contemporary Europe. International Labour Review 136(2), 155-72.

Sianesi, B. (2008). Differential effects of active labour market programs for the unemployed. Labour economics 15(3), 370-399.

Snel, E., J. de Boom, and G. Engbersen (2008). The silent transformation of the Dutch welfare state and the rise of in-work poverty. In H.J. Andreß and H. Lohmann (ed.). The working poor in Europe: employment, poverty and globalisation, 124.

Stegeman, H. (2005). De conjunctuurgevoeligheid van ziekteverzuim. Technical Report 99, Centraal Planbureau.

Stevens, M. (1994). A theoretical model of on-the-job training with imperfect competition. Oxford Economic Papers 46(4), 537-562.

Stock, J. and M. Yogo (2005). Testing for Weak Instruments in Linear IV Regression. In D.W. Andrews and J.H. Stock (eds.): Identification and Inference for Econometric Models: Essays in Honor of Thomas Rothenberg. 10, 80-108.

Strauss-Kahn, V. (2003). The Role of Globalization in the Within-Industry Shift Away from Unskilled Workers in France. NBER Working Papers.

TNS-NIPO (2003). Ziekteverzuim en WA.

van den Berg, Y. (2005-2008). Annual Report Philips Employment Scheme. Philips Human Resources Nederland.

van der Bruggen, T. (1991-2003). Rapportage werkgelegendheidsplan / Annual report. Philips Personeelszaken.

van der Bruggen, T. (2004). De lange weg naar Den Haag. Ton van der Bruggen. van der Bruggen, T. and J. van Schagen (2001). Met het oog op de arbeidsmarkt: 
ervaringen met het Philips werkgelegenheidsplan. Philips Electronics Nederland.

Van der Steeg, M., R. v. Elk, and D. Webbink (2010). Het effect van de lerarenbeurs op scholingsdeelname docenten. CPB document no. 205.

Van der Veen, R. (2009). The Transformation of the Welfare State. What is Left of Public Responsibility. In W. Schinkel (ed.). Globalization and the State. Sociological Perspectives on the State of the State, 173-195.

Van der Veen, R. and W. Trommel (1999). Managed liberalization of the Dutch welfare state: a review and analysis of the reform of the Dutch social security system, 19851998. Governance 12(3), 289-310.

van Oorschot, W. and C. Boos (2001). The battle against numbers: Dutch disability policies 1980-2000'. European Journal of Social Security 2(4), 343-362.

Visser, J. (1998). Two cheers for corporatism, one for the market: industrial relations, wage moderation and job growth in the Netherlands. British Journal of Industrial Relations 36(2), 269-292.

Visser, J. and A. Hemerijck (1997). A Dutch Miracle: Job Growth, Welfare Reform and Corporatism in the Netherlands. Amsterdam University Press Amsterdam.

Webster, J. and J. Martocchio (1993). Turning work into play: Implications for microcomputer software training. Journal of Management 19(1), 127-146.

Welters, R. (2005). Efficiency of Employment Subsidies and Firms' Recruitment Strategies. Welters, Maastricht, P.h.D. thesis.

Zagha, R. and G. Nankani (2005). Economic Growth in the 1990s: Learning from a Decade of Reform. World Bank Publications. 



\section{Nederlandse samenvatting (Summary in Dutch)}

Tijdens de nasleep van de twee wereldwijde oliecrises in de jaren 70 is in veel OECD landen, inclusief Nederland, de werkloosheid sterk gestegen. Figure 1.1 in de introductie van dit proefschrift laat zien dat de werkloosheid in Nederland sterk is toegenomen tot 1983 en pas in de tweede helft van de jaren 90 weer sterk is gedaald.

Langdurige werkloosheid is slecht voor de betrokken individuen en tevens voor de samenleving als geheel. De kosten van werkloosheid komen tot uitdrukking in een veelvoud van uitkomsten. Deze variëren van productieverlies voor de economie als geheel tot psychologische schade aan het werkloze individu (zie Sen (1997) voor een overzicht).

De Nederlandse overheid heeft individuen door middel van de verzorgingsstaat sinds jaar en dag verzekerd tegen de financiële gevolgen van werkloosheid. De verzorgingsstaat is echter niet toegerust om de niet-financiële (sociale en psychologische) kosten te verminderen, terwijl het juist ook deze sociale en psychologische kosten zijn die belastend zijn voor het werkloze individu. Het is dus beter om werkloosheid te voorkomen dan om het te genezen. Daarbij heeft de overheid onder de noemer van marktwerking en deregulering in toenemende mate privatiseringen doorgevoerd en meer en meer vertrouwen gegeven aan de markt om een grote rol te spelen in de financiering en afhandeling van sociale zekerheid.

De veranderende rolverdeling tussen publieke sector en private sector die het gevolg is van marktwerking en dereguling, alsmede de gevolgen die dat heeft voor de uitvoering van arbeidsmarktbeleid, zijn twee thema's die centraal staan in dit proefschrift. Ons eerste doel is om de voornaamste arbeidsmarkthervormingen sinds de jaren 80 in kaart te brengen en te testen welke van deze hervormingen het meest succesvol zijn geweest in het terugdringen van werkloosheid. 
Gegeven de steeds grotere rol die de overheid heeft gelegd bij de private sector is ons tweede- en tevens hoofddoel om een antwoord te vinden op de vraag of initiatieven binnen bedrijven een rol kunnen spelen bij het verminderen en voorkomen van werkloosheid. Om deze vraag te beantwoorden bestuderen we drie initiatieven binnen Philips op het gebied van werkloosheidsbestrijding en de bevordering van duurzame inzetbaarheid van werknemers ('employability'). Deze initiatieven zijn het Philips Werkgelegenheidsplan (WGP), Certificering Vakmanschap (CV ofwel VQP) en het 'E-miles' training-cheque programma.

In Hoofdstuk 2 hebben we een periode van 25 jaar van hervormingen in de Nederlandse sociale zekerheid geanalyseerd. Op basis van een literatuuronderzoek hebben we onderzocht welke hervormingen hebben gewerkt en welke niet. Met name hervormingen op het vlak van ziekteverzuim zijn relatief succesvol geweest vergeleken met hervormingen op andere terreinen. De voornaamste factor waarvan het succes van een hervorming af hangt is van welk type de hervorming is. Hervormingen die de toegang tot uitkeringen en voorzieningen beperken of de uitkeringsduur verkorten presteren verhoudingsgewijs goed. Hervormingen die trachten de druk op het sociale zekerheidsstelsel te verminderen door het stimuleren van individuen en bedrijven, het verschuiven van verantwoordelijkheden of het verlagen van uitkeringen blijken minder goed te werken. Tevens tonen we dat de geschiedenis van hervormingen beïnvloed is door de timing van kabinetswisselingen. Kabinetten zijn over het algemeen in de eerste twee jaar meer geneigd tot hervormen dan in de jaren kort voor nieuwe verkiezingen. Tot slot bevestigen we de anticyclische relatie tussen de conjunctuur en het aantal werklozen en arbeidsongeschikten en de procyclische relatie tussen de conjunctuur en ziekteverzuim.

In Hoofdstuk 3 analyseren we het WGP. In het WGP krijgen werklozen met een grote afstand tot de arbeidsmarkt gemiddeld een jaar werkervaring en training aangeboden binnen Philips, waarna de deelnemers uistromen naar werk buiten of binnen Philips, weer gaan studeren of terug in werkloosheid terecht komen. Onze analyse toont aan dat het gemiddelde effect van deelname aan het WGP $18 \%$ is. Dit betekent dat een WGP deelnemer een 18 procent punt grotere baanvindkans heeft dan een werkloze persoon met vergelijkbare kenmerken die niet aan het WGP heeft deelgenomen. De impact van het WGP is stukken groter dan de impact van deelname in publieke reintegratietrajecten. Daarbij kent het WGP enkele voordelen voor Philips, bijvoorbeeld doordat Philips met regelmaat deelnemers vanuit het WGP een reguliere baan bij Philips biedt en zo bespaart op de kosten van werving en selectie. Het WGP bestaat sinds 1983 en nadert haar dertigste verjaardag in 2013. De continuïteit van het WGP is een van de kenmerken waarmee het zich onderscheidt van publieke reintegratieprogramma's, welke doorgaans niet langer duren dan een regeringsperiode, zoals Hoofdstuk 2 laat zien. 
Onze analyse van het programma Certificering Vakmanschap (VQP) toont aan dat werknemers die de training in het VQP succesvol doorlopen en daarmee een startkwalificatie behalen, gemiddeld 4,3\% meer loon verdienen vergeleken met werknemers die de training niet doorlopen. Tevens laten we zien dat het positieve effect van de training op lonen afneemt in de jaren nadat men de training succesvol heeft afgesloten. $\mathrm{Na}$ ongeveer 7 jaar is het effect van de training niet meer waarneembaar vergeleken met werknemers die niet in training zijn gegaan. Dit suggereert dat werknemers moeten blijven leren ('Een leven lang leren') om ook op de langere termijn hard in salaris te kunnen groeien. We vinden tevens twee effecten die duiden op een verbeterde duurzame inzetbaarheid ('employability') van de werknemers. Ten eerste hebben werknemers die de training succesvol hebben doorlopen een grotere kans om binnen Philips promotie te maken dan diegenen die niet aan de training deel hebben genomen of deze niet hebben afgemaakt. Ten tweede leidt het succesvol afronden van de training tot een lagere kans op gedwongen ontslag. Deze effecten laten zien dat het VQP kan worden gezien als een preventieve maatregel tegen werkloosheid van laagopgeleiden. Het VQP helpt daarmee de kloof tussen laag en hoog opgeleiden te nivelleren.

De voortdurende groei in het aantal hoger opgeleide arbeiderskrachten in de beroepsbevolking leidt tot een toenemend risico van verdrukking ('crowding out') in alle lagen van de arbeidsmarkt. Met verdrukking bedoelen we dat iemand een baan aanneemt waarvoor men overgekwalificeerd is en daardoor iemand die precies de juiste kwalificaties heeft voor deze positie verdrukt. Als deze verdrukte persoon vervolgens ook genoodzaakt is een baan onder zijn of haar niveau aan te nemen dan wordt op dit lagere niveau weer een nieuwe werknemer verdrukt. Dit proces werkt zo door tot op de laagste kwalificatieniveaus waar, aan de onderkant van de arbeidsmarkt, de meeste moeilijkheden ontstaan om een baan te krijgen of behouden. Om deze reden is het van belang voor werknemers op alle opleidingsniveaus om blijvend aan persoonlijke ontwikkeling te werken. Om werknemers binnen Philips hiervan bewust te maken is Philips in 2009 gestart met het E-miles programma. Dit houdt in dat alle Philips medewerkers een cheque ter waarde van 1.000 E-miles hebben gekregen, welke ze mogen besteden aan persoonlijke ontwikkelingstraining.

In Hoofdstuk 5 analyseren we het programma van de E-miles cheques en tonen we aan dat werknemers die hun cheque hebben besteed en dus een persoonlijke ontwikkelingstraining hebben gevolgd, een significant gestegen bewustzijn hebben van het belang van persoonlijke ontwikkeling, vergeleken met werknemers die hun cheque niet besteed hebben. Tevens blijken werknemers die hun cheque besteed hebben een gestegen bereidheid te hebben om in de toekomst aan training deel te nemen ten opzichte van werknemers die hun cheque niet hebben besteed. Het stimuleren van dit bewustzijn en de trainingsbereidheid kan worden beschouwd als een vroege interventie om de toekomstige werkgelegenheid van werknemers te bevorderen. 
We kunnen concluderen dat de drie bedrijfsinitiatieven WGP, VQP en E-miles succesvol zijn in het bereiken van hun respectievelijke doelen van reintegreren van werklozen, vergroten van de 'employability' van lager opgeleiden en verhogen van het bewustzijn omtrent persoonlijke ontwikkeling onder werknemers. Dit toont aan dat bedrijven een meetbare en significante bijdrage kunnen leveren aan het verminderen van werkloosheid en de bevordering van de 'employability van laag opgeleiden'.

Deze initiatieven verdienen lof aangezien ze bijdragen aan het verlichten van het werkloosheidsprobleem in brede zin. Deze initiatieven verdienen navolging bij andere bedrijven. Met name in het geval van het WGP heeft dit een duidelijk geaggregeerd potentieel om langdurige werkloosheid te helpen bestrijden. Wij hopen dat het langdurige en stabiele succes van het WGP bedrijven, sociale partners en de overheid inspireert tot navolging. 


\section{Short Curriculum Vitae}

Ruud Gerards (The Hague, 25-12-1977) obtained his Master degree in General Economics in 2000 from Maastricht University. Since then he has held various academic and corporate positions. First, he worked as statistical researcher for Statistics Netherlands (CBS). After that he joined PricewaterhouseCoopers as grant/subsidy consultant, working on 6th framework program (FP6) applications and on a number of national subsidy programs. He also worked in a smaller consultancy firm advising local governments and city councils in urban and spatial planning projects. His academic experience includes 7 years as (junior) lecturer at Maastricht University before and while conducting his $\mathrm{PhD}$ research. Ruud has presented his results at numerous international conferences and has spent two months as visiting researcher at the School of Business of James Cook University, Australia. At present, Ruud holds a position as lecturer at Fontys University of Applied Sciences and works freelance as thesis supervisor for Zuyd University of Applied Sciences. 